\title{
EFICIÊNCIA AGRICOLA DE UM FOSFATO NATURAL PARCIALMENTE SOLUBILIZADO E DE UM FOSFATO DE FUSÃO PARA ARROZ, SOJA E CAPIM COLONIÃO
}

FREDY ORLANDO VEGAS COLMENAREZ

Orientador: Dr. EURIPEDES MALAVOLTA

Dissertaçāo apresentada à Escola Superior de Agricultura "Luiz de Queiroz", da Universidade de Sāo Paulo, para obtenção do título de Mestre em Agronomia - Área de Concentraçāo: Solos e Nutriçāo de Plantas.

PIRACICABA

Estado de São Paulo - Brasil

Novembro - 1987 
.ii.

Ao meu pai e irmãos,

OFEREÇO,

A 'minha esposa,

Eddy;

Aps meus filhos,

Jonathan e Josuë,

DEDICO. 
. ii .

A memōria de minha mae, MINHA HOMENAGEM ESPECIAL. 


\section{AGRADEC IMENTO}

Ao Prof. Dr. Euripedes Malavolta pela sua atenciosa orientaçao, apoio e amizade.

A Escola Superior de Agricultura "Luiz de Queiroz", da Universidade de São Paulo, pela acolhida.

Ao Centro de Informatica na Agricultura - CIAGRI, do Campus da Universidade de São Paulo em Piracicaba, SP, pelas ana 1 ises estatisticas.

$\AA$ Universidade Centro Occidental "Lisandro Alvarado" - Basquisimeto - Venezuela, pela oportunidade concedida.

As senhoritas Cleusa Pereira Cabral e Maria Ligia Malavolta, pela ajuda e amizade.

A COPEBRAS pelo suporte financeiro para a realizaça desta pesquisa.

Aos colegas que cursaram comigo as diferentes disciplinas do curso de Solos e Nutrição de Plantas, pela amizade.

A todos que direta ou indiretamente contribuiram para o bom desenvolvimento da presente pesquisa. 
1. INTRODUÇ

2. REvisão de literatura. $\ldots \ldots \ldots \ldots$

2.1. Resultados experimentais de culturas anuais e pastagens à adubação com diferentes fontes de

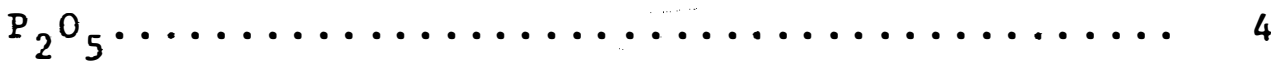

2.2. Comportamento dos fosfatos naturais........ 7

2.3. Comportamento dos fosfatos parcialmente acidu-

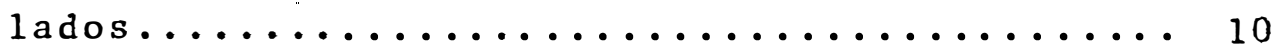

2.4. Comportamento dos termofosfatos.......... 12

3. MAteriais E MÉtodos..................... 15

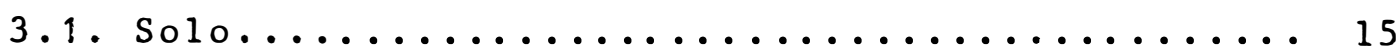

3.2. Culturas empregadas................. 16

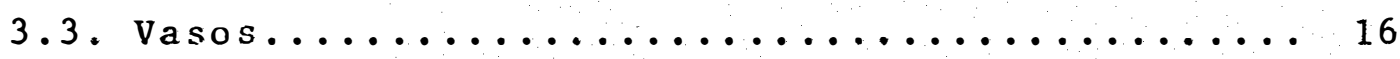

3.4. Doses e Fontes..................... 17

3.5. Soluções e Suspensões.................. 19

3.6 . Tratamentos..................... 22

3.6 .1 . Calagem.................... 22

3.6.2. Delineamento experimental ........ 22

3.7. Instalação do ensaio com arroz e soja...... 23

3.8. Instalação do ensaio com capim Colonião...... 26

3.9 . Condução....................... 27 
Pảgina

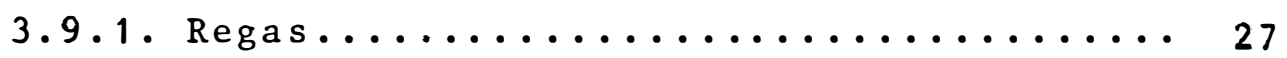

3.9 .2 . Desbaste......................... 27

3.9.3. Adubação em cobertura............... 27

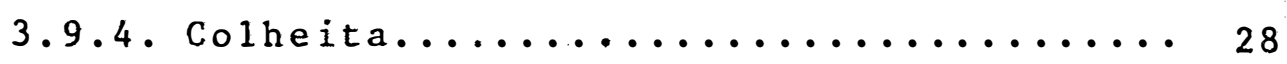

3.10. Anälises quimicas..................... 29

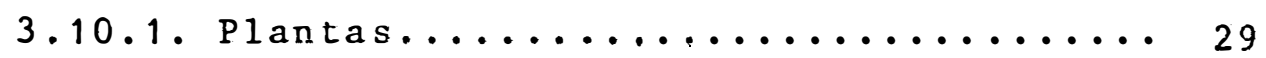

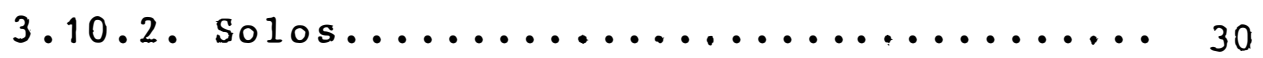

3.11. Anälises estatisticas................. 30

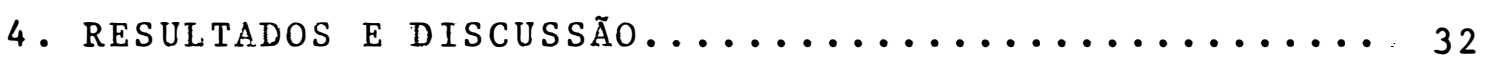

4.1. Ensaio com arroz de sequeiro e soja para deter minar o efeito direto do. fosfato de Catalão par cialmente solubilizado (FCPS) e com tratamento de fusão (FCTF) sobre a produção de matéria se ca da parte aẻrea e produção de grãos e vagens

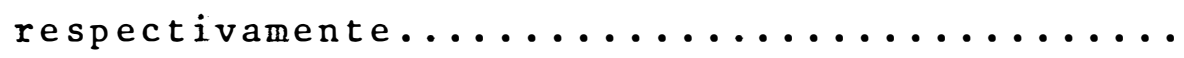

4.1.1. Produção de matéria seca da parte aérea de arroz e produção de grãos com casca..

4.1.2. Produção de matéria seca da parte aērea da soja e produção de vagens.........

4.2. Teores e absorção de nutrientes corresponden tes aos dois ensaios realizados............ 40 4.2.1. Teores e absorção de nutrientes no arroz parte aērea e grãos com casca.... 40 
4.2.2. Teores e absorção de nutrientes na soja, parte aérea e nas vagens....... 49

4.3. Ensaios com capim Colonião após arroz e após soja para determinar o efeito residual do fosfato de Catalão parcialmente solubilizado (FCPS) e com tratamento de fusão (FCTF) sobre a produ ção de matéria seca da parte aërea (três cor-

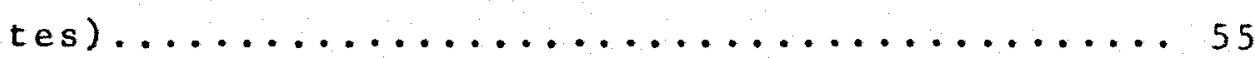

4.3.1. Produção de matēria seca do capim Colonião após arroz (très cortes)....... 55

4.3.2. Produção de matéria seca de capim Colonião após soja (très cortes) .......6 62

4.4. Teores e absorção de nutrientes do capim Colonião, nos ensaios após arroz e após soja....667 4.4.1. Teores e absorção de nutrientes do capim Colonião apös arroz (três cortes)..67 4.4.2. Teores e absorção de nutrientes do capim Colonião após soja (três cortes)...78

4.5. Anälise conjunta dos ensaios...........88 4.5.1. Arroz e capim Colonião..........88 4.5.1.1. Matèria seca total........88 4.5 .1 .2 . Absorção de fösforo......993 4.5.2. Soja e Capim Colonião............998 
.viii.

Pägina

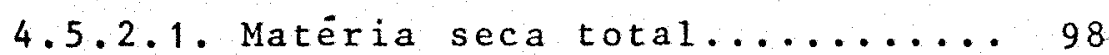

4.5 .2 .2 . Absorção de fösforo.........105

4.6. Efeitos sobre as caracteristicas do solo..... 109

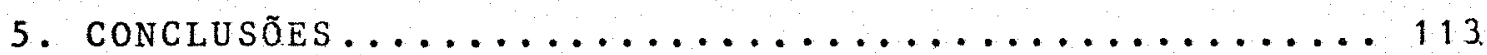

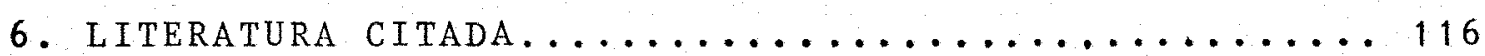


ix.

\section{LISTA DE TABELAS}

TABELA

pàgina

1

Anàlise de solubilidade e composição química do fosfato de Catalão .....

2

Anāilise química do solo utilizado nos ensaios, antes do primeiro cultivo ..

Doses de adubos em solução ou suspensäo aplicados para o arroz $(\mathrm{ml} / 2 \mathrm{~kg}$

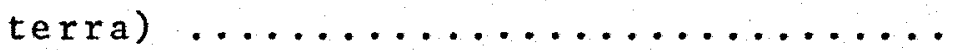

Doses de adubos em solução ou suspensão aplicados para a soja $(\mathrm{ml} / 2 \mathrm{~kg}$ terra $\ldots \ldots \ldots \ldots \ldots \ldots \ldots \ldots$

Tratamentos empregados em cada cultu-

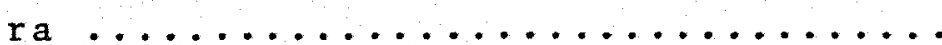

Esquema de análise de variancia aplicado nos ensaios com arroz, soja e co

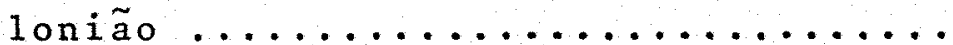


7. Produção de matéria seca (parte aérea e grãos) de arroz de sequeiro e soja (par te aảrea e vagens), em função do efeito direto das diferentes fontes de $P$ com e

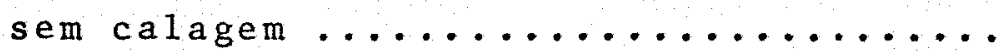

8 Efeitos dos tratamentos sobre os teores de macronutrientes contidos na matéria seca da parte aērea do arroz (média de 2 repetições) $\ldots \ldots \ldots \ldots \ldots \ldots \ldots$

9. Efeitos dos tratamentos sobre as quanti dades de macronutrientes absorvidos pe1 a parte aérea do arroz (média de 2 re petições) $\ldots \ldots \ldots \ldots \ldots \ldots \ldots \ldots \ldots \ldots \ldots \ldots \ldots \ldots \ldots \ldots \ldots$

10 Efeito dos tratamentos sobre os teores de macronutrientes contidos nos gräos de arroz mais casca (mg/vaso) (média de 2 repetições) $\ldots \ldots \ldots \ldots \ldots \ldots \ldots \ldots$

11 Efeito dos tratamentos sobre as quantidades de macronutrientes absorvidos nos grãos do arroz mais casca (mg/vaso) (mē

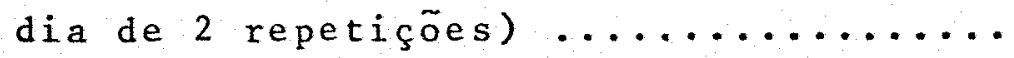


12 Efeito dos tratamentos sobre os teores de macronutrientes contidos na matéria seca da parte aérea da soja (média de 2 repetições) $\ldots \ldots \ldots \ldots \ldots \ldots \ldots \ldots \ldots \ldots \ldots \ldots$

13 Efeito dos tratamentos nas quantidades de macronutrientes absorvidos pela par te aérea da soja (mg/vaso) (mëdia de 2 repetições) $\ldots \ldots \ldots \ldots \ldots \ldots \ldots \ldots$

14 Efeito dos tratamentos sobre os teores de macronutrientes contidos nas vagens de soja (média de 2 repetições) .....

15 Efeito dos tratamentos nas quantidades de macronutrientes absorvidos nas vagens de soja (mg/vaso) (média de 2 re

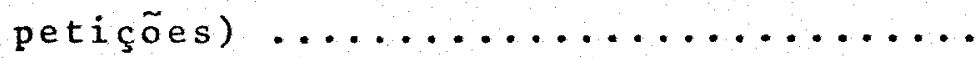

16 Produção de matéria seca de capim colo nião em três cortes sucessivos após ar roz de sequeiro e apás soja sobre o efeito residual das diferentes fontes de fósforo com e sem calagem ........ 
Efeito dos tratamentos sobre os teores de macronutrientes contidos na matéria seca do capim Colonião após arroz no 10 corte (média de 3 repetiçōes) .....

18 Efeito dos tratamentos sobre as quanti dades de macronutrientes absorvidos pe 10 capim Colonião após arroz no 19 cor te (mg/vaso) (média de 3 repetições)..

19 Efeito dos tratamentos sobre os teores de macronutrientes contidos na matéria seca do capim Colonião após arroz no 2 o corte (média de 3 repetiçöes) .....

Efeito dos tratamentos sobre as quanti dades de macronutrientes absorvidos pe 1o capim Colonião apös arroz no 2 p cor te (mg/vaso) (mẻdia de 3 repetições)..

21. Efeito dos tratamentos sobre os teores de macronutrientes contidos na matéria seca de capim Colonião após arroz no 3 o corte (média de 3 repetiçôes) ..... 
.xiii.

TABELA

pāgina

22 Efeito dos tratamentos sobre as quanti dades de macronutrientes absorvidos pe 10 capim Colonião após arroz no 39 cor te (mg/vaso) (média de 3 repetições)..

23 Efeitos dos tratamentos sobre os teores de macronutrientes contidos na ma téria seca do capim Colonião após soja no 19 corte (média de 3 repetições)...

Efeito dos tratamentos sobre as quanti dades de macronutrientes absorvidos pe 10 capim Coloniäo após soja no 19 corte (mg/vaso) (mēdia de 3 repetições).. Efeito dos tratamentos sobre os teores de macronutrientes contidos na matéria seca do capim Colonião apôs soja no 2 ? corte (mëdia de 3 repetiçôes) .......

26 Efeito dos tratamentos sobre as quanti dades de macronutrientes absorvidos pe 10 capim Colonião após soja no 29 corte (mg/vaso) (mēdia de 3 repetiçöes).. 
Efeito dos tratamentos sobre os teores de macronutrientes contidos na matēria seca do capim Colonião após soja no 3 ? corte (médias de 3 repetições) ......

Efeito dos tratamentos sobre as quanti dades de macronutrientes absorvidos pe 10 capim Colonião após soja no 39 corte (mg/vaso) (médias de 3 repetiçōes).

Produçäo relativa de matêria seca com relação à produzida com SPT para o efeito direto e residual do FCPS e FCTF sem calagem em arroz e capim Coloniäo (três cortes) $\ldots \ldots \ldots \ldots \ldots \ldots \ldots$

Produção relativa de matéria seca com relação à produzida com SPT para o efeito direto e residual do FCPS e FCTF com calagem em arroz e capim colonião (3 cortes).

31 Matéria seca do arroz e capim colonião (trēs cortes) dos tratamentos em auséncia de calagem (g/vaso) e produção relativa em relação ao tra tamento com SPT (mëdias de 3 repetições).... 
Matéria seca do arroz e capim Colonião (três cortes) dos tratamentos em presença de calagem (g/vaso) e produção re lativa em relaçāo ao tratamento com SPT

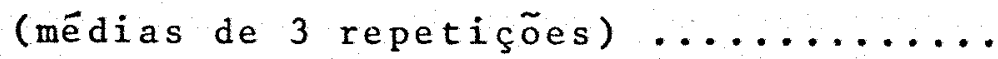

Quantidade de $P$ absorvido pelo arroz e capim Colonião (três cortes), dos trata mentos em ausência de calagem (mg/vaso) e absorção relativa de $P$ em relação ao tratamento com SPT (médias de 3 repetições ) $\ldots \ldots \ldots \ldots \ldots \ldots \ldots \ldots \ldots$

Quantidade de $P$ absorvido pelo arroz e capim Coloniāo (três cortes) dos tratamentos em presença de calagem (mg/vaso) e absorção relativa de $\mathrm{P}$ en relação ao tratamento com SPT (médias de 3 repetições ) $\ldots \ldots \ldots \ldots \ldots \ldots \ldots \ldots \ldots \ldots$

Produção relativa de matéria seca em re lação à produzida com SPT para o efeito direto e residual do FCPS e FCTF sem ca lagem em soja e capim Colonião (três

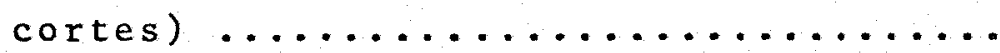


Produção relativa de matéria seca em re lação à produzida com SPT para ofeito direto e residual do FCPS e FCTF com ca lagem em soja e capim Colonião (três

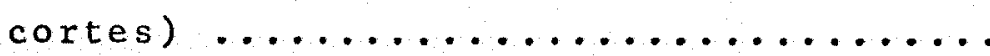

Matéria seca da soja e capim Colonião (três cortes) dos tratamentos em ausência de calagem (g/vaso) e produção rela tiva em relação ao tratamento com SPT

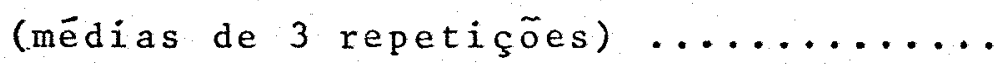

Matéria seca da soja e capim Colonião (três cortes) dos tratamentos em presen ça de calagem (g/vaso) e produção relativa em relação ao tratamento com SPT (médias de 3 repetições) $\ldots \ldots \ldots \ldots \ldots$

39 Quantidade de $P$ absorvido pela soja e capim Colonião (três cortes) dos tratamentos em ausência de calagem (mg/vaso) e absorção relativa de $P$ em relação ao tratamento com SPT (médias de 3 repeti-

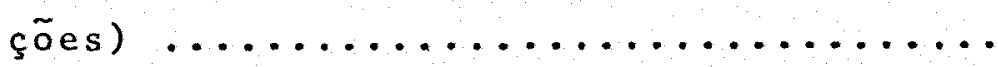


xvii.

TABELA

Página

40 Quantidade de $P$ absorvido pela soja e capim Colonião (três cortes) dos tratamentos em presença de calagem (mg/vaso) e absorção relativa de $\mathrm{P}$ em relação ao tratamento com SPT (médias de 3 repetiçōes) .....

41 Anälise química do solo utilizado nos en saios após a colheita do 39 corte de capim Colonião após arroz .............. 110

42. Anāilse química do solo utilizado nos en saios após a colheita do 3 o corte de ca-

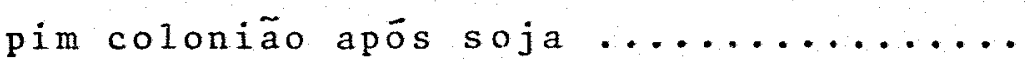




\section{LISTA DE FIGURAS}

F IGURA

Pàgina

Efeito das doses de $P$ empregadas sobre a produção de matéria seca do arroz

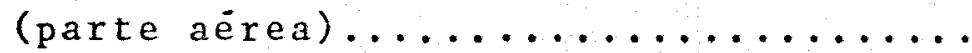

Efeito das doses de $P$ empregadas sobre a produção de grãos mais casca do ar-

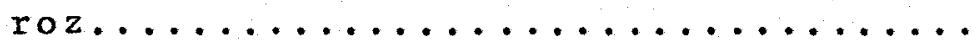

Efeito das doses de $\mathrm{P}$ empregadas sobre a produção de matéria seca da soja (par

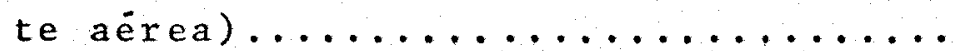

Efeito das doses de $P$ empregadas sobre a produção de vagens de soja........

Efeito das doses de $\mathrm{p}$ sobre a produção de matéria seca do capim Colonião apös arroz $(19$ corte $) \ldots \ldots \ldots \ldots \ldots$

Efeito das doses de $P$ sobre a produção de matéria seca do capim Colonião após $\operatorname{arroz}(2$ o corte $) \ldots \ldots \ldots \ldots \ldots$ 
Efeito das doses de $P$ sobre a producão de matéria seca do capim colonião após arroz $(39$ corte $\ldots \ldots \ldots \ldots \ldots \ldots$

Efeito das doses de $P$ sobre a produção de matéria seca do capin colonião após soja $(1$ o corte $\ldots \ldots \ldots \ldots \ldots \ldots \ldots$

Efeito das doses de $P$ sobre a produça de matéria seca do capim Colonião apōs soja $(2$ o corte $\ldots \ldots \ldots \ldots \ldots \ldots \ldots \ldots \ldots \ldots \ldots \ldots \ldots$

Efeito das doses de $P$ sobre a produça de matéria seca do capim colonião apōs soja $(3 \circ$ corte $) \ldots \ldots \ldots \ldots \ldots \ldots$

Produção de matéria seca do arroz e capim Colonião (três cortes) com rela ção à produção com superfosfato triplo. . . . . pim Colonião (três cortes) com relação à produção com superfosfato triplo...... 


\section{EFICIENCIA AGRICOLA DE UM FOSFATO NATURAL \\ PARC IALMENTE SOLUBILIZADO E DE UM \\ FOSFATO DE FUSÃO PARA ARROZ, SOJA \\ E CAPIM COLONIÃO}

Autor: FREDY ORLANDO VEGAS COLMENAREZ

Orientador: Dr. EURIPEDES MALAVOLTA

\section{RESUMO}

Em casa-de-vegetação conduziu-se um experimento em vasos com arroz, soja e capim colonião, em solo de cerrado (LVA de Anhembi, SP), äcido e pobre em fösforo, com os objetivos de avaliar a eficiência comparada em presença e ausencia de calagem do fosfato de Catalão parcialmente solubilizado (FCPS) e com tratamento térmico de fusão (FCTF), atravēs dos dados de produção de matēria seca, produção de grãos e vagem e teor e absorção de nutrientes; tendo-se o superfosfato triplo como padrão e utilizando arroz e soja como plantas-testes para - efeito direto e capim colonião para o efeito residua 1 .

Usaram-se doses de 150 e 300 ppm P para ambas as fontes comparadas e dose de 225 ppm para o padrão, além da testemunha que não recebeu fósforo, usou-se um tratamento ex- 
tra sem fösforo e sem magnésio.

$$
\text { os resultados permitiram concluir que: }
$$

a) Otratamento padrão (SPT) foi mais eficiente nas duas primeiras culturas, e a calagem influenciou positivamente este comportamento, quando se considera o efeito direto.

b) o FCPS mostrou boa eficiência na cultura da soja, comparävel ao SPT e no caso do arroz chegou a superar ao SPT na produção de grãos.

c) o FCTF mostrou boa eficiência só nas doses maiores com e sem calagem.

d) O SPT foi superior como fornecedor de fósforo para as plan tas.

e) a calagem não teve efeito significativo para ambas as fontes testadas tanto no efeito direto como residual.

f) os fosfatos testados mostraram ser boas fontes de fósforo, cälcio e magnésio.

g) para o efeito residual o FCPS foi equivalente a SPT nos três cortes realizados e o FCTF somente nas doses maiores. 
AGR ICULTURAL EFF IC IENCY OF A

PARTIALLY ACIDULATED ROCK PHOSPHATE AND CF A

THERNOPHOSPHATE FOR RICE,

SOYBEAN AND GUINEA GRASS

Autor: FREDY ORLANDO VEGAS COLMENAREZ

Adviser: EURIPEDES MALAVOLTA

\section{SUMMARY}

An experiment was carried out in the greenhouse using an acid, low phosphorus soil (LVA, Anhembi, SP) with the objective of comparing three $\mathrm{P}_{2} \mathrm{O}_{5}$ sources, namely: partially acidulated rock phosphate from Catalão, Go (FCPS), Catalão thermophsphate (FCTF) and triple superphosphate (TSP).

The direct effect was evaluated by using both rice and soybean as test crops. The residual effect was assessed by growing guinea grass after the first crop.

FCPS and FCTF were supplied at the rates of 0 , 150 and $300 \mathrm{ppm}$, based on the total phosphorus content. An intermediate rate of $225 \mathrm{ppm}$ was used in the case of TSP. An additional treatment without $P$ and $M g$ was also included. 
.xxiit.

The effect of the treatments was studied both in the presence and absence of 1 iming. All plants received a uniform dressing of all other elements, both macro and micro.

The results obtained allowed for the following conclusions to be drawn:

a) TSP was the most efficient source insofar the direct effect is concerned; its performance was improved by liming;

b) FCPS was almost as efficient as TSP for soybean, giving a higher grain yield in the case of rice;

c) FCTF, on the other hand, was shown good efficiency only when supplied at higher rate;

d) TSP gave the highest $P$ levels in the plants;

e) The effect of either FCPS or FCTF was nor influenced by 1 iming;

f) Plant analyses has shown that the experimental products were sources of $\mathrm{P}, \mathrm{Ca}$ and $\mathrm{Mg}$.

g) With respect to the residual effect FCPS was equivalent to TSP when the three cuttings were considered; FCTF, however, showed comparable results only when supplied at higher $P$ rates. 
1. INTRODUÇAO

o esgotamento de solos originalmente férteis, causado por várias décadas de cultivos, sem reposição de nu trientes, bem como a exploração de äreas com solos de baixa fertilidade natural, constituem os dois motivos de maior im portância para tornar a agricultura brasileira dependente, em forma crescente e irreversível, de aplicações maciças de fer tilizantes (RAIJ et alii, 1982).

E indiscutivel a essencialidade no uso de fer tilizantes químicos para aumentar ou mesmo só para manter a produtividade das culturas. Mas os grandes aumentos produzi dos nos ültimos anos às custas de fertilizantes, têm levado a incrementar os custos de produção das exploraçóes agrícolas a 
niveis economicamente proibitivos.

Assim, a busca de fontes alternativas de me nor custo e de uma aceitāvel eficiência agronômica torna-se vital na procura de um máximo benefício para o agricultor.

Por ser o fósforo um dos fatores de maior importāncia para a exploração agricola, pelo fato de que os solos das regiões tropicais "fixam" fösforo, requerendo aplicacões de quantidades bem mais elevadas desse nutriente que àquelas exigidas pelas culturas é, ainda, tendo em vista que sua deficiēncia é bastante frequente nos solos brasileiros e que, para a maioria das culturas a sua adiça provoca aumentos substanciais de produção, vem sendo pesquisado nas diversas jazidas de fosfatos brasileiro, o uso de fosfatos naturais, apenas moidos e concentrados, que apresentam custos de fabricaça bem mais baixos por causa do menor processamentoin. dustrial. Além desses fosfatos naturais vêm também sendo ava liados fosfatos que recebem alguns tratamentos para melhorar a sua solubilidade, destacando-se a acidulaçõo parcial e os tratamentos térmicos moderados.

Em estudos recentes tem sido testados os fosfa tos brasileiros (Patos de Minas, Araxā, Catalão, Jacupiranga, Abaeté, Alvorada e Olinda), tendo mostrado uma eficiência ini cial baixa $(3-20 \%)$ em relação ao superfosfato triplo, me 1 ho 
rando um pouco após alguns anos $(27-45 \%)$. Dentre eles os fos fatos Alvorada e olinda, bem como ofosfato de alumínio cal cinado de Maranhão, são os mais eficientes (RAIJ et alii, $1982)$.

Considerando a baixa eficiência agronômica dos fosfatos naturais, e os resultados proporcionados pela pesqui sa com fosfatos naturais parcialmente acidulados ou com trata mento térmico moderado, surge a necessidade de continuar as pesquisas no sentido de avaliar àquelas fontes que têm mostra do menor eficiência até agora, tal é o caso do fosfato de ca ta 1 ào.

Dentro deste contexto, este trabalho reflete essa necessidade, testando como hipotese que o fosfato de ca ta 1 ão, de baixa eficiência na forma natural, deve ter sua eficiência aumentada, quando submetido aos tratamentos de aci dulação parcial ou térmico. Este objetivo procura realmente verificar num ensaio com vasos, a eficiência agrícola compara da do fosfato de Cata 1 ão parcialmente solubilizado (FCPS) e do fosfato de Catalão em tratamento térmico de Fusão (FCTF) em relação ao superfosfato triplo, avaliando seu efeito direto e residual en auséncia e presença de calagem, usando como plantas testes uma graminea (arroz de sequeiro) e uma leguminosa (soja) para avaliar o efeito direto, e capim colonião após arroz e soja para avaliar o efeito residual em três cortes. 
.4 .

\section{REVISAO DE LITERATURA}

2.1. Resultados experimentais de culturas anuais e pastagem à adubação com diferentes fontes de $\mathrm{P}_{2} \mathrm{O}_{5}$.

As respostas das culturas as diferentes fontes de $\mathrm{P}_{2} \mathrm{O}_{5}$ variam amplamente de local para local, dependendo da planta cultivada, do nivel de manejo e principalmente da disponibilidade de fósforo no solo.

MALAVOLTA et alii (1981), comparando a eficien cia do fosfato de Araxả parcialmente acidulado com àcido sulfürico (FAPS), com a do super simples (SS) e do fosfato de Araxä original, em solos poucos ácidos e pobres em $\mathrm{P}$ disponi- 
vel, lograram verificar que o aproveitamento do FAPS pelas culturas de arroz de sequeiro, milho e soja não diferiu estatisticamente em =termos de producão com o aproveitamento do SS sendo maiores que as conseguidas com FA.

Em uma série de quatorze experimentos instalados pelo Programa Integrado de Pesquisas Agropecuärias do Estado de Minas Gerais $(1972-1973)$, e usando soja, como plantateste em solos latossolos do Triangulo Mineiro com baixos teo res de $\mathrm{P}$ disponível e pH variando de 4,2 a 5,9 . FERRARI et alii (1976) verificaram respostas altamente significativas pa ra fösforo e tambëm efeito benëfico da calagem. Resultados se melhantes foram obtidos por SANTOS et alii (1977, 1978a e 1978 b) e SANTOS (1980).

Costa (1980), em ensaios com arroz de sequeiro no estado do Paranā, onde a baixa produtividade foi decorrēncia de fatores climäticos adversos, destacou que as respos tas eram maiores para as menores doses de fósforoutilizadas.

Em Paragominas, PA em solos de textura argilosa, os rendimentos acumulados de capim colonião (Panicum maximum) mostraram tendēncia linear em função de níveis de $P$, a plicadas à lanco como superfosfato triplo (Empresa Brasileira de Pesquisa Agropecuäria, 1980).

MORAIS e GONTIJO (1978), em experimentos com 
arroz de sequeiro no Triângulo Mineiro, observaram que producões mäximas foram obtidas com doses de 70 a $80 \mathrm{~kg}$ de $\mathrm{P}_{2} \mathrm{O}_{5} / \mathrm{ha}$ associadas a $60 \mathrm{~kg}$ de $\mathrm{N} / \mathrm{ha} e \mathrm{~kg}$ de $\mathrm{K}_{2} 0 / \mathrm{ha}$, em dois locais, em outro foi observada respostas 1 inear ate $120 \mathrm{~kg}$ de $\mathrm{P}_{2} \mathrm{O}_{5} / \mathrm{ha}$. Não houve efeito direto da calagem nos solos que apresentam pH de 4,7 a 5,1 . Respostas 1 ineares a adubacáo fosfatada de $120 \mathrm{~kg}$ de $\mathrm{P}_{2} \mathrm{O}_{5} / \mathrm{ha}$ foram tambëm obtidas por souzA et alii (1978) com a cultura do trigo nos mesmos solos.

BORKERT et alii(1978), estudando a eficiēncia de diversos fosfatos naturais brasileiros num Latossolo Bruno distrófico de Guarapuava (PR) com baixos teores de fósforo, verificaram que o fosfato de Catalão em forma natural foi in ficiente como fornecedor de fósforo para a soja.

Experimento com pastagem, tanto de gramineas como de leguminosas, tem tambēm evidenciado amplas respostas a adubaça fosfatada. Resultados obtidos por FERREIRA e CARVA LHO (1978) indicam que a maior produção acumulada de matéria seca de uma consorciação, capim gordura mais Stilosanthes, foi obtida com uma combinaça de $500 \mathrm{~kg}$ de $\mathrm{P}_{2} \mathrm{O}_{5} / \mathrm{ha}$ de fosfato de Araxá mais $250 \mathrm{~kg}$ de $\mathrm{P}_{2} \mathrm{O}_{5} /$ ha de superfosfato simples. 


\subsection{Comportamento dos fosfatos naturais}

A experiência acumulada nos ültimos anos tem demonstrado, como regra, que os fosfatos naturais brasileiros não podem competir com os fosfatos solubilizados (por via tér mica ou via àcida) como fonte de $\mathrm{P}_{2} \mathrm{O}_{5}$ para as plantas deverdo o seu uso concentrar-se principalmente na adubaçáo corretiva. MALAVOLTA (1981).

Diversos trabalhos foram conduzidos no Brasil com o objetivo de avaliar a eficiéncia agronómica dos fosfatos naturais. Trabalhos de DYNIA (1977), FEITOSA et alii (1978), KORNDURFER (1978) e BRAGA et alii (1980) mostraram, alèm de baixa eficiéncia dos fosfatos naturais apatiticos em relacão ao superfosfato triplo, a grande variabilidade desses fosfatos como fonte de fósforo para as plantas.

Inümeros autores tem demonstrado a maior efica cia das rochas fosfatadas em condições de acentuada acidez. GOEDERT e LOBATO (1980) estudaram a eficiência agronómica de onze fontes de fósforo, num Latossolo vermelho escuro de cerrado, e evidenciaram que a eficiencia dos fosfatos naturais è maior com o aumento da acidez do solo. BLANCo et alii (1965), trabalhando com o fosfato de Araxä, alëm de outros em très condições de $\mathrm{pH}$, verificaram que na faixa de $\mathrm{pH}^{4}, 7-5,0$, hou- 
ve melhor aproveitamento desses fosfatos. A calagem visando a elevação do $\mathrm{pH}$ acima de 5,5 proporcionou perdas da eficiéncia dos fosfatos empregados. ATANASIU (1971) tambëm encontrou melhores resultados para o fosfato natural aplicado em Latossolos de regióes tropicais com pH 4,9-5,1 quando comparados com uma fonte de fósforo solüvel em ägua.

A avaliação da eficiência agronômica de diferentes fosfatos naturais, em solos sob vegetaça de cerrado durante oito anos em experimentos de campo foi efetuada por GOEDERT e LOBATO (1984). Após esse tempo de reação com o so10, algumas das fontes estudadas não promoveram aumentos significativos nos teores de fósforo "disponível" e nas de cà cio e magnésio trocäveis. Tais resultados sugerem a baixa solubilidade dos fosfatos naturais ao longo do tempo.

Segundo RUSSEL (1973) "O efeito do fosfato de rocha como fertilizante é erratico; ele é ineficiente em alguns casos em solos äcidos com culturas para as quais era prevista a eficiência. $\hat{E}$ um fertilizante de valor muito limitado para a agricultura temperada intensiva, visto não poder manter uma alta concentração de $P$ na solução do solo para altas produções de culturas com grandes demandas iniciais de fósforo; e é usualmente inerte em solos neutros e calcários. Pode no entanto ser adequado para alguns solos nos sistemas 
de agricultura tropical onde não são esperadas altas produções e o $\mathrm{S}$ não è deficiente. KHASAWNEH e DoLl (1978), afirmam que as divergentes opiniões com respeito à eficiencia do fosfato de rocha podem ser resolvidas se forem consideradas as diferenças na compusição química e mineralógica das värias fon tes de fosfato de rocha e se os fatores que afetam a dissolucão das mesmas nos solos forem quantificadas pela aplicaço dos conhecimentos e aceitação dos principios de química de solos. Como ponto especifico, afirmam que, embora a fonte e a forma do fosfato de rocha sejam importantes, sua eficiência em um solo especifico, pode grandemente ser determinadas pelos fatores de solo.

De acordo com SILVA JR (1979), o fosfato objeto de este estudo, o fosfato de Catalão é de origem ignea pri mária de diferenciaça magmatica, ocorrências onde a apatita esta filiada a manifestações bäsico-alcalinas. Uma anälise típica do fosfato de Catalão é ada na Tabela 1.

Tabela 1 - Anälise de solubilidade e composição química do fosfato de Catalão.

\begin{tabular}{rcccccc}
\hline & \multicolumn{2}{c}{ Teor de $\mathrm{P}_{2} \mathrm{O}_{5}(\%)$} & & $\mathrm{CaO}$ & $\mathrm{F}_{2} \mathrm{O}_{3}$ & $\mathrm{Al}_{2} \mathrm{O}_{3}$ \\
Total & $\mathrm{CiNH}_{4}$ & Ac. Formico & Ac. Citrico & & $\%$ & \\
37,3 & 0,1 & 2,2 & 2,5 & 4,9 & $1,5-1,7$ & $0,2-0,5$ \\
\hline
\end{tabular}


2.3. Comportamento dos fosfatos parcialmente acidulados

Em decorréncia de o fösforo remanescente, que não é aproveitado pelas plantas, ser fixado formando complexas de aluminio e ferro de dificil solubilidade emägua, o uso de fosfatos solúveis pode não ser vantajoso. Segundo ILCHENKO e GUIMARÃES, citado por BRAGA et alii (1979), seria preferivel produzir um fertilizante rico em fosfato bicälcico em relação ao fosfato monocálcico, em razão das diferentes tạ xas de absorção pelas plantas. Vários trabalhos utilizando com binações de materiais fosfäticos solüveis com insolúveis, menores quantidades de äcido sulfürico para o ataque da rocha fosfätica e mesmo outras fontes de modificaçã mostraram resultados promissores (LUTZ, 1973; FERREIRA e KAMINSKI, 1979; ROCHA, 1981; NAKAYAMA, 1982 e FREIRE et alii, 1983).

MCLEAM e WHEELER (1964), acreditam que as respostas das plantas, comparativamente favoráveis a material parcialmente acidulado e à economia de sua produção parecem ter aplicação prätica promissora.

Em experimentos comparativos com fosfato natural acidulado a $20 \%$ e $100 \%$, LUTZ (1971) observou superioridade do material $100 \%$ acidulado, enquanto McLEAM e WHEELER (1964) estudando acidulaçóes semelhantes verificaram equiva - 
lēncia entre os tratamentos. Posivelmente tenham usado fosfatos naturais e solos diferentes.

$$
\text { FRANCO et alii (1979) e BUENO et alii }
$$

desenvolveram estudos, ensaiando diversos niveis de acidulacão de fosfatos de Patos e $\operatorname{Araxa}(5,15$ e $25 \%) \operatorname{com} \mathrm{H}_{3} \mathrm{PO}_{4}, \mathrm{HCl}$ e $\mathrm{H}_{2} \mathrm{SO}_{4}$, usando sorgo como planta teste, em solo com baixo teor de fösforo e que recebeu calagem a pH 7. As doses de fós foro aplicadas foram 25,50 e $100 \%$ de absorço mäxima. os resultados para produção de matéria seca em dois cultivos sucessivos, evidenciaram efeitos positivos de aumento no grau de acidulaça dos fosfatos naturais e doses de fósforo aplicado, havendo tratamentos que em certos casos superaram as producões obtidas com superfosfato triplo. BUENo et alii, (1979), observaram no terceiro cultivo, quedas sensiveis na produção de matéria seca de sorgo para todos os tratamentos envolvendo $\mathrm{H}_{3} \mathrm{PO}_{4}$ e HCl, e mesmo para o superfosfato triplo. Entretanto a acidulação parcial com $\mathrm{H}_{2} \mathrm{SO}_{4}$, tanto de fosfato de Patos, como de fosfato de Araxä mostrou considerável efeito residual no 3 o cultivo.

Outros trabalhos desenvolvidos em casa de vege tação tem mostrado as possibilidades dos FNPS. Razoãvel eficiência do fosfato de Patos $(61-68 \%)$, acidulado com $25 \%$ de $\mathrm{H}_{3} \mathrm{PO}_{4}$, em comparacão com superfosfato triplo foi observada em 
dois solos do Rio Grande do Sul que receberam calagem a pH 6,0 usando soja como planta teste (FERREIRA e KAMINSKI (1974).

MALAVOLTA et alii (1981) conduziram experimentos em um Latossolo Roxo em Jaboticabal, envolvendo as cultaras de soja, arroz emilho, em äreas que receberam calagem a pH 6,0 . Os autores observaram que para as produçós do prime ro ano, não houve diferenças significativas de produção para doses de 60 e $120 \mathrm{~kg} \mathrm{P} 2_{5}$ total/ha usando fosfato de Araxä parcialmente acidulado e $90 \mathrm{~kg} \mathrm{P}_{2} \mathrm{O}_{5}$ na forma de superfosfato simples. Resultados semelhantes foram obtidos para produção de cana planta nas doses de 160 e $120 \mathrm{~kg} \mathrm{P}_{2} \mathrm{O}_{5} / \mathrm{ha}$ usando fosfa to de Araxà parcialmente acidulado e superfosfato simples, res pectivamente (MALAVOLTA et alii, 1982).

\subsection{Comportamento dos termofosfatos}

Dentre todos os métodos conhecidos para aumentar o teor de fósforo solüvel dos fosfatos naturais de pouca reatividade, o mais eficiente, alèm da acidificaça total por ácidos fortes, é o tratamento térmico (fusão), na obtenção dos termofosfatos ou fosfatos de cálcio e magnésio fundidos. Dentre as vantagens deste fertilizante, além da fusão do mate rial apatitico elevando o teor de $\mathrm{P}_{2} \mathrm{O}_{5}$ solüvel em äcido cítri 
co de $5 \%$ para 19\%, cita-se o elevado teor de MgOe Sio, na forma de $\mathrm{CaSiO}_{3}$, sendo que este ültimo tem papel importante na efetividade dos fosfatos pela diminuição na fixação do fösforo em solos tropicais (LOPEZ, et alii, 1982).

o termofosfato è obtido por via térmica, pelo aquecimento da rocha fosfatada à temperatura que varia de $900-1500^{\circ} \mathrm{C}$, com ou sem aditivos, visando aumentar a sua solubilidade. Embora a estrutura da Apatita seja quebrada pelas elevadissimas temperaturas, o fosfato resultante permanece in solúvel em àgua, porém solúvel em äcidos (ANDA, 1975).

MUZILLI et alii (1971) compararam os efeitos de doses crescentes aplicadas a lanço, de termofosfato magnesiano, de fosfatos de Rhenania e do Superfosfato simples, em solos äcidos do Sul do Paranä ( $80 \%$ de alumínio trocävel). 0 fosfato Rhenania foi de boa eficiēncia tanto camo fonte de fösforo, como atenuador dos efeitos da acidez; o termofosfato mostrou melhor efeito na neutralização da acidez mas não foi comparável ao Rhenania no aumento da disponibilidade de fósfo ro. o superfosfato simples, embora tivesse aumentado satisfatoriamente a disponibilidade de fósforo nãomostrou efeitos na neutralização da acidez. Nesse estudo, oteor de fósforo solüvel foi determinado pelo método de Meh1ich.

BORKERT et a11i (1978) estudando a eficiēncia 
de diversos fosfatos naturais brasileiros num Latossolo Bruno distrófico, em condiçóes de primeiro cultivo de soja constata ram que o fosfato de Patos de Minas, olinda e o Termofosfato IPT aplicados a lanço (fosfatagem) mostraram uma eficiencia comparävel a do superfosfato triplo, principalmente quando receberam uma manutenção de $100 \mathrm{~kg}$ de $\mathrm{P}_{2} \mathrm{O}_{5}$ na forma de superfosfato triplo na linha de semeadura. Nessa condição, a eficiência desses fosfatos foj maior que $80 \%$.

o termofosfato pode dar produções $12-45 \%$ maiores que as obtidas com o superfosfato simples; esse efeito pode ser explicado pela combinaço de diversos fatores:

- Neutralização de acidez do solo;

- Fornecimento de cälcio e magnësio como nutrientes;

- Adição de micronutrientes;

- Diminuição na toxidez de Mn pelo silicato presente;

- Diminuicão da fixação de fösforo provocada pelo silicato (MALAVOLTA, 1980). 


\section{MATERIAL E METODOS}

0 ensaio foi conduzido em casa de vegetação no Centro de Energia Nuclear na Agricultura - CENA - Piracicaba, SP, no período de janeiro de 1984 a fevereiro de 1985 . Esse ensaio ficou constituído de cultivos simultâneos de arroz e soja num solo de cerrado e cultivo de Capim Colonião em suces são; visando o estudo do aproveitamento direto do fósforo nas duas primeiras culturas e o aproveitamento do fösforo residual em três cortes de capim, após a colheita de arroz e soja.

3.1. Solo

Foi utilizado um solo äcido de vegetação de cerrado, classificado como Latosol Vermelho Amarelo (LVA) tex tura média, coletado em Anhembi, SP. 
Foram feitas as anälises químicas deste solo, cujos resultados estão apresentados na Tabela 2 .

Tabela 2 - Anälise química do solo utilizado nos ensaios, antes do primeiro cultivo.

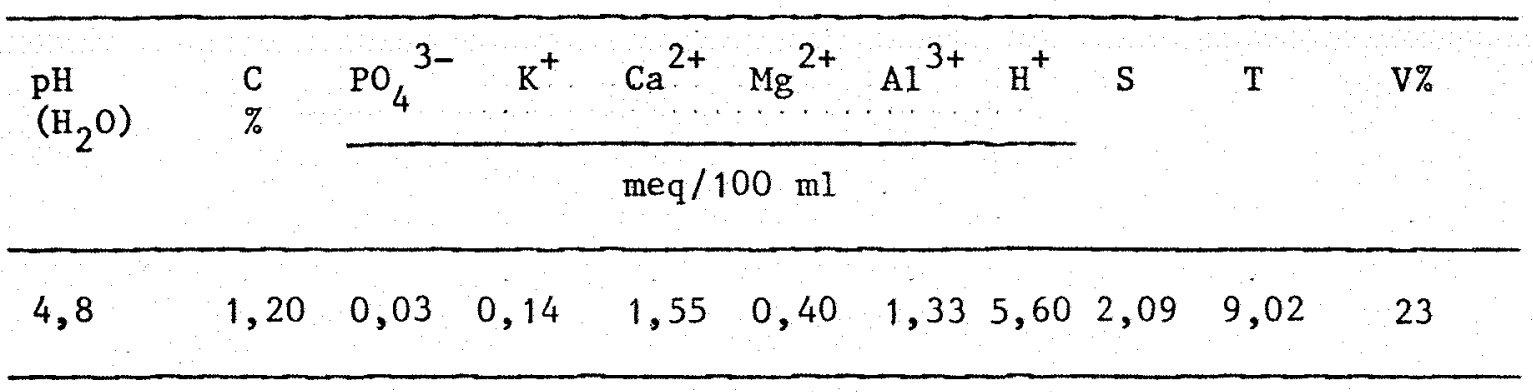

3.2. Culturas empregadas

Foram usadas três espécies, uma gramínea (Arroz IAC 164) e uma leguminosa (Soja IAC 3), no estudo do apro veitamento direto do $P$, e outra graminea (Capim Colinião), no aproveitamento do fósforo residual.

\subsection{Vasos}

Utilizou-se vasos de barro com capacidade para $2 \mathrm{~kg}$ de terra, impermeabilizados internamente com "neutrol"e dotados de coletores de barro, também impermeabilizados. Esses vasos continham no fundo um furo central de $1 \mathrm{~cm}$ de diáme 
tro aproximadamente, para permitir a drenagem.

\subsection{Doses e fontes}

a. Calagem - de acordo com as necessidades de cal para elevar a porcentagem de saturação de bases a $60 \%$ para arroz e $70 \%$ para soja (RAIJ, 1981).

Fonte: $\mathrm{Ca}(\mathrm{OH})_{2} \mathrm{~Pa}$.

b. Fōsforo - foram usadas três doses de P, com base no teor total de $\mathrm{P}_{2} \mathrm{O}_{5}$ dos produtos: 0 , 150 e $300 \mathrm{ppm}$. o Padrão foi empregado numa dose intermediäria de $225 \mathrm{ppm}$.

fontes; F.C.P.S.; fosfato natural de Catalão, do Estado de Goiäs, solubilizado parcialmente com $\mathrm{H}_{2} \mathrm{SO}_{4}$, usando-se cal extinta como moderador. Possui $27-28 \%$ de $\mathrm{P}_{2} \mathrm{O}_{5}$ total e $12 \%$ de $\mathrm{P}_{2} \mathrm{O}_{5}$ solü vel em äcido citrico $(2 \%)^{*}$.

F.C.T.F.; termofosfato magnesiano produzido com fosfato natural de Catalão, do Estado de Goiás. Possui $20 \% \mathrm{P}_{2} \mathrm{O}_{5}$ total, $18 \% \mathrm{P}_{2} \mathrm{O}_{5}$ solúvel em àci do citrico $2 \%$, e $7 \%$ de $\mathrm{Mg}^{*}$

* Dados fornecidos pelo produtor. 


$$
\begin{aligned}
& \text { superfostato triplo; fosfato com } 45 \% \text { de } \mathrm{P}_{2} \mathrm{O}_{5} \text {, } \\
& \text { solúvel em ảgua (padrão), } \\
& \text { c. Nitrogēnio - no caso de Arroz, empregou-se } \\
& 200 \text { ppm de } \mathrm{N} \text { em três aplicações }
\end{aligned}
$$

$$
\begin{aligned}
& 1 \text { a aplicação }-50 \text { ppm no plantio } \\
& 2 \text { a ap licação }-75 \text { ppm no perfilhamento } \\
& 3^{a} \text { ap } 1 \text { icação }-75 \text { ppm } 3 \text { semanas após a } 2^{\text {a aplicação }}
\end{aligned}
$$

No caso de Soja, empregou-se 25 ppm de $N$ só no plantio.

Fonte: Urēia $(46 \% \mathrm{~N})$.

d. Potāssio - 50 ppm de K para cada cultura.

Fontes: Cloreto de Potāssio (KCI)

$$
\begin{aligned}
& \text { e. Magnésio e Enxofre - } 20 \text { ppm de } \mathrm{Mg} \text { e } 28,8 \\
& \text { ppm de S. }
\end{aligned}
$$

Fonte: Sulfato de Magnésio $\left(\mathrm{MgSO}_{4} \cdot 7 \mathrm{H}_{2} \mathrm{O}\right)$

f. Micronutrientes - para ambas as culturas em pregou-se 0,5 ppm de Boro, 0,05 ppm de Mo libdênio e 2,5 ppm de Zinco

Fontes: $\mathrm{H}_{3} \mathrm{BO}_{3} \mathrm{p} \cdot \mathrm{a}, \mathrm{MOO}_{4} \mathrm{NH}_{4} \mathrm{p} \cdot \mathrm{a}$ e $\mathrm{ZnSO}_{4} \cdot 7 \mathrm{H}_{2} \mathrm{O}$ p.a. 
3.5. Soluções e suspensões

$$
\begin{aligned}
& N-5,55 \text { g de uréia em } 1 \text { litro de água } \\
& 10 \mathrm{ml}=25 \mathrm{mg} \mathrm{N} \\
& \mathrm{K}-10,86 \mathrm{~g} \text { de } \mathrm{KCl} \text { em } 1 \text { 1itro de água } \\
& 10 \mathrm{mI}=50 \mathrm{mg} \mathrm{K} \\
& \mathrm{Mg}-20 \mathrm{~g} \mathrm{MgSO} 4 \cdot 7 \mathrm{H}_{2} \mathrm{O} \text { em } 1 \text { litro de àgua } \\
& 10 \mathrm{ml}=20 \mathrm{mg} \mathrm{Mg} \mathrm{e} 28,8 \mathrm{mg} \mathrm{S} \\
& \text { MICRONUTRIENTES - } 300 \mathrm{mg} \mathrm{H}{ }_{3} \mathrm{BO}_{3}+10 \mathrm{mg} \text { molibdato de amo } \\
& \text { nio+1.14 } \mathrm{g} \mathrm{ZnSO}_{4} \cdot 7 \mathrm{H}_{2} \mathrm{O} \text { em } 1 \text { litro } \\
& \text { de àgua } \\
& 10 \mathrm{ml}=0,5 \mathrm{mg} \quad \text { B } 0,05 \mathrm{mg} \\
& \text { de } \mathrm{Mo}+2,5 \mathrm{mg} \mathrm{Zn} \\
& \text { F.C.P.S. - } 16,6 \text { g em } 1 \text { 1itro de ägua } \\
& 25 \mathrm{~m} 1=50 \mathrm{mg} \mathrm{P} \text {. } \\
& \text { F.C.T.F. - 22,2 g em } 1 \text { litro de ägua } \\
& 25 \mathrm{ml}=50 \mathrm{mg} \cdot \mathrm{P} \\
& \text { S.P.T. - } 10,2 \text { g em } 1 \text { litro de água } \\
& 25 \mathrm{ml}=50 \mathrm{mg} \mathrm{P}
\end{aligned}
$$

As doses de adubos em solução ou suspensão en contram-se nas Tabelas 3 e 4 . 


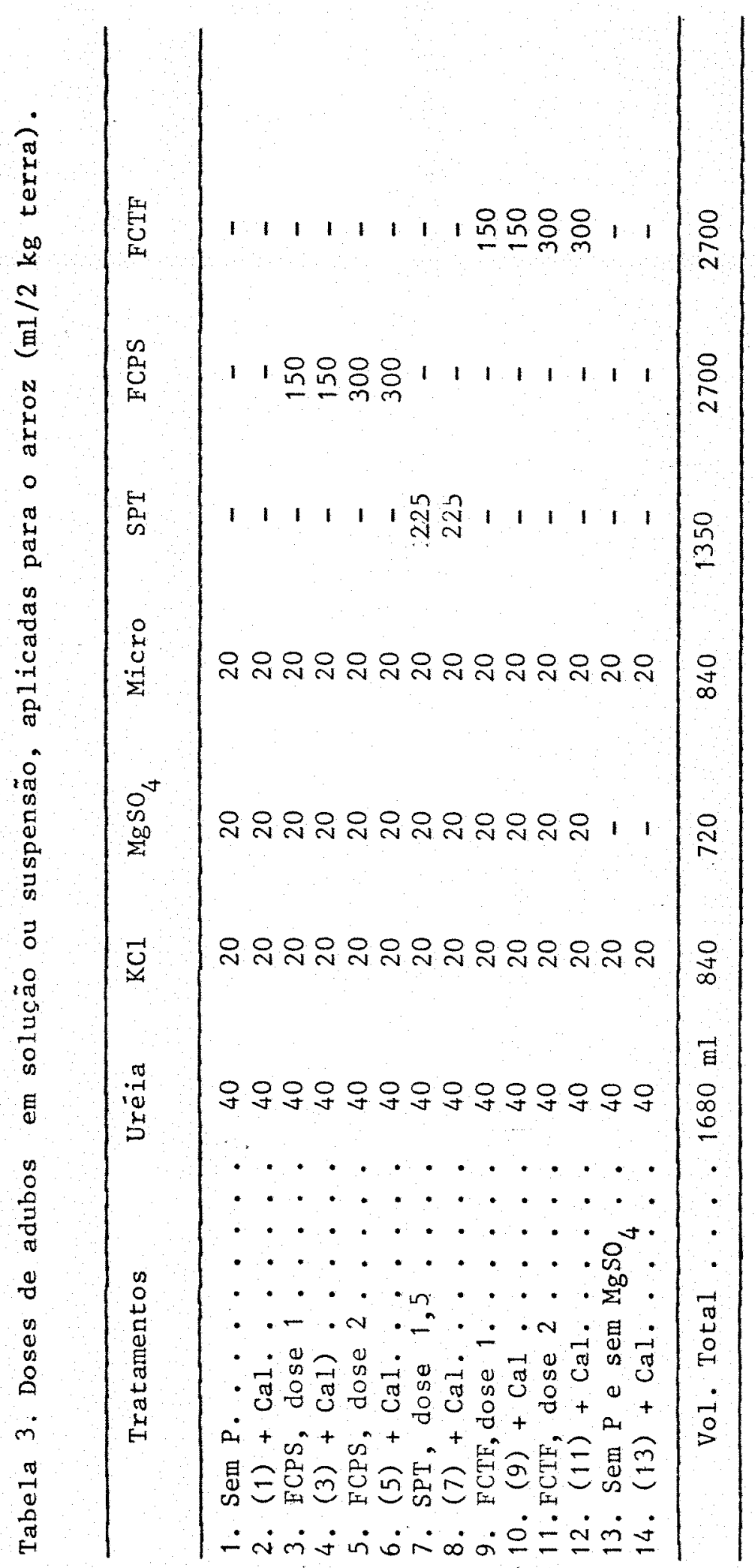




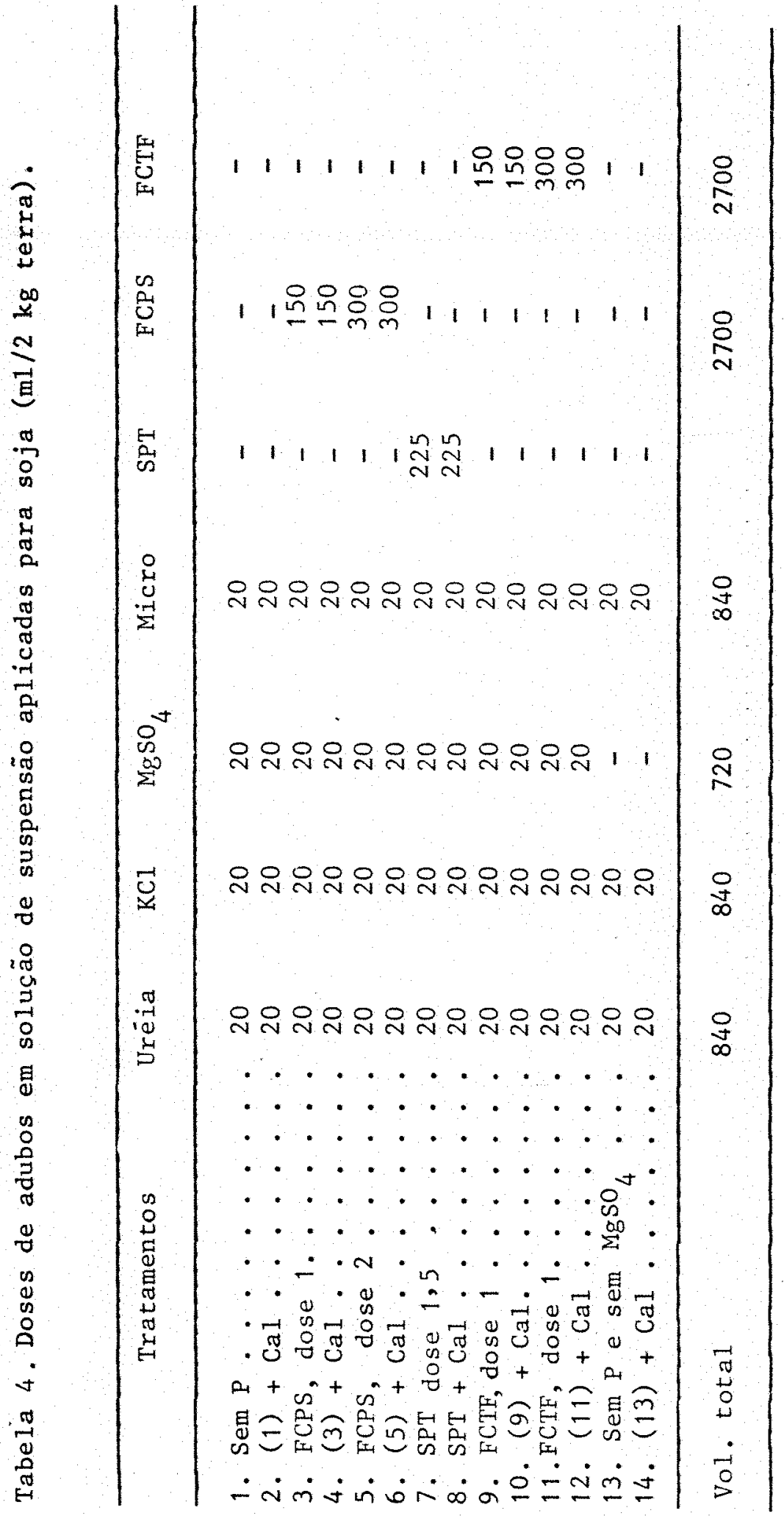




\subsection{Tratamentos}

Os tratamentos empregados para cada cultura fo ram os da Tabela 5 .

\subsubsection{Calagem}

A quantidade de carbonato de cälcio determina da pela anälise de solo para satisfazer a necessidade de cal transformada em quantidade de cal extinta, para lograr uma mo dificação do $\mathrm{pH}$ em menor tempo.

os vasos que receberam calagem foram mantidos com $60 \%$ de poder de embebição durante 15 dias; : retirou-se a terra dos vasos, deixou-se secar e se devolveu novamente aos vasos.

3.6.2. Del ineamento experimental

o delineamento experimental utilizado foi o inteiramente casualizado com quatorze tratamentos e três repe tições, perfazendo um total de quarenta e dois vasos para arroz e soja, respectivamente. 
A relação dos quatorze tratamentos e as doses e fontes de adubos fosfatados encontram-se na Tabela 5 .

Como pode ser observado na Tabela 5, colocou -se um tratamento extra, tirando além do fósforo o sulfato de magnésio. Este tratamento foi colocado para avaliar o efeito do magnésio nativo do solo, pois o FCTF contém óxido de magné sio na sua composição.

3.7. Instalação do ensaio com arroz e soja

(1) Foram colocados $2 \mathrm{~kg}$ de terra (TFSA) em cada um dos 84 vasos, em metade dos vasos foi apiicada cal extinta em suspensão na dose correspondente à necessidade de cal.

(2) Os vasos que receberam calagem foram mantidos com 60 e $70 \%$ de poder de embebição durante 15 dias para arroz e soja respectivamente; logo após a terra foi retirada dos vasos, deixou-se secar e devolveu-se aos vasos novamnte.

(3) Os vasos foram numerados consecutivamente, fican do 3 para cada tratamentio.

(4) Foram aplicados os adubos de acordo com a Tabe 


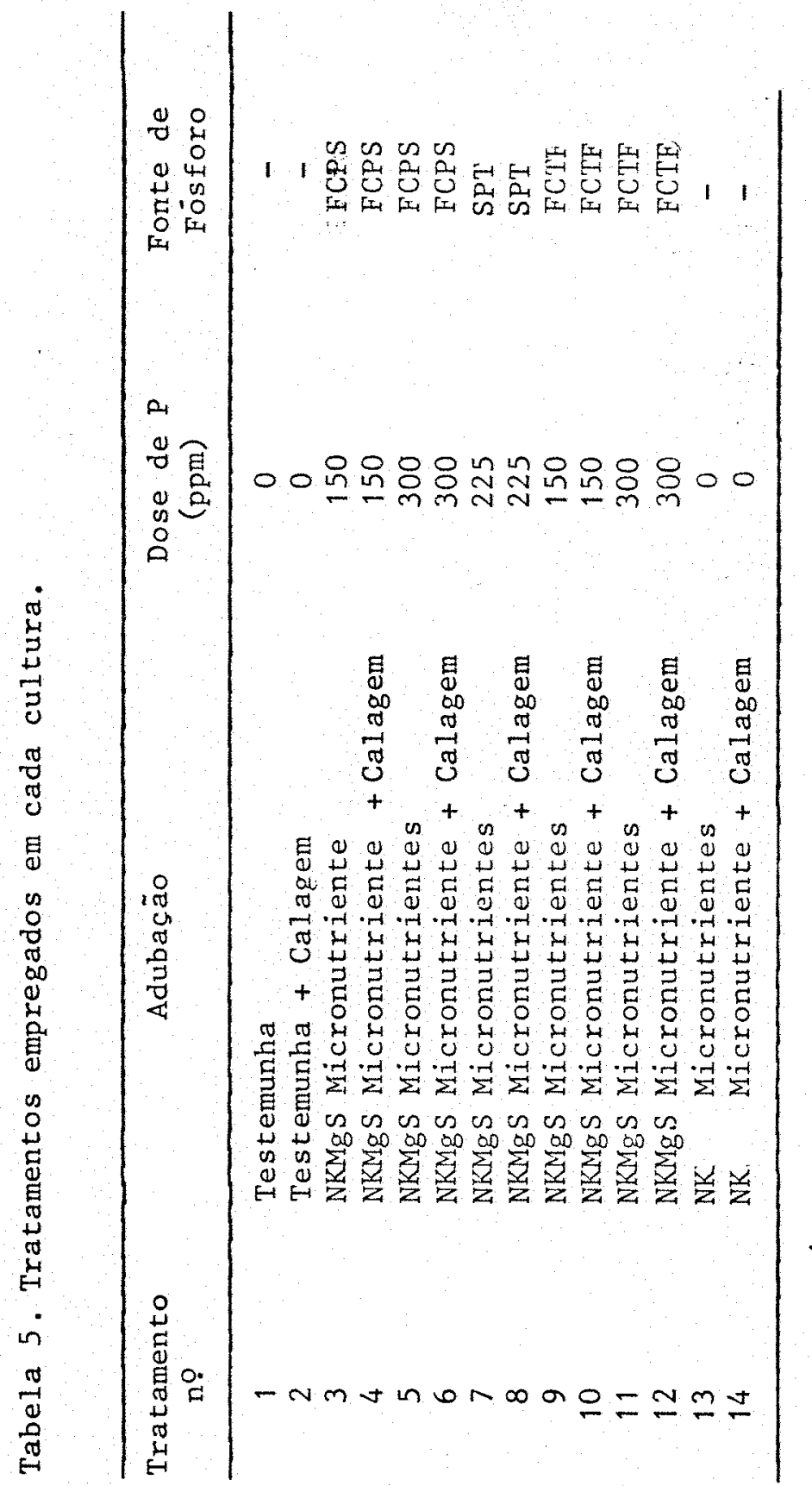


la 3 e Tabela 4, espalhando a terra de 3 vasos ( $=3$ repetições), de um mesmo tratamento sobre um plästico 1 impo, juntando otriplo das quantida des da tabela, misturando tudo uniformemente e devolvendo-os aos vasos.

(5) Juntou-se a quantidade de água destilada necessạ ria para completar $60 \%$ e $70 \%$ de poder de embeb ção, descontando o volume das soluções aplicadas : Em seguida alguns vasos foram escolhidos ao acaso pesadas e seus pesos anotados.

(6) Foram plantadas 10 sementes de arroz nos vasos correspondentes e 10 sementes de soja inoculadas com Rhizobium, 0s plantios foram realizados em $08 /$ $02 / 84$ e $02 / 03 / 84$, respectivamente.

(7) Foi feito o desbaste deixando 5 plantas de arroz e três de soja.por vaso.

(8) Este ensaio foi conduzido durante 3 meses, no fim do ciclo do arroz e no início do amadurecimento das vagens da soja. Então realizou-se a co 1heita. 
3.8. Instal ação do ensaio com Capim Colonião

(1) Após a colheita do arroz e da soja, os vasos con tendo a terra com as raízes de ambas as cultu ras. Foram deixadas durante certo tempo para a terra se secar.

(2) Logo após esse período foram retiradas as raízes e a terra novamente, colocada em cada va so.

(3) Foram colocados os adubos: Uréia, cloreto de po tássio e micronutrientes conforme Tabela 3 do ensaio sobre o efeito direto em arroz.

(4) Foi feito o plantio nos 84 vasos, sendo realiza do em $12 / 07 / 84,20 / 07 / 84$ e $04 / 08 / 84$. No ültimo plantio colocou-se uma camada fina de areia para auxiliar a germinação.

(5) Os vasos mantiveram a mesma numeração anterior, sendo dividido o ensaio em: Capim Colonião após arroz, vasos com numeração desde 1 até 42 e Ca pim colonião após soja, vasos com numeração des de 43 até 84 . 
(6) Este ensaio foi conduzido até o dia $08 / 02 / 85$, da ta em que realizou-se o teceiro corte. Logo apös esperou-se certo tempo para deixar a terra secar em 25/04/85 foram extraídas as raízes e poste riormente tomadas as amostras de solo.

\subsection{Condução}

\subsubsection{Regas}

Durante todo o período experimental foi adi cionada água diariamente. Nos primeiros dias, os vasos foram pesados e restituido o peso da água evaporada e consumida pe las plantas, tirando-se uma média que se aplicou a todos os vasos. Na medida que as plantas cresceram a quantidade de $\underline{a}$ gua não foi mais estimada pelo peso dos vasos, sendo feita essa estimativa observando-se o grau de umidade e a aparência das plantas. Estas regas foram efetuadas comágua destilada.

\subsubsection{Desbaste}

Após a germinação fez-se o desbaste deixando 5 plantas de arroz, 3 plantas de soja e 5 plantas de capim por vaso.

\subsubsection{Adubação em cobertura}

A adubação em cobertura de nitrogênio e potás sio foram aplicadas nos vasos individualmente nas épocas e vo 
lumes indicados, sendo para arroz $2 / 3$ das doses de $N$ e $K$ no perfilhamento, para soja $1 / 3$ da dose de $\mathrm{K} 1$ mês após o plan tio e para Capim Colonião cobertura com $\mathrm{N}$ e $\mathrm{K}$ de acordo com o desenvolvimento.

\subsubsection{Colheita}

0 arroz foi colhido 3 meses após o plantio, em 14.05.84, no fim do ciclo. Foi realizada a colheita dos grãos (com casca) e as plantas foram cortadas ao nível do solo, am bos os materiais foram colocados separadamente em sacolas de pa pe1. A seguir foram secados em estufa a $70-80^{\circ} \mathrm{C}$ até peso cons tante, pesados, inoidos e guardados para posterior anālise.

A soja foi colhida na mesma época em 14.05.84, no amadurecimento das vagens. Primeiro foi realizada a colhei ta das vagens e logo as plantas foram cortadas ao nível do so 10, e do mesmo modo que para arroz ambos os materiais foram colocados em sacolas de papel e encaminhados ao laboratório para seguirem os mesmos passos.

No caso do Capim, o primeiro corte foi realiza do dois meses após o plantio, o segundo corte dois meses após - 19 e o terceiro 2 meses após o 29 e se deram nas seguintes ē pocas: $08.10 .84,11.12 .84$ e 08.02 .85 . As plantas foram corta das ao nível do solo, colocadas em sacolas de papel e enca minhadas ao igual que para arroz e soja. 
o solo foi deixado secar nos vasos durante a1gum tempo.

De cada vaso retirou-se uma pequena amostra de terra e combinaram-se as 3 repeticões numa amostra ünica, sen do um total de 28 amostras de solo.

3.10. Anälises quǘmicas

\subsubsection{Plantas}

Para se efetuarem as anälises minerais, foram preparados extratos através de digestão nitro perclörica fim de determinar-se P, K, Ca, Mg e S ( SARRUGE e HAAG, 1979). os procedimentos analiticos utilizados foram: para N - determinação por titulação (micro-Kjeldahl), P - colorimetria $K$, Ca e Mg por espectrofotometria de absorcão atómica e $S$ por turbidimetria.

Todas essas anälises foram realizadas na matéria seca das trés culturas. 


\subsubsection{Solos}

As amostras de solo foram analisadas no Departamento de Solo e no Departamento de Quimica da Escola Superior de Agricultura "Luiz de Queiroz" da Universidade de São Paulo. o método utilizado na determinação de fósforo foi o da resina trocadora de ions (RAIJ e QUAGGIO, 1983),

\subsection{Anāijses estatísticas}

As anälises estatísticas foram efetuadas

no Centro de Informātica da "ESALQ/USP".

Foram considerados 4 experimentos com 14 trat a mentos cada e três repetições por tratamento. Assim, conside rando-se um delineamento experimental inteiramente casualiza do, submetido à anāise de variância, de acordo com o esquema da Tabe1a 6 . 
Tabela 6. Esquema da anālise de variância aplicado nos ensaios com arroz, soja e capim.

Fontes de variação G.L.

Tratamentos

Resíduo

14

Tota 1

Foram ainda efetuadas anälises de médias de tratamentos pelo teste de Tukey e anälise de regressão polino minal para fontes de fósforo com três doses. 


\section{RESULTADOS E DISCUSSÃO}

4.1. Ensaios com arroz de sequeiro e soja para determinar o efeito direto do fosfato de Catalão parcialmente so lubilizado (FCPS) e com tratamento de fusão

( $F C T F)$ sobre a produção de matēria seca da parte aérea e produ cão de grãos e vagens respectivamente

4.1.1. Produção de matéria seca da parte aérea de arroz e produção de grãos comi cascas

Na Tabela 7 são apresentados os dados de produ cão de matéria seca da parte aérea e grãos de arroz de sequeí ro, e igualmente são apresentados os dados para soja. 

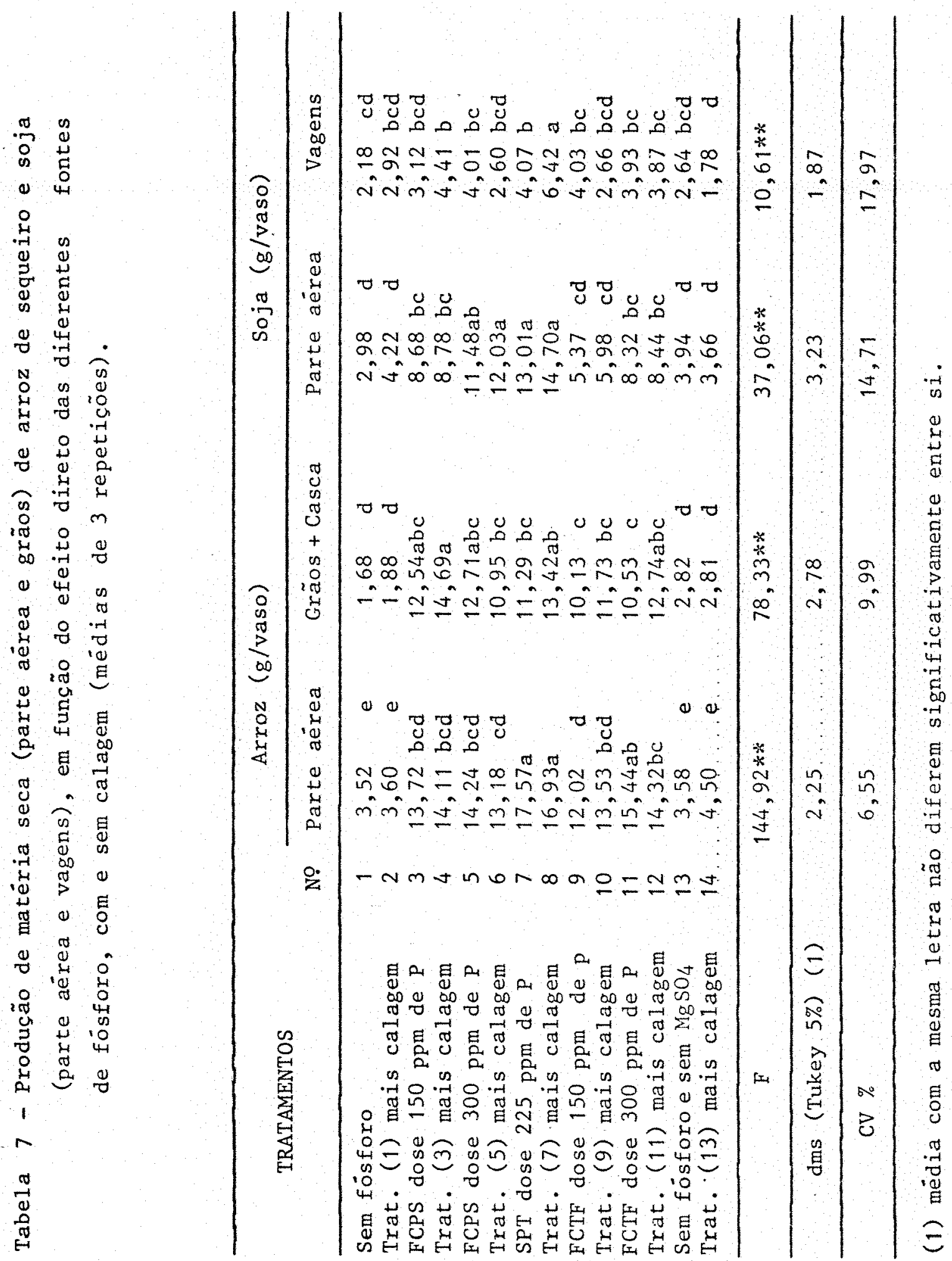
A anälise da variancia mostrou uma diferença altamente significativa entre os tratamentos, tanto para produção de matéria seca da parte aērea, quanto da produção de grãos. Ao proceder a anälise de contraste de médias gerais dos tratamentos, pelo teste de Tukey $5 \%$ verifica $=s e:$

a) os tratamentos que receberam superfosfato triplo na dosagem intermediäria independentemente da aplicação de calagem, tiveram produções superiores àqueles em que se empregou o fosfato de Catalão parcialmente solubilizado (FCPS) e com tratamento de fusão (FCTF), embora o FCTF na dose de $300 \mathrm{ppm}$ de $\mathrm{P}$ sem calagem igualou-se estatisticamente, ao SPT. Quando se compararamentre si o FCPS e FCTF não houve diferencas entre eles para producão de matéria seca, porém superaram os tratamentos que não receberam fósforo.

b) em relação aos dados de produção de grãos na mesma tabela pode-se observar que o melhor tratamento foi para o FCPS na dose 150 ppm de $P$ com calagem, não diferin do estatisticamente, da mesma dosagem sem calagem, e da dosagem dupla sem calagem para a mesma fonte, de igual forma do SPT na dose intermediária com calagem e do FCTF na dose de $300 \mathrm{ppm}$ de $\mathrm{P}$ com calagem. Todos os tratamentos que receberam fösforo, com exceção dos dois melhores tratamentos não diferi ram entre si, ou seja, que ambos os adubos competiram com o 
SPT respeito de produção de grãos com cascas. os resultados obtidos mostram que o fosfato de Catalão modificado parcialmente é mais eficiente que o produto na sua forma natural, pois os trabalhos desenvolvidos até agora com o fosfato de Catalão puro a eficiência encontrada tem sido muito baixa com relação ao superfosfato triplo (KLIEMANN et alii, 1977 ; COSTA et alii, 1978; BORGES et alii, 1979; MENDOZA et a1ii, 1979 ; MACHADO et aIii, 1978; LIMA, 1981).

Com respeito as doses empregadas, nos tratamen tos em que se utilizou o FCPS e o FCTF com e sem calagem ( ig. 1 e 2), houve correlação positiva e altamente significativa com exceção de doses de FCPS com calagem que mostrou uma rela ção quadrätica, sendo linear e positivo o aumento na produção de matéria seca e de grãos verificados da dose 0 para a dose 150 ppm de $\mathrm{P}$ experimentando uma diminuição na dose dupla. Este comportamento do FCPS, era de se esperar tratando-se de um fosfato natural tratado pois a elevaçáo do pH do solo e o aumento da concentração de Ca na solução tem efeito antagónico na solubilidade do fosfato (KHASAWNEH e DOLL, 1978). 

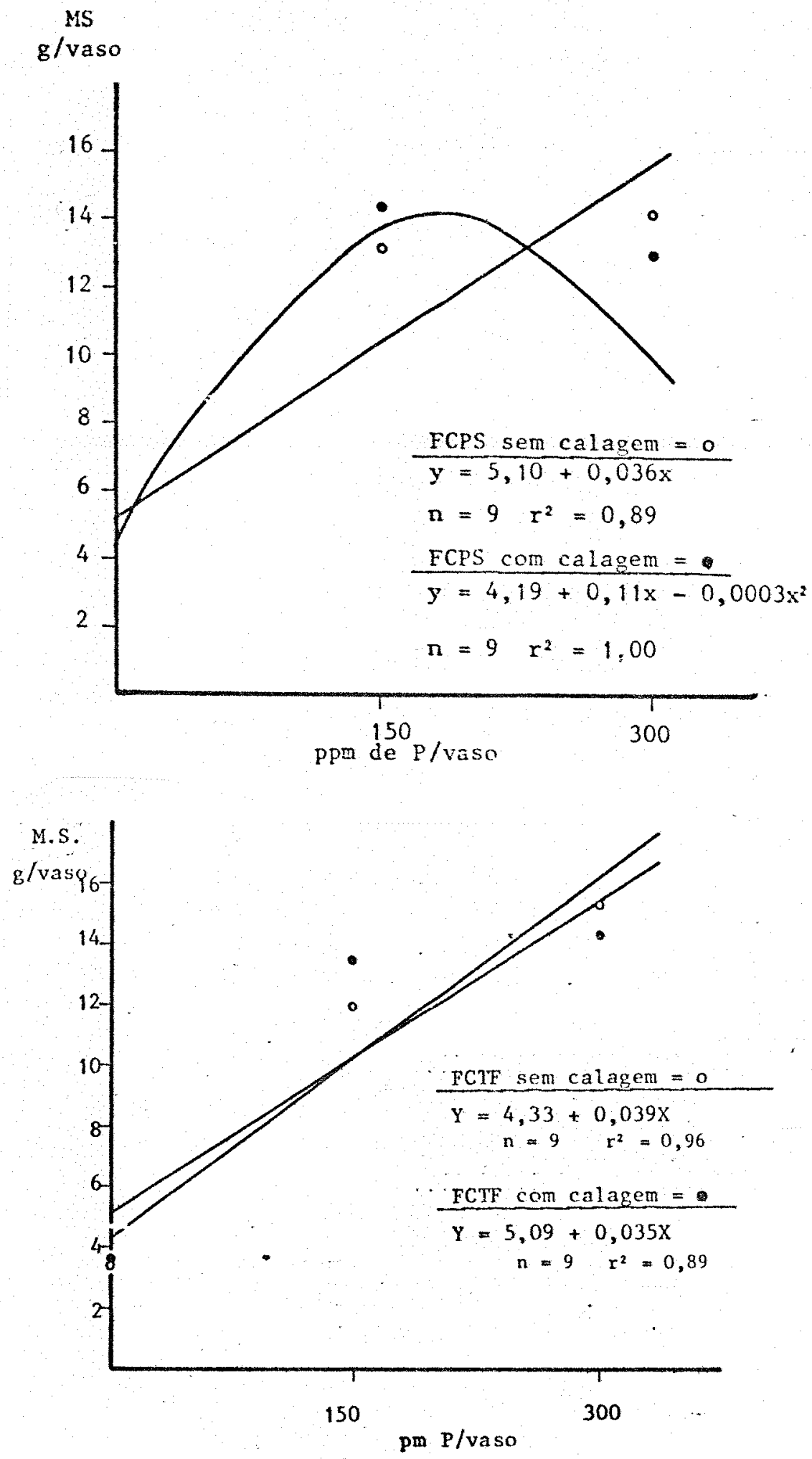

Figura 1 - Efeito das doses de P empregadas sobre a produção de matéria seca do arroz (parte aérea). 
g/vaso
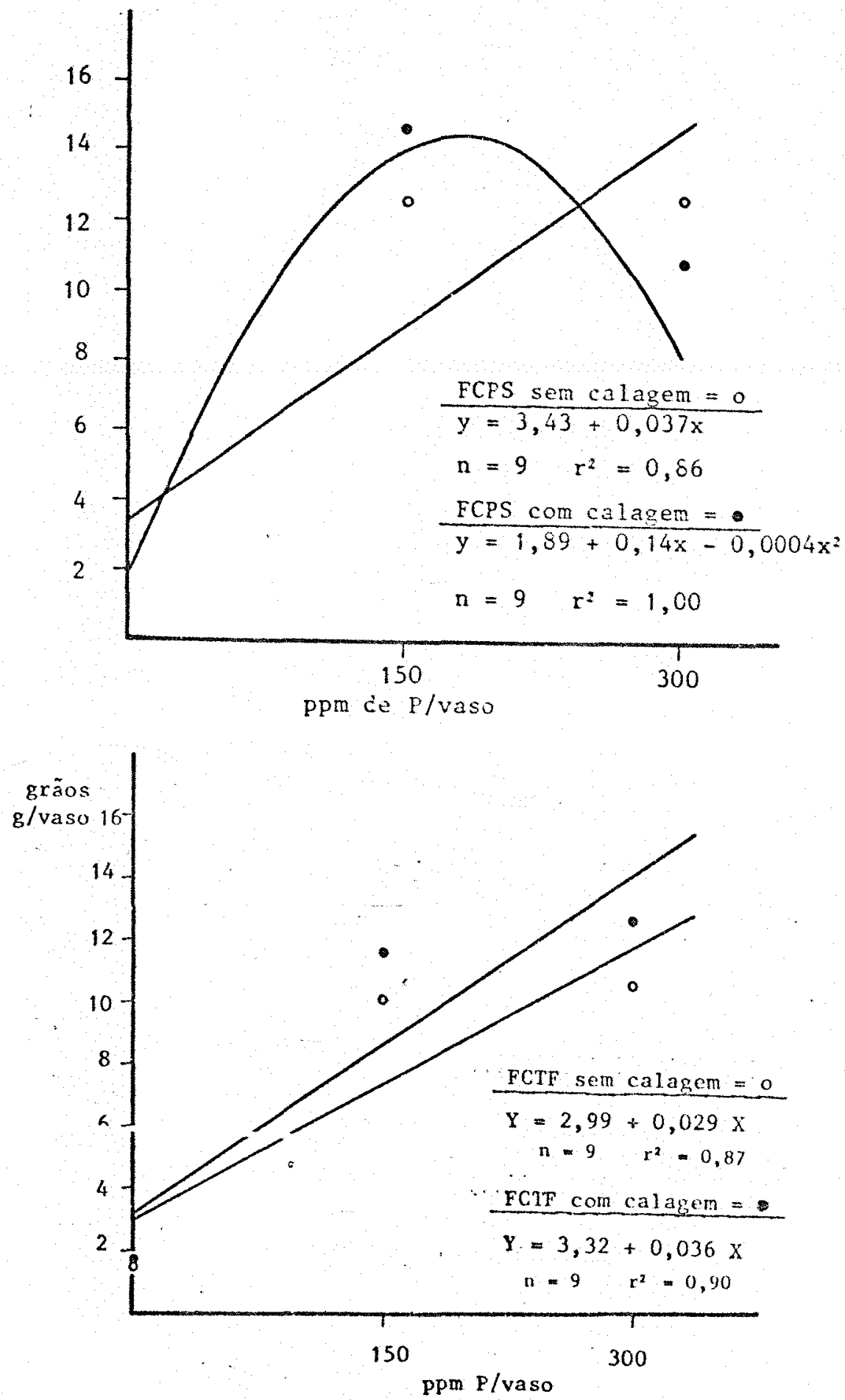

Figura 2 - Efeito das doses de $\mathrm{P}$ empregadas sobre a produção de grãos com casca do arroz. 
4.1.2. Produção de matéria seca da parte aērea da so ja e produção de vagens.

os ảados de produção, estão apresentados na Tabela 7. A análise de variância mostrou ser altamente signi ficativo, o efeito dos tratamentos nos dois casos. A anälise das médias de tratamentos pe10 Teste de Tukey $5 \%$ mostrou a) como era de se esperar as maiores produção de matéría seca foram para os tratamentos com SPT independentemente da aplicação de calagem. O FCPS mostrou-se estatisticamente tão efi ciente quanto o SPT; o FCTF foi menos eficiente, porém as mëdias de seus tratamentos não diferiram dos tratamentos com FCPS, mas também não diferiu dos tratamentos que não receberam fösforo; b) na produção de vagens novamente as maiores produções foram para o SPT, mas não houve diferenças estatís ticas com os outros tratamentos a exceção do tratamento sem fósforo e tratamento sem fósforo e sem magnésio com calagem (tratamentos 1 e 14 respectivamente).

Pode-se verificar que em termos de equivalència das fontes de fösforo em relação ao superfosfato triplo, - FCPS encontra-se numa posição quase equivalente. Trabalhos usando fosfatos parcialmente solubilizados, tem demonstrado ser possivel obter produções iguais ou mesmo superiores às verificadas para fontes solúveis (MCLEAN e WHEELER, 1964 ; 
FERREIRA e KAMINSKI, 1979 e FRANCO et alii, 1979). Por outro lado o FCTF mostrou resultados contraditórios com as pesqui sas realizadas envolvendo termofosfatos, as quais, em diversas ocasiöes tem demonstrado ser tão eficientes quanto os fer tilizantes fosfatados soluveis em àgua (SILVA et alii, 1973; MUZILLI et alii, 1971 ; BORKERT et alii, 1978 ; e COEDERT e LOBA To, 1984). A diferenca de comportamentos do FCTF com respeito a outros termofosfatos podem ser atribuidos a suas constituições pois o fosfato de Catalão é um fosfato apatitico de origem ignea com pequeno grau de substituição em sua estrutura cristalina e os fosfatos empregados na fabricaço de outros termofosfatos apresentam alto grau de substituicão de $\mathrm{PO}_{4} 3-$ pe 10 $\mathrm{CO}_{3}{ }^{2-}$, sendo por isso, mais facilmente solubilizados que o primeiro (LEHR et alii, 1967 e LEHR e McCLEHAN, 1972).

FERREIRA e KAMINSKI (1979), trabalhando com fosfato de Patos de Minas calcinado, a 300,600 e $900^{\circ} \mathrm{C}$ com resfriamento em ambiente natural, obteve resultados de rendimento de matéria seca e fósforo absorvido equivalentes ao pro duto não tratado.

Com relação às doses empregadas nos tratamentos com FCPS e FCTF come sem calagem, a anälise de regressão para ambas as fontes na produção de matéria seca houve uma correlaça linear positiva e altamente significativa sendo os coeficientes de correlação $\left(r^{2}\right)$ de $0,98,0,91,0,98$ e. 0,99 pa 
ra FCPS e FCTF com e sem calagem respetivamente (Fig. 3 e 4). No caso de producão de vagens os resultados foram muito diferentes, o FCPS sem calagem manteve uma correlação linear positiva $\left(r^{2}=1,00\right)$, porém, com calagem apresentou uma corre lação quadrätica, tendo uma elevada producão com a dose 150 ppm de $\mathrm{P}$ e uma diminuicão na dose dupla, para o FCTF ambas as curvas foram quadräticas, mas a diminuição da produção nas dosagens sem calagem nãofoi significativa, poder-se-ia dizer que a produ ção alcançada com a dose $150 \mathrm{ppm}$ p se manteve na dose de 300 ppm de P. Com as coses que receberam calagem a diminuição de produ ção ocorreu com a dose $150 \mathrm{ppm}$ de $\mathrm{P}$ e a maior produção com a dose dupla de $P$, ou seja que o FCTE mostrou-se mais eficiente na dosagem maior de $P$ com calagem.

4.2. Teores e absorção de nutrientes correspondentes aos dois ensaios realizados

4.2.1. Teores e absorcão de nutrientes no arroz parte aérea e grãos mais cascas

os resultados sobre os teores de nutrientes na matëria seca e quantidades absorvidas encontram-se nas Tabelas 8 e 9 respectivamente. As anälises estatisticas realizadas (Tes 

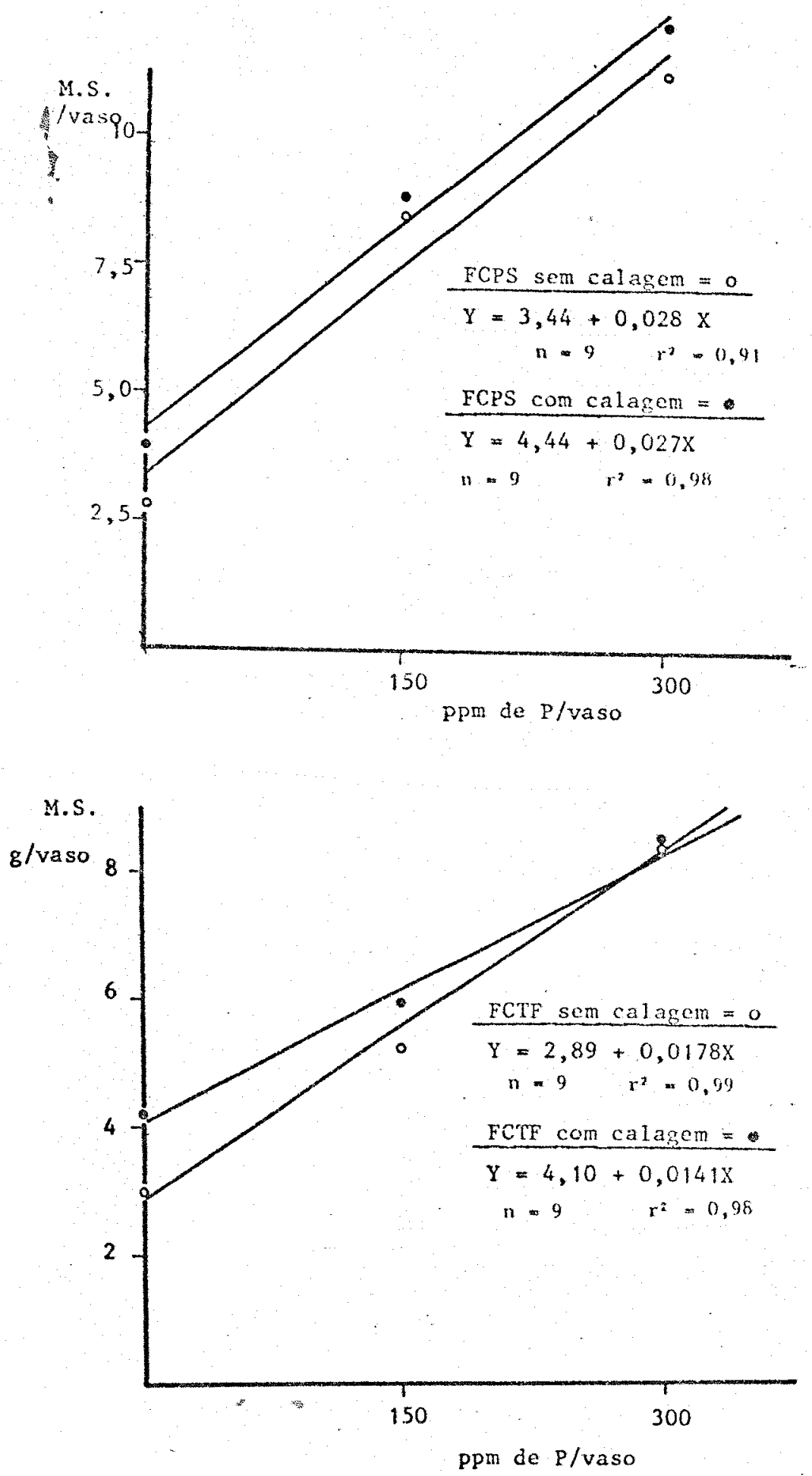

Figura 3 - Efeito das doses de p empregadas sobre a producão de matéria seca da soja (parte aérea). 

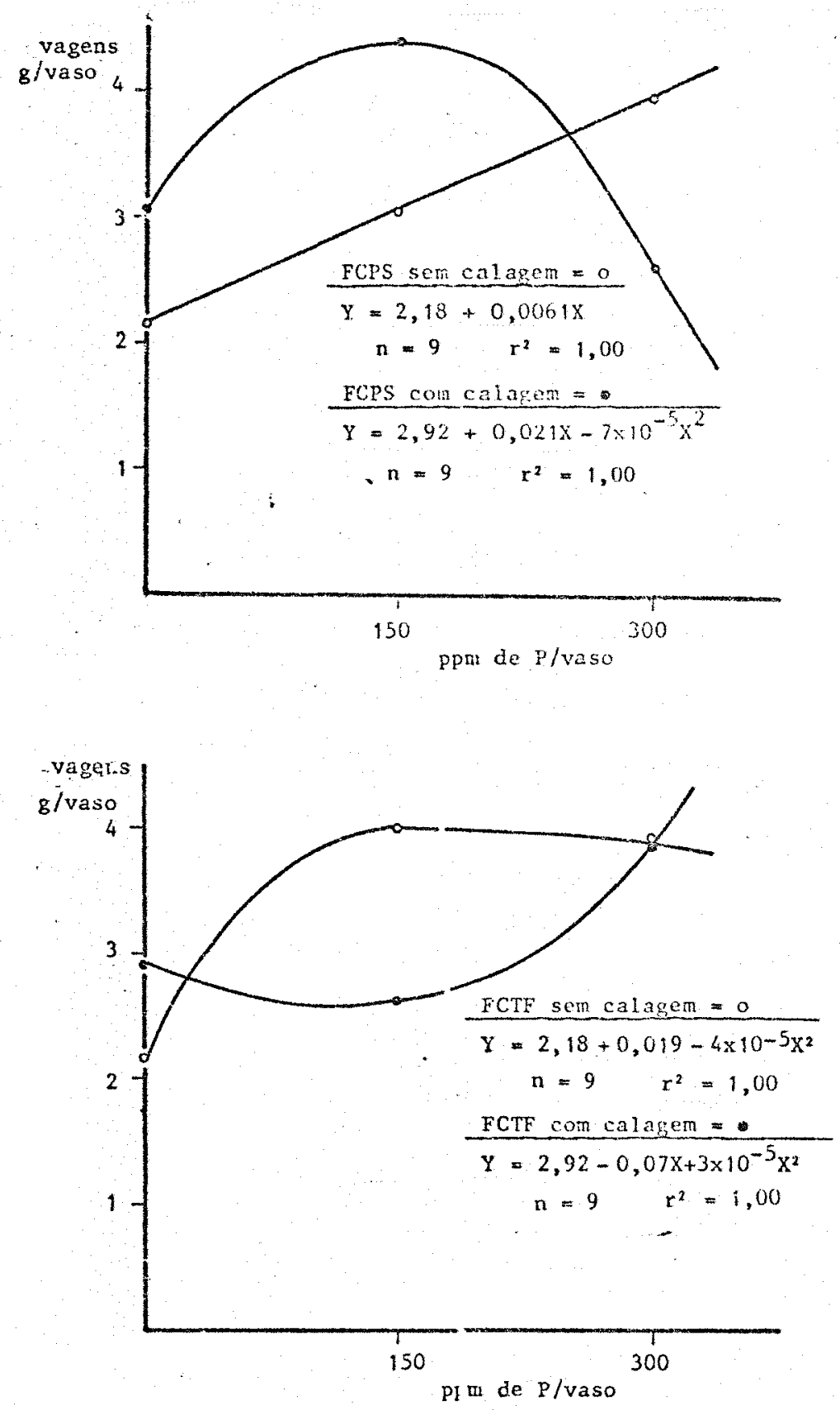

Figura 4 - Efeito das doses de $\mathrm{P}$ sobre a produção de vagens ảa soja. 
te de Tukey 5\%), indicam que nos tratamentos que. receberam FCPS, independetemente nas doses e da aplicação de calagem, os teores de $\mathrm{N}, \mathrm{K}, \mathrm{Ca}$; $\mathrm{Mg}$ e não diferiram estatisticamente dos encontrados para o tratamento que recebeu SPT na dose intermediäria sem calagem (padrão). No caso do P, todos os tratamentos que receberam FCPS não diferiram estatisticamente dos tratamentos que não receberam fösforo. Na absorção dos nutrientes a situação se manteve quase igual, houve mais absorção de $N$ quando os tratamentos não receberam calagem, o conträrio ocorreu com $\mathrm{K}, \mathrm{Ca}$ e $\mathrm{Mg}$; o $\mathrm{S}$ não apresentou diferencas entre dosagens, nem calagem. 0 P foi absorvido em quantidades muito inferiores às obtidas com o padrão e estatisticamente équivalentes aos tratamentos que não receberam fósforo. Isto concorda com os trabalhos realizados por FERREIRA e KAMINSKI (1979) com fosfato de Catalão e Patos parcialmente a cidulados, as quais promoveram um suprimento de $P$, para as plantas maiores do que os fosfatos naturais puros, mais insuficiente porque não aumentou a eficiēncia do fosfato natural restante, não acidulado.

Nos tratamentos em que se utilizou FCTF, os teores de nutrientes encontrados na matéria seca para $N, \quad K$, $\mathrm{Ca}, \mathrm{Mg}$ e $\mathrm{S}$ tiveram valores muito semelhantes aos encontrados para FCPS, ou seja não se afastaram em muito do tratamento pa drão (SPT); mas, o tratamento que recebeu FCTF na dose 300 ppm 
Tabela 8 - Efeito dos tratamentos sobre os teores

(1) de macronutrientes, contidos na matéria seca da parte aérea do arroz (média de 2 repetições.

\begin{tabular}{|c|c|c|c|c|c|c|c|}
\hline TRAT & TAMENTOS & $\% \mathrm{~N}$ & ZP & $\% \mathrm{~K}$ & $\% \mathrm{Ca}$ & $\% \mathrm{Mg}$ & $\% \mathrm{~S}$ \\
\hline (1) $s$ & Sem fósforo & 1,45 & $0,01 f$ & $1,45 \mathrm{~g}$ & $0,33 c$ & $0,35 \mathrm{~cd}$ & 0,09 \\
\hline (2) 1 & 1) +Calagem & 1,71 & $0,02 \mathrm{ef}$ & $3,82 \mathrm{ab}$ & $0,66 a b$ & $0,70 \mathrm{ab}$ & 0,11 \\
\hline (3) $\mathrm{F}$ & FCPS $150 \mathrm{ppm} \mathrm{P}$ & 1,53 & $0,02 \mathrm{ef}$ & $2,42 \mathrm{def}$ & $0,51 \mathrm{abc}$ & $0,54 \mathrm{abcd}$ & 0,09 \\
\hline (4) 3 & 3)+Calagem & 0,94 & $0,02 \mathrm{ef}$ & $3,54 a b c$ & $0,71 a$ & $0,77 \mathrm{ab}$ & 0,10 \\
\hline (5) $\mathrm{E}$ & FCPS $300 \mathrm{ppm} P$ & 1,12 & $0,03 \mathrm{def}$ & $2,59 \mathrm{cdef}$ & $0,71 \mathrm{a}$ & $0,53 \mathrm{abcd}$ & 0,11 \\
\hline (6) 5 & 5)+Calagem & 1,17 & $0,05 \mathrm{cde}$ & $3,15 \mathrm{bcde}$ & $0,57 a b c$ & $0,78 \mathrm{ab}$ & 0,10 \\
\hline (7) $s$ & SP'T 225 ppm P & 1,12 & $0,17 \mathrm{a}$ & $2,93 \mathrm{bcdef}$ & $0,50 a b c$ & $0,49 \mathrm{bcd}$ & 0,08 \\
\hline (8) 7 & 7) + Calagem & 1,43 & $0,10 \mathrm{~b}$ & $4,67 a$ & $0,52 a b c$ & $0,89 a$ & 0,08 \\
\hline (9) $\mathrm{F}$ & FCTF $150 \mathrm{ppro} P$ & 1,38 & $0,01 \mathrm{f}$ & $2,69 \mathrm{cdef}$ & $0,54 \mathrm{abc}$ & $0,54 \mathrm{abcd}$ & 0,09 \\
\hline$(10)$ & 9) + Calagen & 1,07 & $0,02 \mathrm{ef}$ & $2,14 \mathrm{fg}$ & $0,50 \mathrm{abc}$ & $0,85 \mathrm{ab}$ & 0,10 \\
\hline (11) & FCTF 300 ppm $\mathrm{P}$ & 1,25 & $0,09 b c$ & $2,24 \mathrm{efg}$ & $0,53 \mathrm{abc}$ & $0,64 \mathrm{abc}$ & 0,10 \\
\hline (12) & $11)+$ Calagem & 1,07 & $0,06 \mathrm{bcd}$ & $3,48 a b c$ & $0,44 a b c$ & $0,75 \mathrm{ab}$ & 0,09 \\
\hline (13) & Sem $\mathrm{P}$ e $\mathrm{s}_{\mathrm{Kg} \mathrm{SO}}$ & $4^{1,45}$ & $0,02 \mathrm{ef}$ & $3,47 \mathrm{bc}$ & $0,50 a b c$ & $0,31 \mathrm{~d}$ & 0,10 \\
\hline \multirow[t]{2}{*}{ (14) } & $13)+$ Calagem & 1,73 & $0,01 f$ & $3,26 \mathrm{bcd}$ & $0,38 \mathrm{bc}$ & $0,35 \mathrm{~cd}$ & 0,09 \\
\hline & $\mathrm{F}$ & $2,79 \mathrm{~ns}$ & $37,71 * *$ & $20,65 * *$ & $3,69 *$ & $9,68 * *$ & $0,67 \mathrm{~ns}$ \\
\hline \multicolumn{8}{|c|}{ (2) dms (Tukey 5\%) } \\
\hline & $\mathrm{CV}$ & 7,91 & 11,23 & 4,42 & 7,74 & 7,53 & 7,80 \\
\hline
\end{tabular}

1 - Transformação das observaçoẽs segundo arc sem $\sqrt{x / 100}$.

2 - Medias com a mesma letra não diferem significativamente entre si. 
Tabela 9 - Efeito dos tratamentos sobre as quantidades de macronutrientes absorvido pela parte aërea do arroz (mg/vaso) (média de 2 repe tições).

\begin{tabular}{|c|c|c|c|c|c|c|}
\hline TRATAMENTOS & $\mathrm{N}$ & $\mathrm{P}$ & $\mathrm{K}$ & $\mathrm{Ca}$ & $\mathrm{Mg}$ & S \\
\hline (1) Sem fösforo & $50,20 f$ & $0,35 \mathrm{~d}$ & $49,61 \mathrm{~g}$ & $10,28 d$ & $12,41 \mathrm{e}$ & $3,12 b$ \\
\hline (2) 1)+Calagem & 63,45 ef & $0,75 \mathrm{~d}$ & $163,11 \mathrm{fg}$ & $28,18 \mathrm{bcd}$ & $29,89 \mathrm{cde}$ & $4,04 b$ \\
\hline (3) FCPS $150 \mathrm{ppm} P$ & $212,97 \mathrm{ab}$ & $2,77 \mathrm{~d}$ & $333,98 \mathrm{de}$ & $71,11 \mathrm{ab}$ & $75,21 \mathrm{bc}$ & $13,23 a$ \\
\hline (4) 3)+Calagem & $151,51 \mathrm{cde}$ & $3,41 \mathrm{~d}$ & $482,40 \mathrm{bcd}$ & $98,35 a$ & $104,65 \mathrm{ab}$ & $13,61 a$ \\
\hline (5) FCPS $300 \mathrm{ppm} P$ & $164,54 \mathrm{abc}$ & $5,12 d$ & $378,78 \mathrm{cde}$ & $113,98 a$ & $78,92 \mathrm{bc}$ & $16,09 a$ \\
\hline (6) 5) + Calagem & $156,24 \mathrm{bcd}$ & $6,63 \mathrm{~cd}$ & $386,95 b c d e$ & $76,47 a b$ & $163,72 \mathrm{ab}$ & $14,00 \mathrm{a}$ \\
\hline (7) $\mathrm{sPT} 225 \mathrm{ppmP}$ & $199,59 \mathrm{abc}$ & $30,81 \mathrm{a}$ & $530,50 \mathrm{~b}$ & $90,62 a$ & $88,83 b$ & $15,42 \mathrm{a}$ \\
\hline (8) 7) + Calagem & $233,61 \mathrm{a}$ & $17,42 b$ & $768,10 a$ & $85,49 a$ & $146,69 a$ & $13,82 \mathrm{a}$ \\
\hline (9) FCTF $150 \mathrm{ppm} P$ & $170,80 a b c$ & $1,23 \mathrm{~d}$ & $330,58 \mathrm{e}$ & $66,22 a b c$ & $68,91 \mathrm{bcd}$ & $10,85 a$ \\
\hline (10) 9)+Calagem & $173,33 a b c$ & $3,32 \mathrm{~d}$ & $284,85 \mathrm{ef}$ & $67,66 \mathrm{abc}$ & $113,54 a b$ & $13,95 a$ \\
\hline (11) FCTF $300 \mathrm{ppm} \mathrm{P}$ & $199,34 a b c$ & $15,11 \mathrm{bc}$ & $354,74 \mathrm{cde}$ & $86,00 a$ & $102,38 \mathrm{ab}$ & $16,64 a$ \\
\hline$(12) 11)+$ Calagem & $151,70 \mathrm{bcd}$ & $9,20 b c d$ & $1492,92 b c$ & $62,29 a b c$ & $106,70 \mathrm{ab}$ & $13,42 a$ \\
\hline (13) $\mathrm{Sem} \mathrm{Pes} / \mathrm{MgSO}_{4}$ & $48,08 f$ & $0,65 d$ & $113,47 \mathrm{~g}$ & $16,28 \mathrm{~cd}$ & $10,28 \mathrm{e}$ & $3,27 b$ \\
\hline (14) 13) + Calagem & $80,95 \mathrm{def}$ & $4,68 d$ & $151,52 \mathrm{fg}$ & $17,67 \mathrm{~cd}$ & $16,58 \mathrm{de}$ & $4,16 b$ \\
\hline$F$ & $20,57 * *$ & $28,19 * *$ & $51,12 * *$ & $12,82 * *$ & $19,97 * *$ & $19,39 * *$ \\
\hline \multirow[t]{2}{*}{ (1) dms (Tukey 5\%) } & 76,90 & 9,11 & 150,38 & 51,96 & 54,08 & 6,52 \\
\hline & 13,26 & 31,51 & 10,95 & 20,49 & 17,93 & 1472 \\
\hline
\end{tabular}

1 - Mëdias com a mesma letra não diferem significativamente entre si. 
$P$ sem e com calagem igualou-se estatisticamente ao padrão (SPT) com calagem, a dose $150 \mathrm{ppm}$ de $\mathrm{P}$, mostrou-se igual aos tratamentos que não receberam fósforo. Este comportamento dos tratamentos com FCTF foi o mesmo para a absorção dos elementos sem variações significativas para doses e aplicação de calagem.

Em relação aos teores e absorção de nutrientes nos grãos com casca do arroz, os dados correspondentes estão nas Tabelas 10 e 11 , respectivamente. Os tratamentos que receberam FCPS independentemente da dose e da aplicacão de calagem, apresentaram teores de $\mathrm{N}, \mathrm{P}, \mathrm{K}, \mathrm{Ca}, \mathrm{Mg}$ e S não diferentes estatisticamente com os teores obtidos com o SPT na dose intermediária; para as quantidades absorvidas dos mesmos elementos, ñão houve grande variação com respeito ao padrão, com exceção na absorção de $S$ no tratamento com a dose de 300 ppm de $p$ com calagem que apresentou um menor valor e igual estatisticamente ao apresentado pelo tratamento com SPT sem calagem, contudo, mais que os tratamentos que não receberam fósforo. $\bar{E}$ importante lembrar os resultados obtidos com a parte aérea para teores e quantidades absorvidas de $p$, que fo ram muito baixas, porque o elemento foi redistribuido para os grãos, diante da deficiēncia do elemento no solo.

Nos tratamentos com ECTF os teores de N, K, $\mathrm{Ca}$ e $\mathrm{S}$ foram equivalentes aos obtidos com os tratamentos pa- 
Tabela 10 - Efeitos dos tratamentos sobre os teores ${ }^{(1)}$ de macronutrientes con tidos nos grãos do arroz mais casca (mèdias de 2 repetições).

\begin{tabular}{|c|c|c|c|c|c|c|}
\hline TRATAMENTOS & $\% \mathrm{~N}$ & $\% \mathrm{P}$ & $7 \% \mathrm{~K}$ & $\% \mathrm{Ca}$ & $\% \mathrm{Mg}$ & $\% \mathrm{~S}$ \\
\hline (1) Sem fösforo & 1,58 & $0,12 \mathrm{~d}$ & $0,35 a b$ & 0,06 & $0,07 \mathrm{def}$ & 0,08 \\
\hline (2) 1) + Calagem & 1,35 & $0,12 \mathrm{~d}$ & $0,32 \mathrm{ab}$ & 0,05 & $0,06 \mathrm{ef}$ & 0,06 \\
\hline (3) FCPS $150 \mathrm{ppm} \mathrm{P}$ & 1,66 & $0,20 \mathrm{bcd}$ & $0,27 \mathrm{ab}$ & 0,06 & $0,09 \mathrm{bcdef}$ & 0,09 \\
\hline (4) 3) + Calagem & 1,62 & $0,20 \mathrm{bcd}$ & $0,27 \mathrm{ab}$ & 0,05 & $0,10 \mathrm{abcde}$ & 0,09 \\
\hline (5) FCPS $300 \mathrm{ppm} P$ & 1,46 & $0,94 \mathrm{abc}$ & $0,44 \mathrm{a}$ & 0,08 & $0,11 \mathrm{abcd}$ & 0,08 \\
\hline (6) 5) + Calagem & 1,63 & $0,28 \mathrm{ab}$ & $0,37 \mathrm{ab}$ & 0,06 & $0,11 \mathrm{abcd}$ & 0,07 \\
\hline (7) $\mathrm{SPT} 225 \mathrm{ppmP}$ & 1,64 & $0,33 a$ & $0,47 \mathrm{a}$ & 0,07 & $0,12 \mathrm{abc}$ & 0,08 \\
\hline (8) 7) + Calagem & 1,83 & $0,31 \mathrm{ab}$ & $0,28 \mathrm{ab}$ & 0,04 & $0,12 \mathrm{abc}$ & 0,09 \\
\hline (9) FCTF 150 ppm P & 1,72 & $0,13 \mathrm{~d}$ & $0,31 \mathrm{ab}$ & 0,04 & $0,07 \mathrm{def}$ & 0,09 \\
\hline$(10) 9)+$ Calagem & 1,58 & $0,18 \mathrm{~cd}$ & $0,27 a b$ & 0,04 & $0,09 \mathrm{bcdef}$ & 0,09 \\
\hline (11) FCTF $300 \mathrm{ppm} \mathrm{P}$ & 1,43 & $0,30 \mathrm{ab}$ & $0,51 a$ & 0,08 & $0,13 \mathrm{a}$ & 0,10 \\
\hline$(12) 11)+C a l$ agem & 1,45 & $0,32 a$ & $0,37 \mathrm{ab}$ & 0,04 & $0,13 \mathrm{a}$ & 0,10 \\
\hline (13) Sem Pe s/MgSO & 1,88 & $0,13 \mathrm{~d}$ & $0,21 \mathrm{~b}$ & 0,03 & $0,05 \mathrm{f}$ & 0,08 \\
\hline (14) 13)+Calagem & 1,78 & $0,11 \mathrm{~d}$ & $0,29 a b$ & 0,06 & $0,08 \mathrm{cdef}$ & 0.09 \\
\hline $\mathrm{F}$ & $1,26 \mathrm{~ns}$ & $18,51 * x$ & $4,08 * *$ & $1,66 \mathrm{~ns}$ & $16,81 * *$ & $1,56 \mathrm{~ns}$ \\
\hline \multirow[t]{2}{*}{ (2) dms (Tukey 5\%) } & - & - & - & - & - & - \\
\hline & 5,98 & 6,73 & 8,57 & 15,51 & 5,83 & 6,08 \\
\hline
\end{tabular}

1 - Transformação das observações segundo arc sen $\sqrt{\mathrm{X} / 100}$.

2 - Médias com a mesma letra não diferem significativamente entre si. 
Tabela 11 - Efeitos dos tratamentos sobre as quantidades de macronutrientes absorvidas nos grãos de arroz mais casca (mg/vaso) (médias de 2 repetições).

\begin{tabular}{|c|c|c|c|c|c|c|}
\hline TRATAMENTOS & $\mathrm{N}$ & $\mathrm{P}$ & $\mathrm{K}$ & $\mathrm{Ca}$ & $\mathrm{Mg}$ & ${ }^{*} \mathrm{~S}$ \\
\hline (1) Sem fösforo & $22,88 \mathrm{c}$ & $1,77 \mathrm{c}$ & $5,15 \mathrm{~d}$ & $0,82 \mathrm{e}$ & $1,04 \mathrm{~d}$ & $1,18 \mathrm{~d}$ \\
\hline (2) 1) + Calagem & $30,33 c$ & $2,60 \mathrm{c}$ & $7,22 d$ & $1,13 \mathrm{de}$ & $1,36 \mathrm{~d}$ & $1,36 \mathrm{~d}$ \\
\hline (3) FCPS $150 \mathrm{ppm} \mathrm{P}$ & $202,41 \mathrm{ab}$ & $24,10 a b$ & $32,10 b c$ & $7,23 \mathrm{ab}$ & $10,41 \mathrm{abc}$ & $10,23 a b c$ \\
\hline (4) 3) + Calagem & $231,33 a b$ & $27,98 \mathrm{ab}$ & $38,52 \mathrm{abc}$ & $7,14 a b$ & $13,52 \mathrm{ab}$ & $12,84 a$ \\
\hline (5) FCPS $300 \mathrm{ppm} \mathrm{P}$ & $186,03 \mathrm{ab}$ & $31,50 \mathrm{ab}$ & $56,43 a$ & $9,57 a$ & $13,41 \mathrm{ab}$ & $9,48 \mathrm{abc}$ \\
\hline (6) 5)+Calagem & $168,78 \mathrm{ab}$ & $29,12 \mathrm{ab}$ & $41,56 \mathrm{abc}$ & $6,15 b c$ & $10,92 a b c$ & $7,24 c$ \\
\hline (7) $\mathrm{spT} 225 \mathrm{ppm} P$ & $164,86 a b$ & $33,27 \mathrm{ab}$ & $46,87 \mathrm{abc}$ & $7,06 \mathrm{abc}$ & $11,59 a b c$ & $8,07 c$ \\
\hline (8) 7) + Calagem & $238,55 a$ & $40,67 a$ & $37,4^{1} \mathrm{abc}$ & $?, 26 a b$ & $15,35 \mathrm{ab}$ & $11,83 \mathrm{ab}$ \\
\hline (9) FCTF $150 \mathrm{ppm} P$ & $170,23 a b$ & $12,87 \mathrm{~b}$ & $30,61 c$ & $3,94 \mathrm{cde}$ & $6,43 \mathrm{~cd}$ & $8,89 b c$ \\
\hline$(10) 9)+$ Calagem & $189,43 \mathrm{ab}$ & $21,02 \mathrm{abc}$ & $32,33 b c$ & $4,17 \mathrm{bcd}$ & $10,19 \mathrm{bc}$ & $10,17 a b c$ \\
\hline (11) FCTF 300 ppm P & $148,95 b$ & $31,35 \mathrm{ab}$ & $51,34 \mathrm{ab}$ & $4,89 b c$ & $12,93 \mathrm{ab}$ & $9,81 \mathrm{abc}$ \\
\hline (12) 11) + Calagem & $181,84 \mathrm{ab}$ & $40,29 a$ & $46,55 \mathrm{abc}$ & $5,04 \mathrm{bc}$ & $16,36 \mathrm{a}$ & $11,95 \mathrm{ab}$ \\
\hline (13) $\mathrm{Sem}^{\mathrm{P} \text { es} / \mathrm{MgSO}_{4}}$ & $49,50 c$ & $3,32 c$ & $5,59 d$ & $0,80 \mathrm{e}$ & $1,33 \mathrm{~d}$ & $2,11 \mathrm{~d}$ \\
\hline \multirow[t]{2}{*}{$(14)$ 13) + Calagem } & $54,65 c$ & $3,22 c$ & $9,01 \mathrm{~d}$ & $1,70 \mathrm{de}$ & $2,32 \mathrm{~d}$ & $2,62 d$ \\
\hline & $26,78 * *$ & $15,35 * *$ & $24,48 * *$ & $25,55 * *$ & $26,90 * *$ & $41,75 * *$ \\
\hline \multirow[t]{2}{*}{ (1) dms (Tukey 5\%) } & 80,81 & 20,54 & 20,30 & 3,15 & 5,99 & 3,61 \\
\hline & 13,91 & 23,80 & 16,18 & 16,53 & 16,56 & 11,76 \\
\hline
\end{tabular}

1- Mëdiàs com a mesma letra não diferem significativamente entre si. 
drões independentemente das doses e da calagem; mas, no caso de $\mathrm{P}$ e Mg somente a dose de $300 \mathrm{ppm}$ de $\mathrm{P}$ mostrou valores comparáveis com o padrão (foram os valores maiores). Na absor ção dos elementos houve uma maior absorção de $\mathrm{P}$ e Mg na dosagem de 300 ppm de $\mathrm{P}$ com calagem, sem diferença significativas do tratamento padrão, a absorção dos outros elementos não diferiu dos tratamentos padröes.

4.2.2. Teores e absorção de nutrientes na soja, parte aérea e nas vagens.

Os teores de nutrientes e quantidades absorvidas estão nas tabelas 12 e 13. A anảlise estatistica destes resultados nos tratamentos que receberam FCPS mostrou, que os teores dos seis nutrientes analisados não diferiram estatisti camente do padrão sem calagem. Para a absorção dos nutrientes, somente o P mostrou-se diferentes dos resultados obtidos para teores, neste caso o ünico tratamento que não diferiu do padrão com calagem foi a dose de 300 ppm de $\mathrm{P}$ com calagem.

Nos tratamentos que utilizaram o FCTF como fonte de fósforo, a anālise estatistica mostrou que os teores de $N, K, C a, M g$ e $S$ não variaram significativamente em re lação ao SPT sem calagem; a porcentagem de P foi comparävel com o tratamento padrão só na dose maior sem e com calagem respecti - 
Tabela 12 - Efeito dos tratamentos subre os teores ${ }^{(1)}$ de macronutrientes contidos na matéria seca da parte aérea da soja (média de 2 repetições.

\begin{tabular}{|c|c|c|c|c|c|c|}
\hline TRATAMENTOS & $\% \mathrm{~N}$ & $\% \mathrm{P}$ & $\% \mathrm{~K}$ & $\% \mathrm{Ca}$ & $\% \mathrm{Mg}$ & $\% \mathrm{~S}$ \\
\hline (1) Sem fösforo & $1,54 \mathrm{ab}$ & $0,03 \mathrm{de}$ & $2,08 \mathrm{ab}$ & 0,92 & $0,46 \mathrm{ab}$ & $0,09 a b c$ \\
\hline (2) 1)+Calagen & $1,70 \dot{a}$ & $0,02 \mathrm{e}$ & $2,59 a$ & 0,88 & $0,40 \mathrm{abc}$ & $0,05 \mathrm{abc}$ \\
\hline (3) FCPS $150 \mathrm{ppm} \mathrm{P}$ & $0,74 \mathrm{bc}$ & $0,13 \mathrm{bc}$ & $1,06 \mathrm{cde}$ & 0,77 & $0,31 \mathrm{bc}$ & $0,13 a b c$ \\
\hline (4) 3)+Calagem & $0,84 b c$ & $0,17 \mathrm{ab}$ & $0,93 \mathrm{e}$ & 0,89 & $0,40 \mathrm{abc}$ & $0,21 \mathrm{ab}$ \\
\hline (5) FCPS $300 \mathrm{ppm} \mathrm{P}$ & $0,73 \mathrm{c}$ & $0,17 \mathrm{ab}$ & $0,72 \mathrm{e}$ & 0,87 & $0,29 \mathrm{bc}$ & $0,14 a b c$ \\
\hline (6) 5)+Calagem & $1,39 \mathrm{abc}$ & $0,23 a$ & $0,98 \mathrm{de}$ & 1,04 & $0,40 \mathrm{abc}$ & $0,21 \mathrm{ab}$ \\
\hline (7) $\mathrm{SPT} 225 \mathrm{ppm} \mathrm{P}$ & $0,79 \mathrm{bc}$ & $0,31 \mathrm{a}$ & $0,77 \mathrm{e}$ & 0,80 & $0,36 \mathrm{abc}$ & $0,11 \mathrm{abc}$ \\
\hline (8) 7) + Calagem & $0,71 \mathrm{c}$ & $0,26 \mathrm{a}$ & $2,81 \mathrm{a}$ & 0,97 & $0,46 \mathrm{ab}$ & $0,07 c$ \\
\hline (9) FCTF $150 \mathrm{ppm} P$ & $1,53 \mathrm{ab}$ & $0,06 \mathrm{cde}$ & $1,14 \mathrm{cde}$ & 1,64 & $0,36 \mathrm{abc}$ & $0,09 \mathrm{abc}$ \\
\hline$(10) 9)+$ Calagem & $0,83 \mathrm{bc}$ & $0,10 \mathrm{bcd}$ & $1,23 \mathrm{cde}$ & 1,04 & 0,47 & $0,12 \mathrm{abc}$ \\
\hline (11) FCTF 300 ppm $P$ & $1,44 \mathrm{abc}$ & $0,24 a$ & $1,23 \mathrm{cde}$ & 0,90 & $0,42 \mathrm{ab}$ & $0,11 \mathrm{abc}$ \\
\hline (12) 11) + Calagem & $0,70 \mathrm{c}$ & $0,30 a$ & $1,14 \mathrm{cde}$ & 1,19 & $0,53 a$ & $0,24 \mathrm{a}$ \\
\hline (13) Sem Pe s/MgSO 4 & $4^{1,28 a b c}$ & $0,04 \mathrm{de}$ & $1,59 \mathrm{bcd}$ & 0,56 & $0,24 \mathrm{c}$ & $0,16 a b c$ \\
\hline (14) 13)+Calagem & $0,93 \mathrm{abc}$ & $0,05 \mathrm{de}$ & $1,61 \mathrm{bc}$ & 0,89 & $0,37 \mathrm{abc}$ & $0,09 \mathrm{bc}$ \\
\hline $\mathrm{F}$ & $7,06 * *$ & $35,84 * *$ & $27,37 x *$ & $1,48 \mathrm{~ns}$ & $4,90 * *$ & $5,84 * *$ \\
\hline \multirow{2}{*}{$\frac{(2) \text { dms (Tukey 5\%) }}{\mathrm{CV} \%}$} & - & - & - & - & - & - \\
\hline & 8,96 & 9,78 & 5,98 & 13,64 & 6,31 & 13,35 \\
\hline
\end{tabular}

1 - Transformação das observações segundo arc sen $\sqrt{\mathrm{X} / 100}$.

2 - Mēdias com a mesma letra não diferem significativamente entre si. 
Tabela 13 - Efeito dos tratamentos nas quantidades de macronutriertes absorvidas pela parte aérea da soja (mg/vaso) (média de 2 repeti ções).

$\mathrm{P}$

$\mathrm{K}$

$\mathrm{Ca}$

$\mathrm{Mg}$

S

(1) Sem fösforo $\quad 32,65 \mathrm{e} \quad\left[\begin{array}{lllllll}0,55 \mathrm{~g} & 43,83 \mathrm{c} & 20,50 \mathrm{~d} & 10,30 \mathrm{~d} & 1,91 \mathrm{~d}\end{array}\right.$

(2) 1) + Calagem 77,51bcde $0,92 \mathrm{~g} \quad 118,10 \mathrm{bc} \quad 40,13 \mathrm{~cd} \quad 18,01 \mathrm{~cd} \quad 2,06 \mathrm{~d}$

(3) FCPS 150 ppm P 51,55bcde 11,00defg 89,35c 64,78bcd 25,74bcd 10,60abcd

(4) 3) +Calagem 70,31 bcde 14,20cdef $77,42 c: 74,07$ abcd $33,06 b c d \quad 17,57 a b c$

(5) FCPS 300 ppm P 78,17bcde 18,32cde 77,29c 93,04abcd 31,10bcd 14,48abcd

(6) 5) +Calagem $164,58 \mathrm{a} \quad 26,63 \mathrm{bc} 116,25 \mathrm{bc} \quad 123,76 \mathrm{ab} \quad 47,15 \mathrm{ab} \quad 24,89 \mathrm{a}$

(7) SPT 225 ppmP 102,10bcd 39,70a 100,16c 103,30abc 46,17ab 13,69abcd

(8) 7) +Calagem $107,53 \mathrm{abc} \quad 39,22 \mathrm{ab} \quad 427,59 \mathrm{a} \quad 148,76 \mathrm{a} \quad 70,39 \mathrm{a} \quad 9,80 \mathrm{bcd}$

(9) FCTF 150 ppm P 84,11bcde 2,97fg 62,77c 81,70abcd 19,72bcd 4,62bcd

(10) 9) + Calagem $47,41 \mathrm{de} \quad 5,53 \mathrm{efg} \quad 70,00 \mathrm{c} \quad 59,47 \mathrm{bcd} \quad 26,81 \mathrm{bcd} \quad 6,64 \mathrm{bcd}$

(11) FCTF 300 ppm P 116,86ab 19,45cd 99,40c 72,74abca 34,11bcd 8,52bcd

(12) 11) + Calagem $55,10 \mathrm{cde} 23,23 \mathrm{~cd} 89,37 \mathrm{c} \quad 93,37 \mathrm{abcd} 43,78 \mathrm{abc} 18,76 \mathrm{ab}$

(13) SemPes/MgSO $42,52 \mathrm{cde} \quad 1,78 \mathrm{fg} \quad 67,86 \mathrm{c} \quad 24,67 \mathrm{~d} \quad 10,22 \mathrm{~d} \quad 6,76 \mathrm{bcd}$

(14) 13) + Calagem $34,12 \mathrm{e} \quad 1,71 \mathrm{fg} \quad 59,76 \mathrm{c} \quad 32,48 \mathrm{~cd} \quad 13,39 \mathrm{~d} \quad 3,43 \mathrm{~cd}$

\begin{tabular}{rllllll}
\hline $\mathrm{F}$ & $12,55 * *$ & $35,21 * *$ & $43,61 * *$ & $7,60 * *$ & $11,94 * *$ & $6,73 * *$ \\
\hline (1) dms (Tukey & $5 \%) 57,43$ & 13,01 & 80,86 & 76,50 & 27,65 & 14,93 \\
\hline $\mathrm{CV} \%$ & 18,58 & 21,84 & 18,93 & 26,00 & 22,57 & 36,50 \\
\hline
\end{tabular}

1 - Médias com a mesma letra não diferem significativamente entre si. 
vamente. Ao comparar os dados de absorção vé-se que eles refletem a añlise feita para teores, sö que no caso do $P$ a dose maior de $p$ sem calagem e com calagem não se igualou esta tisticamente com o padrão, ainda, que tambèm não comos tratamentos que não receberam fösforo.

Em relação às vagens, os resultados obtidos en contram-se nas tabelas 14 e 15 . A anälise estatistica para teores de nutrientes presentes nas vagens de soja, permite dizer que nos tratamentos com FCPS os teores de $N, P, K, C a$ e $M g$ não diferiram estatisticamente dos tratamentos com SPT (padrão.

$\mathrm{Na}$ anälise dos resultados para absorçäo de nutrientes todos os tratamentos com FCTF sem e com calagem não diferiram nas quantidades de elementos absorvidos do SPT sem calagem. O SPT com calagem mostrou-se sempre com os maiores valores de absorção. Estes resultados indicam que em geral não houve variação nos tratamentos com FCPS, FCTF e SPT para teores e absorção de $\mathrm{N}, \mathrm{K}, \mathrm{Ca}, \mathrm{Mg}$ e $\mathrm{S}$, portanto o efeito dos tra tamentos nos ensaios com arroz e soja foi devido exclusivamen te às fontes de fösforo.

Por outro 1ado, a presença de calagem, em termos gerais não afetou significativamente os tratamentos com FCPS e FCTF para producão, teores e absorção de $P, C a$ e $M g$, 
Tabela 14 - Efeito dos tratamentos sobre os teores ${ }^{(1)}$ demacronutrientes contidos nas vagens da soja (média de 2 repetições).

\begin{tabular}{|c|c|c|c|c|c|c|}
\hline TRATAMENTOS & $\% \mathrm{~N}$ & $\% \mathrm{P}$ & $\% \mathrm{~K}$ & $\% \mathrm{Ca}$ & $\% \mathrm{Mg}$ & $\% \mathrm{~S}$ \\
\hline (1) Sem fösforo & 3,08 & $0,16 f$ & 1,77 & $0,50 \mathrm{~b}$ & 0,54 & $0,18 \mathrm{~h}$ \\
\hline (2) 1) + Calagem & 3,76 & $0,19 \mathrm{ef}$ & 1,84 & $0,55 \mathrm{ab}$ & 0,54 & $0,15 i$ \\
\hline (3) FCPS $150 \mathrm{ppm} P$ & 2,78 & $0,44 \mathrm{bc}$ & 2,32 & $0,94 \mathrm{ab}$ & 0,72 & $0,24 \mathrm{bc}$ \\
\hline (4) 3)+Calagem & 2,56 & $0,44 \mathrm{bc}$ & 2,21 & $0,96 \mathrm{ab}$ & 0,76 & 0,26 def \\
\hline (5) FCPS $300 \mathrm{ppm} P$ & 2,26 & $0,51 \mathrm{ab}$ & 2,35 & $1,03 \mathrm{ab}$ & 0,68 & $0,30 \mathrm{~b}$ \\
\hline (6) 5) + Calagem & 2,41 & $0,51 \mathrm{ab}$ & 2,90 & $1,47 \mathrm{a}$ & 0,85 & $0,34 a$ \\
\hline (7) $\mathrm{SPT} 225 \mathrm{ppmP}$ & 2,51 & $0,54 a$ & 2,48 & $0,83 \mathrm{ab}$ & 0,68 & $0,27 \mathrm{bcde}$ \\
\hline (8) 7) + Calagem & 2,48 & $0,47 a b$ & 2,43 & $0,88 \mathrm{ab}$ & 0,75 & $0,23 \mathrm{fg}$ \\
\hline (9) FCTF $150 \mathrm{ppm} P$ & 2,44 & $0,33 c d$ & 1,98 & $0,93 \mathrm{ab}$ & 0,91 & $0,20 \mathrm{~g}$ \\
\hline$(10) 9)+C a l$ agem & 2,52 & $0,49 \mathrm{ab}$ & 2,58 & $1,07 \mathrm{ab}$ & 0,88 & $0,27 \mathrm{efg}$ \\
\hline (11) FCTF $300 \mathrm{ppm} \mathrm{P}$ & 2,24 & $0,49 \mathrm{ab}$ & 2,54 & $0,92 \mathrm{ab}$ & 0,86 & $0,28 \mathrm{bcd}$ \\
\hline (12) 11$)+$ Calagem & 2,02 & $0,58 \mathrm{a}$ & 2,47 & $1,38 \mathrm{ab}$ & 0,85 & $0,29 \mathrm{bcd}$ \\
\hline 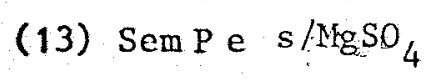 & 2,61 & $0,24 \mathrm{def}$ & 2,44 & $0,90 \mathrm{ab}$ & 0,95 & $0,22 \mathrm{~g}$ \\
\hline (14) 13) + Calagem & 2,98 & $0,27 \mathrm{de}$ & 2,65 & $0,92 \mathrm{ab}$ & 0,86 & $0,19 \mathrm{~h}$ \\
\hline $\mathbf{F}$ & $1,28 \mathrm{~ns}$ & $6,01 * *$ & $2,10 \mathrm{~ns}$ & $2,75 * *$ & $1,37 \mathrm{~ns}$ & $106,43 * *$ \\
\hline \multirow[t]{2}{*}{ (2) dms (Tukey 5\%) } & - & - & - & - & - & - \\
\hline & 10,10 & 3,95 & 6,52 & 12,37 & 10,40 & 1,63 \\
\hline
\end{tabular}

1 - Transformações das observações segundo arc sen $\sqrt{\bar{X} / 100}$.

2 - Mëdias com a mesma letra não diferem significativamente entre si. 
Tabela 15 - Efeito dos tratamentos sobre as quantidades de macronutrientes absorvidos nas vagens da soja (mg/vaso) (médias de 2 repetições).

\begin{tabular}{|c|c|c|c|c|c|c|}
\hline TRATAMENTOS & $\mathrm{N}$ & $\mathrm{P}$ & $\mathrm{K}$ & $\mathrm{Ca}$ & $M g$ & 'S \\
\hline (1) Sem fösforo & 60,45 & $2,98 \mathrm{e}$ & $34,10 \mathrm{e}$ & $9,48 d$ & $10,33 \mathrm{~b}$ & $3,42 c$ \\
\hline (2) 1) + Calagem & 123,77 & $6,19 \mathrm{cde}$ & $60,87 \mathrm{bcde}$ & $17,32 \mathrm{~cd}$ & $17,32 b$ & $4,70 b c$ \\
\hline (3) FCPS $150 \mathrm{ppm} \mathrm{P}$ & 81,09 & $12,84 \mathrm{bcde}$ & $67,32 \mathrm{bcde}$ & $27,22 \mathrm{bcd}$ & $20,78 b$ & $8,45 a b c$ \\
\hline (4) 3) + Calagem & 114,99 & $19,32 \mathrm{abc}$ & $95,11 \mathrm{bcd}$ & $40,19 a b c$ & $32,78 a b$ & $10,68 \mathrm{abc}$ \\
\hline (5) FCPS $300 \mathrm{ppm} \mathrm{P}$ & 86,98 & $19,55 \mathrm{abc}$ & $90,66 \mathrm{bcd}$ & $39,72 \mathrm{abc}$ & $26,16 \mathrm{ab}$ & $11,37 \mathrm{ab}$ \\
\hline (6) 5) + Calagem & 63,52 & $13,25 \mathrm{bcde}$ & $75,63 \mathrm{bcde}$ & $38,12 \mathrm{abc}$ & $22,04 a b$ & $8,97 \mathrm{abc}$ \\
\hline (7) $\mathrm{SPT} 225 \mathrm{ppmP}$ & 108,94 & $23,48 \mathrm{ab}$ & $107,80 \mathrm{ab}$ & $36,09 \mathrm{abc}$ & $29,55 \mathrm{ab}$ & $11,53 \mathrm{ab}$ \\
\hline (8) 7) + Calagem & 162,47 & $31,25 a$ & $158,24 a$ & $56,76 a$ & $48,15 a$ & $15,30 a$ \\
\hline (9) FCTF $150 \mathrm{ppm} P$ & 95,07 & $12,65 \mathrm{bcde}$ & $84,15 \mathrm{bcde}$ & $37,95 a b c$ & $34,70 \mathrm{ab}$ & $7,85 \mathrm{bc}$ \\
\hline$(10) 9)+$ Calagem & 59,46 & $11,42 \mathrm{bcde}$ & $60,37 \mathrm{bcde}$ & $25,21 \mathrm{bcd}$ & $20,74 b$ & $5,77 \mathrm{bc}$ \\
\hline (11) FCTF $300 \mathrm{ppm} \mathrm{P}$ & 84,08 & $18,12 \mathrm{abcd}$ & $94,86 \mathrm{bcd}$ & $34,17 \mathrm{abc}$ & $32,10 a b$ & $10,44 a b c$ \\
\hline (12) 11) + Calagem & 74,26 & $21,10 \mathrm{ab}$ & $98,80 \mathrm{bc}$ & $49,36 a b$ & $30,55 \mathrm{ab}$ & $10,32 \mathrm{abc}$ \\
\hline (13) $\mathrm{Sem} \mathrm{P}_{\mathrm{P}} \mathrm{s} / \mathrm{MgSO}_{4}$ & $4^{97,42}$ & $6,28 \mathrm{cde}$ & $46,11 \mathrm{de}$ & $23,59 \mathrm{~cd}$ & $25,80 \mathrm{ab}$ & $5,83 \mathrm{bc}$ \\
\hline \multirow[t]{2}{*}{ (14) 13) + Calagem } & 59,97 & $5,36 \mathrm{de}$ & $52,74 \mathrm{cde}$ & $18,40 \mathrm{~cd}$ & $17,21 b$ & $5,86 c$ \\
\hline & $1,7 \mathrm{ins}$ & $11,21 * *$ & $11,49 * *$ & $8,81 * *$ & $4,05 * *$ & $6,94 * *$ \\
\hline \multirow[t]{2}{*}{ (1) dms (Tukey 5\%) } & - & 13,51 & 52,12 & 24,61 & 26,35 & 7,33 \\
\hline & 34,92 & 23,27 & 16,23 & 19,05 & 25,13 & 21,72 \\
\hline
\end{tabular}

1 - Mëdias com a mesma letra não diferem significativamente entre si. 
mesmo assim, houve acréscimos nos valores. Isso mostra que a absorcão de fösfuro independentemente da fonte utilizada estä relacionada com a absorção de cälcio e/ou magnésio.

4.3. Ensaios com capim Colonião apōs arroz e apōs soja pa ra determinar o efeito residual do fosfato de Catalão parcialmente solubilizado (FCPS) e com tratamento de fusão (FCTF) sobre a produção de matēria seca da parte aērea (trēs cortes).

4.3.1. Producão de matēria seca do capim colonião apōs arroz (trēs cortes).

os dados de produção de matéria seca do Capim Colonião após a colheita do arroz, em trés cortes sucessivos, encontram-se na Tabela 16, onde igualmente estão os dados de matéria seca para os três cortes de capim após soja. A aná Iise da variancia dos dados obtidos para os três cortes de ca pim efetuados, mostrou um valor de $F$ altamente significativo pa ra o efeito de tratamentos; o teste de Tukey $5 \%$ para a comparação de médias mostrou que no primeiro corte a fonte mais eficiente foi o FCTF na dose $300 \mathrm{ppm}$ P com calagem não dife rindo estatisticamente da dose $150 \mathrm{ppm}$ de $\mathrm{P}$ com calagem e da 


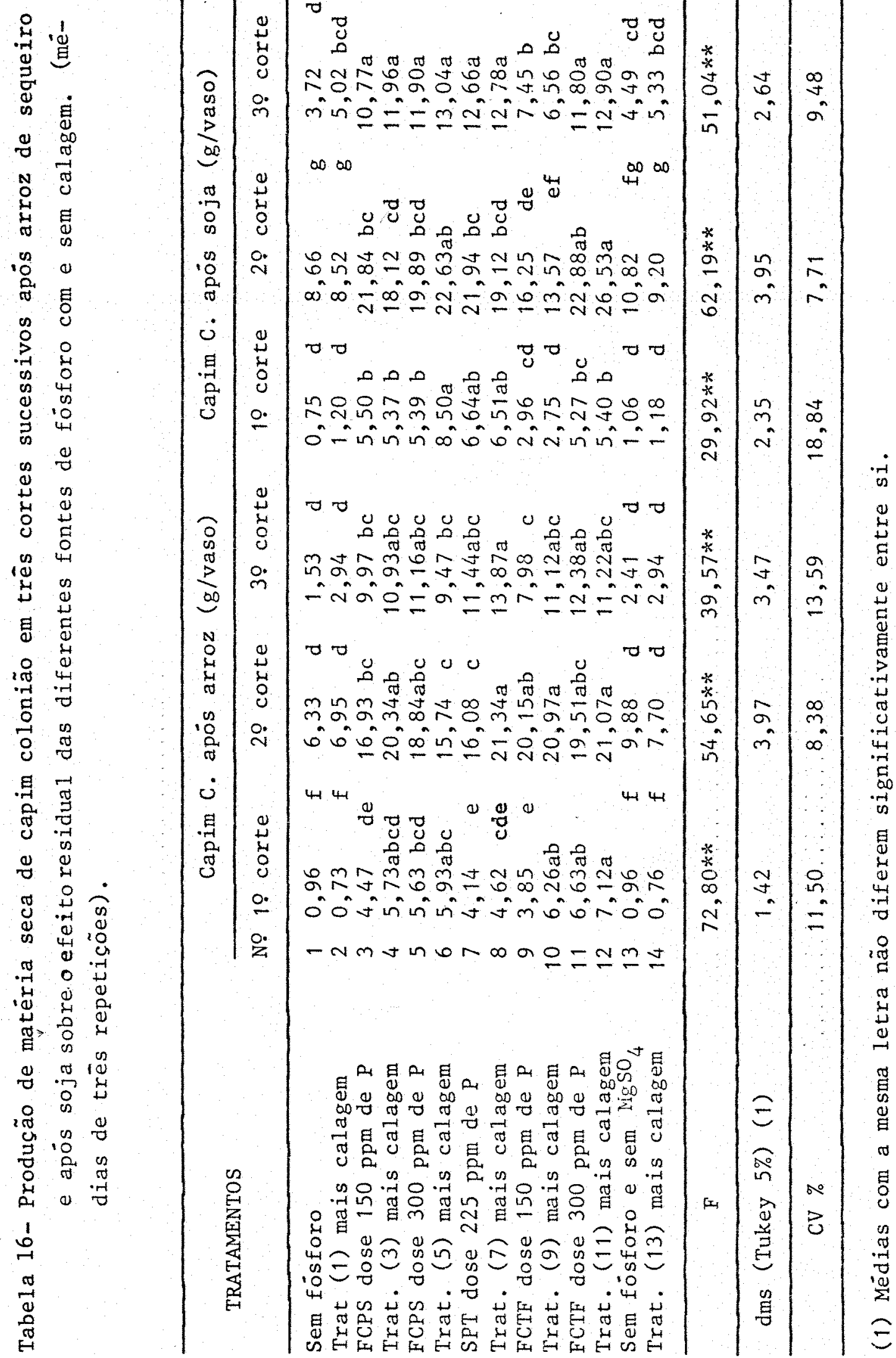


dose 300 ppm sem calagem, sendo igual ao FCPS na dose 300 ppm com calagem; ambas as fontes tiveram uma boa eficiencias nas doses maiores com calagem. O SPT mostrou uma eficiência menor, só comparävel ao FCPS na dose 150 ppm $\mathrm{P}$ com calagem e $300 \mathrm{ppm}$ de $\mathrm{P}$ sem calagem.

No segundo corte novamente a maior eficiência correspondeu ao FCTF na dose de 150 e 300 ppm de p com calagem e ao SPT na dose intermediäria com calagem, sendo estas produções iguais estatisticamente às obtidas com os tratamentos FCTF dóse 150 ppm $P$ e 300 ppm de P, ambas sem calagem; FCPS dose $150 \mathrm{ppm} P$ com calagem e dose 300 ppm P sem calagem. O SPT sem calagem mostrou, uma eficiéncia menor, mesmo assim comparável com os FCPS e FCTF nas doses de 300 ppm de P sem calagem.

Para o terceiro corte, a melhor eficiência foi para o SPT com calagem, não diferindo este valor dos obtidos para SPT sem calagem, FCTF na dose 150 ppm P com calagem e na dose 300 ppm de $P$ com e sem calagem, ao igual que para FCPS na dose 150 ppm $\mathrm{P}$ com calagem e 300 ppm $\mathrm{P}$ sem calagem.

Nos trés cortes realizados, os tratamentos que não receberam fósforo apresentaram as producões mais baixas, as quais não diferiram entre si. Isto concorda com um trabaTho realizado por WERNER et alii (1967), no qual verificaram através de ensaios de vaso com capim Colonião, que o fósforo 
foi o elementoque mais Iimitou o crescimento, seguido do nitrogēnio e do enxōfre.

As curvas de regressão para doses das fontes FCPS e FCTF e produção de matéria seca nos trés cortes de capim Colonião, encontram-se nas Figuras 5,6 e 7 .

No primeiro corte (Figura 5) pode-se observar que para oFCPS, as doses empregadas tiveram um efeito 1 inear e positivo, a calagem não teve um efeito significativo. Para o FCTF, as doses empregadas, tambëm mostraram efeito 1inear positivo e um efeito grande da calagem na dose de 150 p pm $\mathrm{P}$.

Em relação ao segundo corte (Figura 6),

FCPS sem calagem mostrou um efeito linear positivo, mas com calagem o efeito foi quadrätico, tendo um efeito linear positivo e altamente significativa na dose 150 ppre uma diminuição significativa de produção na dose de 300 ppm. P. No caso do FCTF o efeito foi linear, mas as produçóes obtidas com a dose 150 ppm $\mathrm{P}$ sem calagem e com calagem, foram mantidas na dose 300 ppm P.

Na Figura 7 , tem-se as curvas de regressão para o terceiro corte de colonião, neste caso o FCPS sem calagem manteve um efeito linear positivo nas dosagens; com calagem ofeito das doses foi meror. Para ofCTF em ambos 

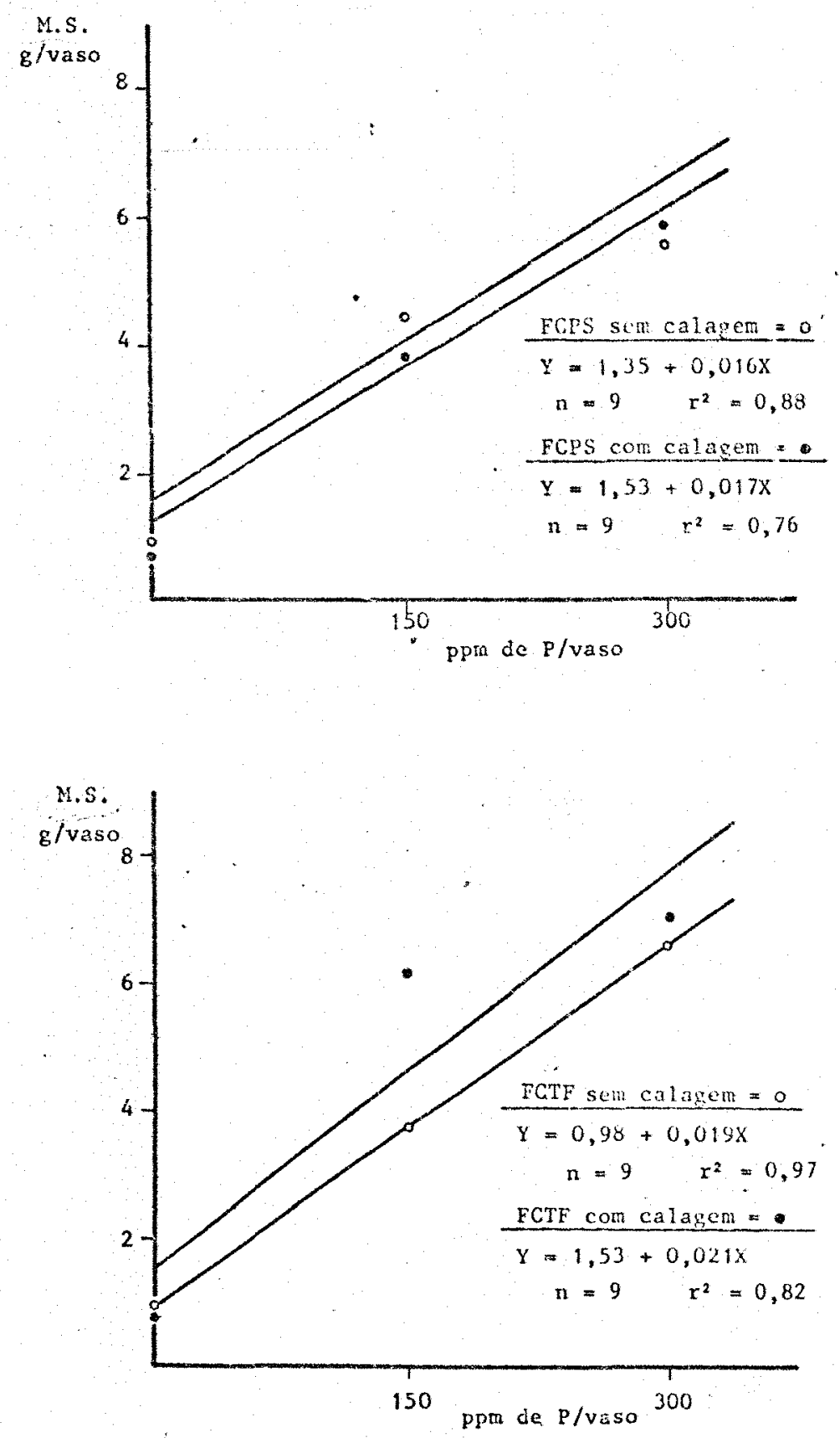

Figura 5 - Efeito das doses de $\mathrm{P}$ sobre a produção de matéría seca do capim Colonião apös arroz (19 corte). 

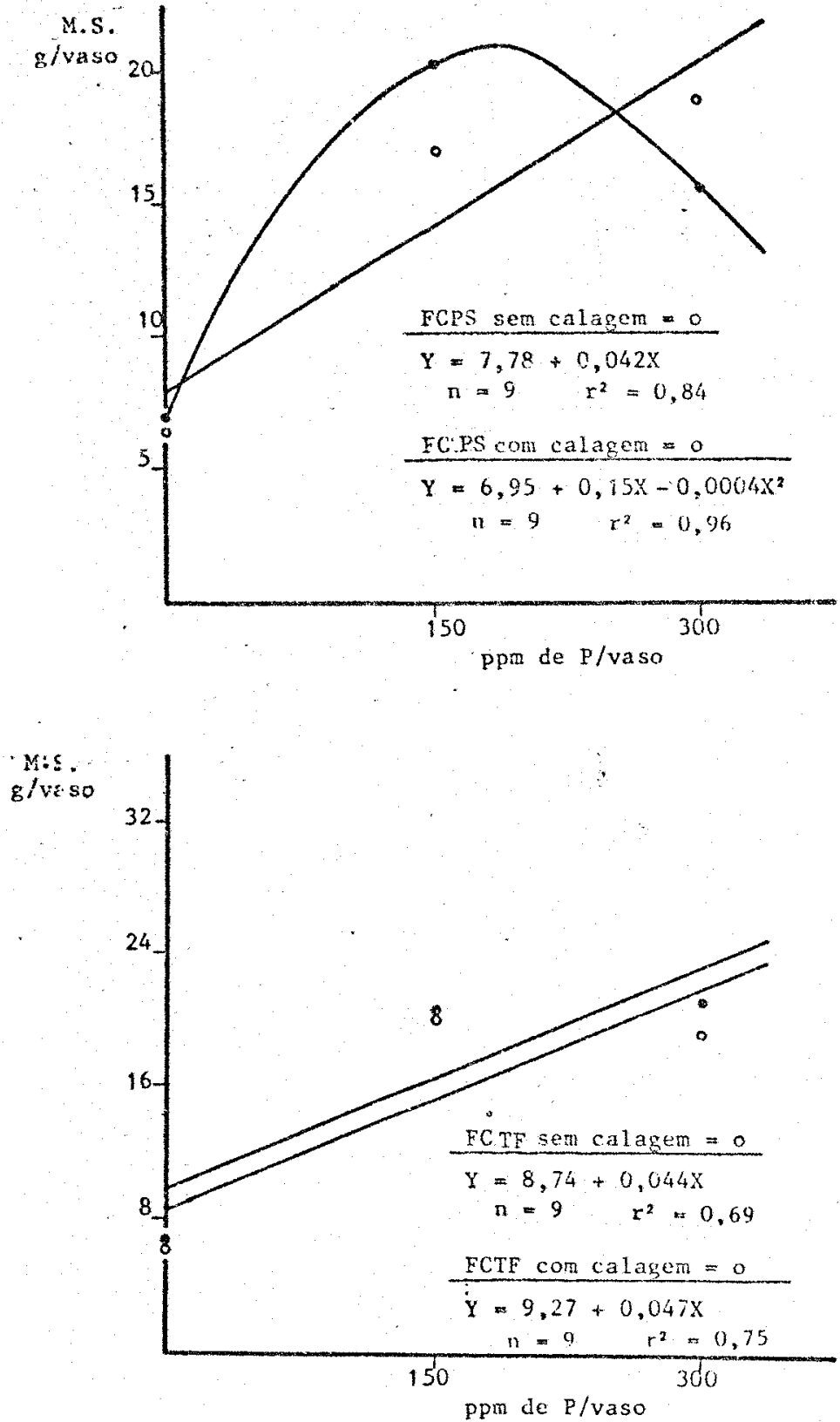

Figura 6 - Efeito das doses de P sobre a produção de matéria seca do capim Colonião após arroz (29 corte). 

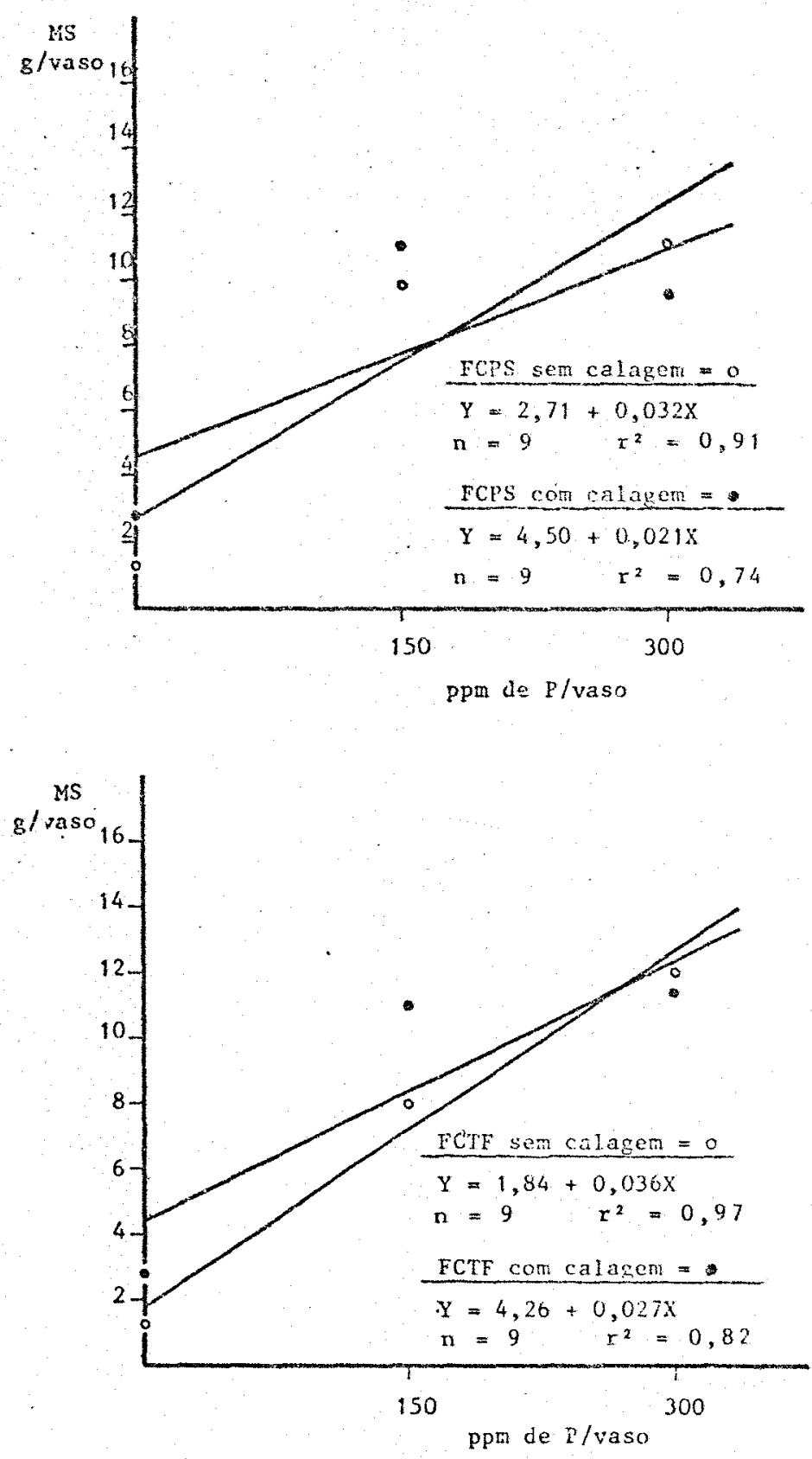

Figura 7 - Efeito das doses de $\mathrm{P}$ sobre a produção de matéria seca do capim Colonião após arroz (39 corte). 
casos, com calagem e sem calagem a relaça foi linear positiva.

4.3.2. Producão de matéria seca de capim colonião apōs soja (trés cortes).

Na Tabela 16, encontram-se os dados de produ ção de matēria seca do capim Colonião apös a colheita da soja, dos trēs cortes sucessivos. A anảlise da variância mostrou efeito dos tratamentos (valor F), altamentesignificativo nos três cortes. O contraste nas mëdias (Teste de Tukey $5 \%$ ), mostrou que no primeiro corte a melhor fonte foi o FCPS na dose maior com calagem, não diferindo estatisticamente do tratamento padrão (SPT com e sem calagem); em segundo lugar aparece 0 FCPS na dose $150 \mathrm{ppm}$ e 300 ppm de $\mathrm{P}$ sem calagem, e o FCTF na dose maior ( $300 \mathrm{ppm}$ de P) com e sem calagem.

No segundo corte o melhor tratamento correspon deu ao FCTF na dose 300 ppm $P$ com calagem não diferindo da mesma dosagem sem calagem e do FCPS na mesma dosagem com cala gem. o efeito do padrão (SPT) igualou-se com os três tratamen tos de FCPS independentemente da dose e da aplicasão de calagem.

Em relação ao terceiro corte, todos os trata- 
mentos com FCPS independentemente da dosagem e da aplicaça de calagem apresentaram a maior eficiencia, junto com o SPT com e sem calagem e com o FCTF na dose 300 ppm p com e sem calagem.

Do mesmo modo observa-se novamente que os tra tamentos que não receberam fósforo apresentaram as produções de matéria seca mais baixas.

A anālise de regressão para doses de FCPS e FCTF, e produções de matéria seca nos trés cortes de capim Co lonião apōs soja, estão nas Figuras 8,9 e 10 . Para o primeiro corte o FCPS, apresentou um efeito linear positivo altamen te significativo para dose e calagem, sendo este efeito menor quando não houve aplicação de calagem. Para o FCTF o comporta mento foi semelhante com a sem calagem, 1 inear positivo.

No segundo corte, novamente, ofeito do FCPS foi linear e positivo para doses com calagem e com efeito qua drätico em auséncia de calagem, apresentando-se uma queda de produção não significativa com a dose maior de P. As curvas no caso do FCTF, como no primeiro corte, mostraram um efeito linear e positivo.

Para o terceiro corte ambas as fontes de fösfo ro apresentaram efeito linear e positivo, com caracteristicas muito semelhantes entre si. 

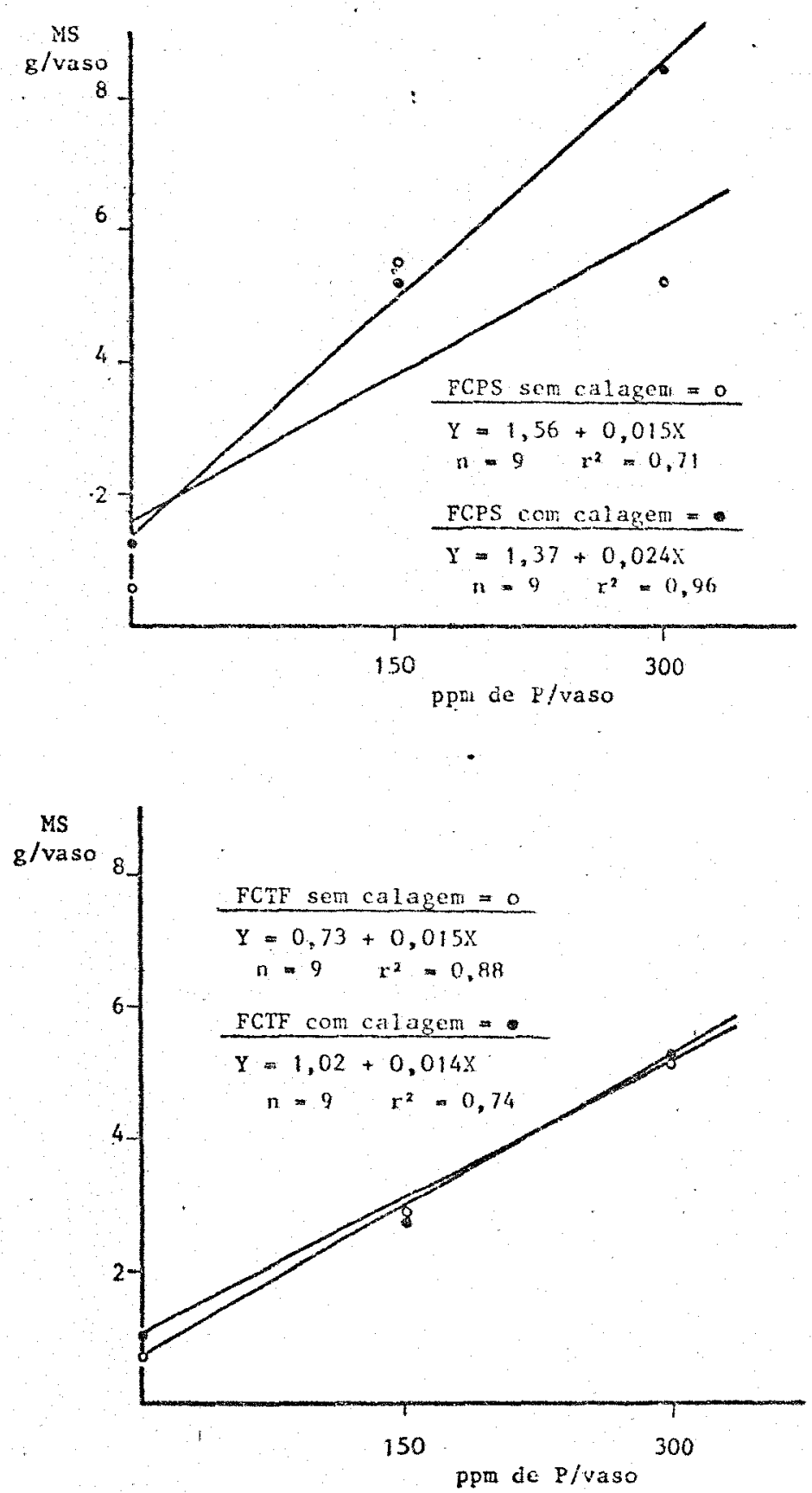

Figura 8 - Efeito das doses de P sobre a produção de matéria seca do capim Colonião após soja (19 corte). 

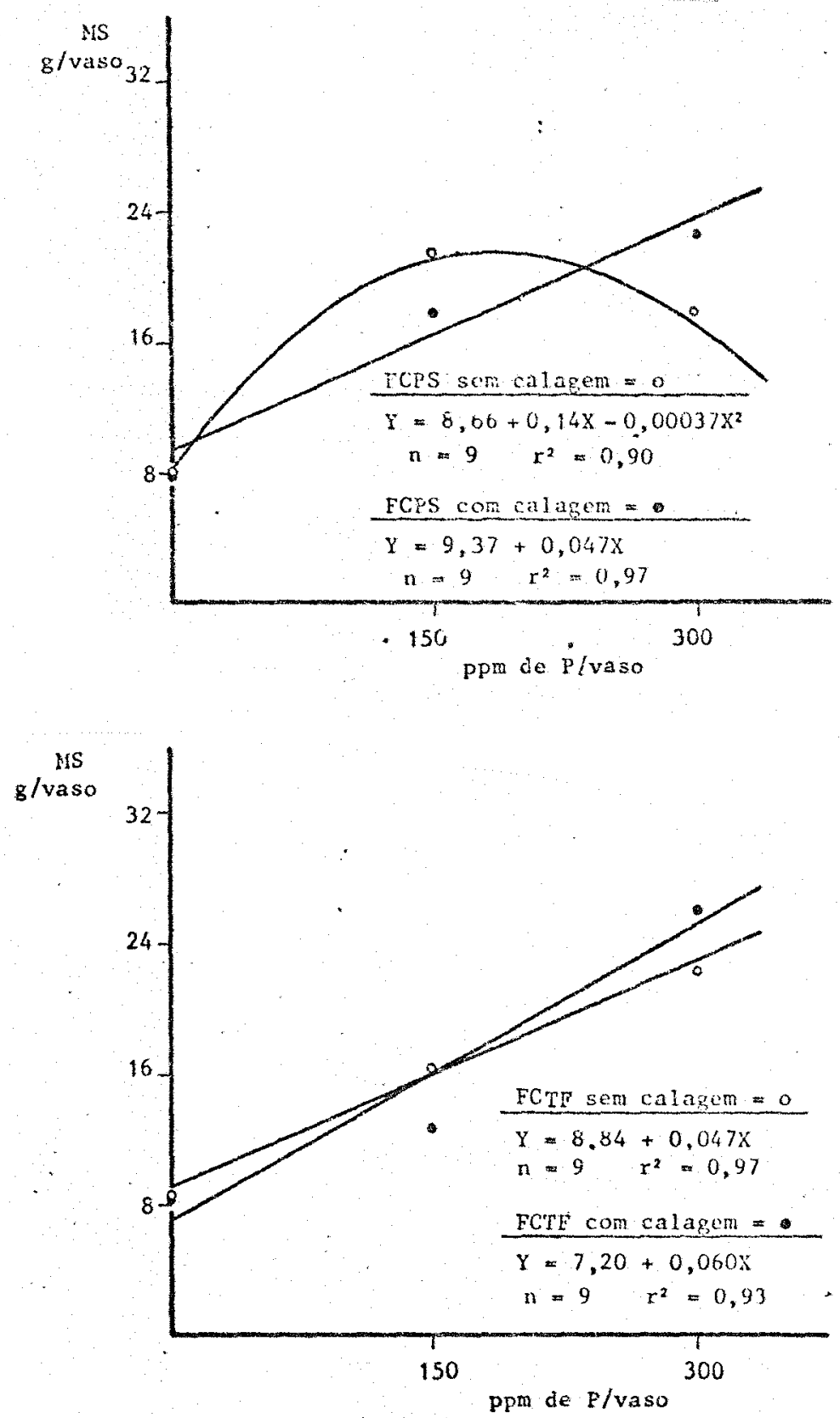

Figura 9 - Efeito das doses de $\mathrm{P}$ sobre a produção de matéria seca do capim Colonião apōs soja (2Q corte). 

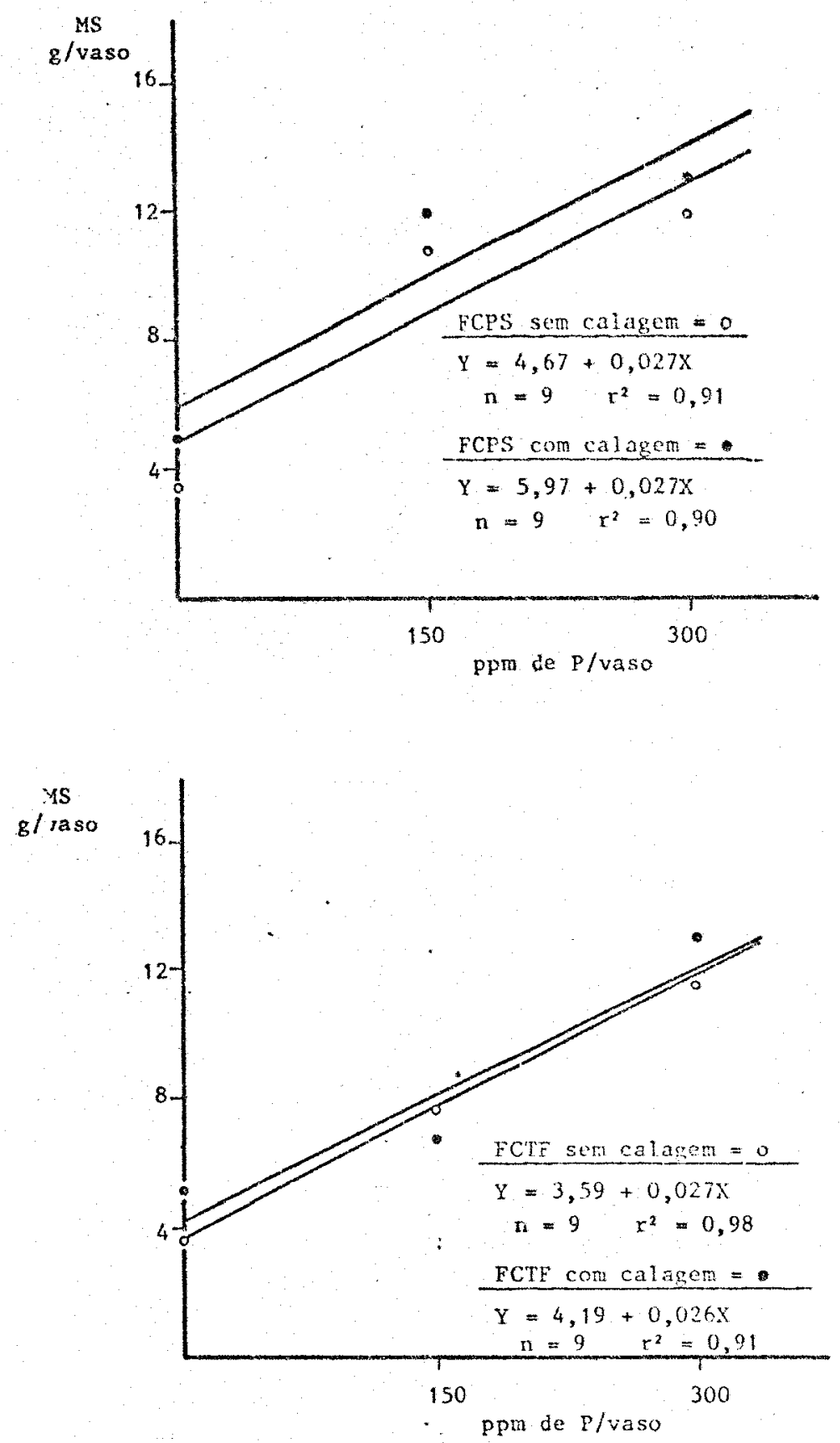

Figura 10 - Efeito das doses de $\mathrm{P}$ sobre a produção de matéria seca do capim Colonião após soja ( 30 corte). 
Na presença de calagem não houve diferença mar cante entre os adubos sobre a produtividade de matéria seca. Na sua ausência os fosfatos testados, de menor solubilidade (FCPS e FCTF), aplicados nas doses maiores e portanto levando grandes quantidades de cälcio, magnésio e enxofre, mostraram igual e até un maior efeito residual que o superfos fato triplo. Dados de (MASCARENHAS et alii, 1978 e BATAGLIA et a1ii, 1983) em traba1hos seme1hantes mostraram a importáncia do magnésio presente no termofosfato e do cálcio no hiperfosfato e fosfato de Araxá em Guaira e São Simão (SP). Evidenciando a importancia dos nutrientes acompanhantes de fósforo dos adubos fosfatados.

4.4. Teores e absorcão de nutrientes do capim Colonião, nos ensaios após arroz e apōs soja.

4.4.1. Teores e absorcão de nutrientes do capim Colonião apōs arroz (trēs cortes).

Os dados encontram-se nas tabelas $17,18,19$, 20,21 e 22 .

Nas tabelas 17 e 18 estão os dados correspondentes ao primeiro corte; nelas pode-se observar que a anäli- 
se da variancia deu valores de F altamente significativos para efeito de tratamentos em todas as variäveis (N, P, K, Ca, Mg e S ). O contraste de médias de tratamentos para teores de nutrientes, mostra que nos tratamentos com FCPS os niveis de $\mathrm{N}, \mathrm{P}, \mathrm{Ca}$ e $\mathrm{S}$ apresentaram valores comparáis aos obtidos com os tratamentos com SPT e muito caracteristicos de plantas normais, comparadas com os dados apresentados por HAAG et a1ii (1967). Estes autores citam para o Colonião, niveis médios de $1,71 \%$ de nitrogênio, $0,20 \%$ de fósforo, $0,33 \%$ de potás sio, $0,29 \%$ de cảlcio e $0,24 \%$ de magnésio em plantas com 56 dias. Teores semelhantes foram encontrados também por ANDREASI et alii (1967). Com respeito a potássio, o teor foi mais baixo que o nivel médio citado; o tratamento com SPT, tambëm não garantiu o nivel indicado. No caso do magnésio só a dose de $300 \mathrm{ppm}$ P com calagem chegou ao nivel médio citado. Em rela ção a absorção de nutrientes pelo capim nos tratamentos com FCPS, pode-se verificar pela comparacão das médias, que as quantidades absorvidas de nitrogênio, potäsio e enxofre acompanharam às quantidades absorvidas nos tratamentos com SPT; no caso do fósforo, os quatro tratamentos com FCPS não diferiram entre si na absorção do elemento; só a dose maior (300 ppm P) com e sem calagem igualou-se ao tratamento padrão (SPT); no caso de cảlcio e magnésio os tratamentos com FCPS superaram nas quantidades absorvidas nos tratamentos com SPT. 
Tabela 17 - Efeito dos tratamentos sobre os teores (1) de macronutrientes, contidas na matëria seca do capim colonião após arroz no 19 corte (mëdias de 3 repetições).

\begin{tabular}{|c|c|c|c|c|c|c|}
\hline TRATAMENTOS & $\% \mathrm{~N}$ & $\% P$ & $\% \mathrm{~K}$ & $\because \mathrm{Ca}$ & $\mathrm{FMg}$ & $\% \mathrm{~s}$ \\
\hline (1) Sem fösforo & $3,44 \mathrm{abc}$ & $0,12 \mathrm{defg}$ & $1,84 a$ & $0,18 \mathrm{de}$ & $0,11 \mathrm{fgh}$ & $0,21 a b$ \\
\hline (2) 1) + Calagem & $4,25 a$ & $0,09 \mathrm{fg}$ & $0,60 d$ & $0,16 \mathrm{e}$ & $0,68 \mathrm{gh}$ & $0,16 b$ \\
\hline (3) FCPS $150 \mathrm{ppm} \mathrm{P}$ & $2,32 \mathrm{def}$ & $0,18 \mathrm{bcde}$ & $0,99 \mathrm{bcd}$ & $0,28 \mathrm{bcd}$ & $0,07 \mathrm{~h}$ & $0,35 \mathrm{ab}$ \\
\hline (4) 3)+Calagem & $1,87 \mathrm{def}$ & $0,14 \mathrm{cdefg}$ & $1,48 \mathrm{ab}$ & $0,25 \mathrm{cde}$ & $0,17 \mathrm{cdef}$ & $0,27 a b$ \\
\hline (5) FCPS $300 \mathrm{ppm} \mathrm{P}$ & $2,82 \mathrm{abcd}$ & $0,21 \mathrm{abc}$ & $0,96 \mathrm{bcd}$ & $0,45 a$ & $0,10 \mathrm{fgh}$ & $0,37 a$ \\
\hline (6) 5) + Calagem & $1,80 \mathrm{def}$ & $0,17 \mathrm{bcde}$ & $1,09 \mathrm{bcd}$ & $0,40 a b$ & $0,23 \mathrm{bcd}$ & $0,27 a b$ \\
\hline (7) $\mathrm{spT} 225 \mathrm{ppm} P$ & $1,83 \mathrm{def}$ & $0,29 a$ & $1,38 \mathrm{ab}$ & $0,23 \mathrm{cde}$ & $0,08 \mathrm{gh}$ & $0,21 a b$ \\
\hline (8) 7) + Calagem & 2,08 def & $0,25 \mathrm{ab}$ & $1,45 \mathrm{ab}$ & $0,29 \mathrm{bcd}$ & $0,14 \mathrm{efg}$ & $0,18 \mathrm{ab}$ \\
\hline (9) FCTF $150 \mathrm{ppm} P$ & $2,72 \mathrm{abcde}$ & $0,16 \mathrm{cdef}$ & $1,36 \mathrm{ab}$ & $0,26 \mathrm{cde}$ & 0,15 defg & $0,37 a$ \\
\hline$(10)$ 9) + Calagem & $1,56 \mathrm{f}$ & $0,16 \mathrm{cdef}$ & $1,04 \mathrm{bcd}$ & $0,25 \mathrm{cde}$ & $0,28 a b$ & $0,27 a b$ \\
\hline (11) FCTF $300 \mathrm{ppm}$ & $\mathrm{P} 1,64 \mathrm{ef}$ & $0,19 b c d$ & $0,63 d$ & $0,31 \mathrm{abc}$ & $0,24 \mathrm{bc}$ & $0,30 a$ \\
\hline (12) 11) + Calagem & $1,58 f$ & $0,19 \mathrm{bcd}$ & $0,63 d$ & $0,28 \mathrm{bcd}$ & $0,23 \mathrm{bcd}$ & $0,31 \mathrm{ab}$ \\
\hline (13) Sem P e s/Mgse & $\frac{3}{4}, 92 \mathrm{ab}$ & $0,11 \mathrm{efg}$ & $0,76 \mathrm{~cd}$ & $0,18 \mathrm{de}$ & $0,38 a$ & $0,30 a b$ \\
\hline (14) 13) + Calagem & $3,48 \mathrm{abc}$ & $0,09 \mathrm{~g}$ & $1,29 a b c$ & $0,26 \mathrm{cde}$ & $0,23 \mathrm{bcde}$ & $0,19 \mathrm{ab}$ \\
\hline $\mathrm{F}$ & $14,15 * *$ & $15,26 * *$ & $12,05 * *$ & $10,64 * *$ & $27,58 * *$ & $3,30 * x$ \\
\hline \multirow[t]{2}{*}{ (2) dms (Tukey 5\% } & \%) - & - & - & - & - & - \\
\hline & 8,43 & 7,80 & 8,73 & 7,73 & 8,46 & 12,27 \\
\hline
\end{tabular}

1 - Transformações das observações segundo arc sen $\sqrt{\mathrm{X} / 100}$.

2 - Médias com a mesma letra não diferem significativamente entre si. 
Tabela 18 - Efeito dos tratamentos sobre as quantidades dos macronutrientes absorvidas pelo capim Colonião após arroz no 10 corte (mg/vaso) (mèdias de $\overline{3}$ repetições).

\begin{tabular}{|c|c|c|c|c|c|c|}
\hline TRATAMENTOS & $\mathrm{N}$ & $\mathrm{P}$ & $\mathrm{K}$ & $\mathrm{Ca}$ & $\mathrm{Mg}$ & $S$ \\
\hline (1) Sem fösforo & $33,07 d$ & $1 ; 14 \mathrm{~d}$ & $17,91 \mathrm{de}$ & $1,72 \mathrm{de}$ & 1,07 ef & $2,10 c$ \\
\hline (2) 1) + Ca lagen & $26,46 \mathrm{~d}$ & $0,69 d$ & $4,59 \mathrm{e}$ & $1,21 \mathrm{e}$ & $0,62 \mathrm{f}$ & $1,90 \mathrm{c}$ \\
\hline (3) FCPS $150 \mathrm{ppm} \mathrm{P}$ & $101,79 b c$ & $8,17 \mathrm{bc}$ & $44,63 \mathrm{bc}$ & $12,60 \mathrm{bc}$ & 3,31 def & $15,55 \mathrm{ab}$ \\
\hline (4) 3)+Calagem & $107,35 \mathrm{bc}$ & $8,38 \mathrm{bc}$ & $82,06 a$ & $14,43 \mathrm{bc}$ & $9,93 b c$ & $15,99 a b$ \\
\hline (5) FCPS $300 \mathrm{ppm} P$ & $157,20 \mathrm{a}$ & $11,99 \mathrm{ab}$ & $53,89 b c$ & $25,94 \mathrm{a}$ & $5,85 \mathrm{cde}$ & $21,25 a$ \\
\hline (6) 5) + Calagem & $118,92 b$ & $10,13 \mathrm{ab}$ & $64,42 a b c$ & $24,02 \mathrm{a}$ & $13,94 \mathrm{ab}$ & $16,17 \mathrm{ab}$ \\
\hline (7) $\mathrm{SPT} 225 \mathrm{ppm} P$ & $75,43 c$ & $13,40 \mathrm{a}$ & $56,43 b c$ & $9,72 \mathrm{~cd}$ & $3,43 \mathrm{def}$ & $8,83 b c$ \\
\hline (8) 7) + Calagem & $94,92 b c$ & $12,64 a$ & $67,37 \mathrm{ab}$ & $13,13 \mathrm{bc}$ & $6,54 \mathrm{~cd}$ & $8,85 b c$ \\
\hline (9) $\mathrm{FCTF} 150 \mathrm{ppm} P$ & $104,08 \mathrm{bc}$ & $6,01 \mathrm{c}$ & $52,53 \mathrm{bc}$ & $10,00 \mathrm{~cd}$ & 5,91 cde & $14,40 c i$ \\
\hline (10) 9) + Ca1agem & $98,37 \mathrm{bc}$ & $9,88 \mathrm{abc}$ & $66,40 a b c$ & $15,62 b c$ & $17,54 a$ & $17,41 \mathrm{ab}$ \\
\hline (11) FCTF $300 \mathrm{ppm} P$ & $108,40 b$ & $12,23 \mathrm{ab}$ & $41,92 \mathrm{~cd}$ & $20,51 \mathrm{ab}$ & $16,43 a$ & $20,06 a$ \\
\hline (12) 11) + Calagem & $112,41 \mathrm{~b}$ & $13,51 \mathrm{a}$ & $45,82 \mathrm{bc}$ & $20,40 \mathrm{ab}$ & $16,70 \mathrm{a}$ & $22,11 \mathrm{a}$ \\
\hline 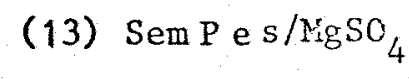 & $4^{37,81 d}$ & $1,10 \mathrm{~d}$ & $7,50 \mathrm{e}$ & $1,75 \mathrm{de}$ & $3,69 \mathrm{def}$ & $2,92 c$ \\
\hline (14) 13)+Calagem & $27,39 d$ & $0,67 \mathrm{~d}$ & $9,99 \mathrm{e}$ & $1,97 \mathrm{de}$ & $1,73 \mathrm{def}$ & $1,45 c$ \\
\hline F & $39,49 * *$ & $40,36 * *$ & $27,17 * *$ & $27,69 * *$ & $37,85 * *$ & $14,44 k \pi$ \\
\hline \multirow{2}{*}{$\frac{(1) \mathrm{dms}(\mathrm{T}}{\mathrm{CV}}$} & 32,85 & 4,10 & 24,61 & 8,36 & 5,16 & 10,43 \\
\hline & 12,89 & 17,45 & 18,73 & 22,61 & 22,65 & 29,02 \\
\hline
\end{tabular}

(1) Mẽdias com a mesma letra não diferem significativamente entre si. 
Com relação aos tratamentos que utilizaram FCTF, os teores de nutrientes encontrados para cālcio, magnésio e enxofre foram normais independentemente da dosagem e da calagem. 0 teor de nitrogênio foi baixo, mas não diferiu do tratamento com SPT; o fósforo apresentou teores comparáveis ao tratamento com SPT, só na dose maior com calagem, e os teores de potássio, somente a dose $150 \mathrm{ppm}$ de $\mathrm{P}$ apresentou valores iguais es tatisticamente com o tratamento padrão. As quantidades absorvidas de nitrogènio, fósforo, cálcio, magnésio e enxōfre nos tratamentos com FCTF, na dose maior com e sem calagem foram as maiores, para potássio a maior absorção apresentou-se no tratamento com a dose $150 \mathrm{ppm}$ de $\mathrm{P}$ com e sém calagem; nos casos do magnésio e enxofre as quantidades absorvidas superaram estatisticamente às obtidas nos tratamentos com SPT. A adição de adubos fosfatados nem sempre é acompanhada de correlações significativas entre o teor fósforo na matéria seca e a produ ção. Frequentemente, os teores de outros nutrientes na planta são mais afetados que o próprio fósforo. MASCARENHAS et alii, (1978), trabalhando com soja, mostraram que a aplicaça o de adubos fosfatados em ausēncia de calagem modificou principalmente os teores de $\mathrm{Ca}$ e $\mathrm{Mg}$, além do Fe, $\mathrm{Zn}$ e A1. Alguns desses nutrientes estão presentes nos fertilizantes como Ca e $\mathrm{Mg}$.

No segundo corte (tabelas 19 e 20), a anälise 
Tabela 19 - Efeito dos tratamentos nos teores (1) de macronutrientes conti das na matéria seca do capim Colonião após arroz no 29 corte (médias de 3 repetições).

\begin{tabular}{|c|c|c|c|c|c|c|}
\hline TRATAMENTOS & $7 \mathrm{~N}$ & ZP & $\% \mathrm{~K}$ & $\% \mathrm{Ca}$ & $\% \mathrm{Mg}$ & $\% \mathrm{~S}$ \\
\hline (1) Sem fösforo & $1,24 \mathrm{bc}$ & $0,085 \mathrm{efg}$ & $2,35 \mathrm{ab}$ & $0,23 b$ & $0,12 \mathrm{~F}$ & $0,66 a$ \\
\hline (2) 1)+Calagem & $1,37 \mathrm{~b}$ & $0,09 \mathrm{efg}$ & $2,22 \mathrm{abc}$ & $0,29 \mathrm{ab}$ & $0,13 f$ & $0,50 \mathrm{abc}$ \\
\hline (3) FCPS $150 \mathrm{ppm} P$ & $0,77 d$ & $0,14 \mathrm{bcd}$ & $0,93 \mathrm{ef}$ & $0,65 \mathrm{ab}$ & $0,16 \mathrm{f}$ & $0,47 b c$ \\
\hline (4) 3)+Calagem & $0,76 \mathrm{~d}$ & $0,11 \mathrm{de}$ & $0,81 \mathrm{f}$ & $0,67 \mathrm{ab}$ & $0,33 \mathrm{bc}$ & $0,39 \mathrm{~cd}$ \\
\hline (5) FCPS 300 ppm P & $1,08 \mathrm{bcd}$ & $0,17 \mathrm{ab}$ & 1,34 def & $0,55 a b$ & 0,18 def & $0,46 \mathrm{bcd}$ \\
\hline (6) 5)+Calagem & $1,01 \mathrm{bcd}$ & $0,15 b c$ & $1,45 \mathrm{cdef}$ & $0,82 \mathrm{a}$ & $0,44 \mathrm{ab}$ & $0,43 \mathrm{~cd}$ \\
\hline (7) $\mathrm{sPT} 225 \mathrm{ppmP}$ & $0,88 \mathrm{~cd}$ & $0,17 \mathrm{ab}$ & $1,48 \mathrm{cde}$ & $0,58 \mathrm{ab}$ & 0,19 def & $0,43 \mathrm{~cd}$ \\
\hline (8) 7) + Calagem & $1,16 \mathrm{bcd}$ & $0,19 a$ & $2,03 \mathrm{bcd}$ & $0,54 a b$ & $0,29 \mathrm{~cd}$ & $0,43 \mathrm{~cd}$ \\
\hline (9) FCTF $150 \mathrm{ppm} P$ & $1,26 \mathrm{bc}$ & $0,10 \mathrm{ef}$ & $1,36 \mathrm{def}$ & $0,45 a b$ & 0,26 cde & $0,51 \mathrm{abc}$ \\
\hline (10) 9) + Calagem & $1,25 b c$ & $0,11 \mathrm{de}$ & $1,47 \mathrm{cdef}$ & $0,74 a$ & $0,51 \mathrm{a}$ & $0,47 \mathrm{bc}$ \\
\hline (11) FCTF $300 \mathrm{ppm} P$ & $1,07 \mathrm{bcd}$ & $0,14 \mathrm{bc}$ & $1,42 \mathrm{cdef}$ & $0,52 \mathrm{ab}$ & $0,43 \mathrm{ab}$ & $0,46 \mathrm{bcd}$ \\
\hline (12) 11) + Calagem & $1,03 \mathrm{bcd}$ & $0,13 \mathrm{~cd}$ & $1,00 \mathrm{ef}$ & $0,69 \mathrm{ab}$ & $0,52 a$ & $0,43 c d$ \\
\hline (13) SemPe $s / M_{t}$ & $2,07 a$ & $0,08 \mathrm{fg}$ & $3,06 a$ & $0,29 a b$ & $0,15 f$ & $0,61 \mathrm{ab}$ \\
\hline$(14)$ 13) + Calagem & $1,94 a$ & $0,07 \mathrm{~g}$ & $2,96 a b$ & $0,28 \mathrm{ab}$ & $0,17 \mathrm{ef}$ & $0,33 \mathrm{~d}$ \\
\hline $\mathrm{F}$ & $14,75 * *$ & $43,35 * *$ & $18,88 * *$ & $3,15 * *$ & $40,70 * *$ & $7,94 * *$ \\
\hline \multicolumn{7}{|l|}{ (2) dms (Tukey 5\%) } \\
\hline $\mathrm{CV}$ & 8,92 & 4,18 & 8,30 & 17,45 & 7,21 & 5,28 \\
\hline
\end{tabular}

(1) Transformação das observações segundo arc sen $\sqrt{x / 100}$.

(2) Mëdias com a mesma letra não diferem significativamente entre si. 
Tabela 20 - Efeito dos tratamentos sobre as quantidades dos macronutrien tes absorvidos pelo capim Colonião após arroz no 29 corte (mg/ /vaso) (mëdias de 3 repetições).

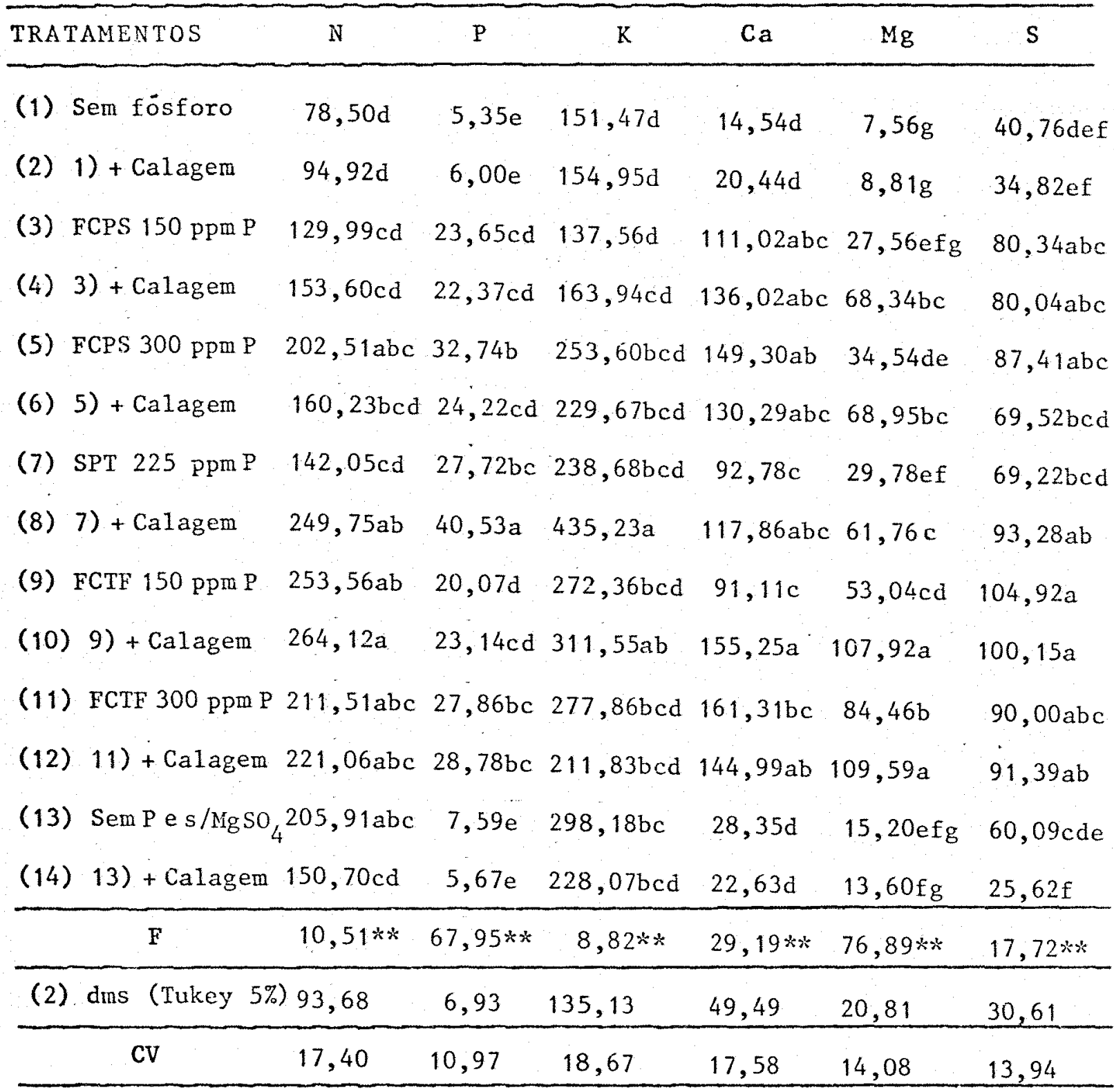

(2) Médias com a mesma letra não diferem significativamente entre si. 
da variancia novamente deu um valor de F, altamente significativo para efeito de tratamento em todas as variāveis estudadas, tanto para teores como no conteüdo. A comparação das mëdias pạ ra tratamentos com FCPS e SPT, mostra que os teores de nitrogênio, câlcio e enxofre não diferem entre si; para o fösforo houve uma diminuição no tratamento para a dose 150 ppm de $\mathrm{P}$ com ca1agem, não comparäve1 com o SPT (padrão); o potássio apresen tou um nivel adequado para a dose maior com e sem calagem; - mesmo aconteceu com o magnésio nas doses de 150 e 300 ppm de p ambos sem calagem. Com relação às quantidades de nutrientes absorvidas tem-se que no caso de nitrogēnio, fösforo, potässio, cälcio e enxōfre, a absorção nos tratamentos com fCPS foi equivalente ao tratamento padrão sem calagem, no caso do magnésio, os tratamentos com FCPS e calagem, superaram aos tratamentos com SPT.

Quanto aos tratamentos com FCTF, os teores de nitrogēnio, potässio, cälcio e enxofre, não diferiram entre tratamentos e foram iguais estatisticamente ao tratamento com SPT sem calagem. No caso do fösforo, o maior teor foi no trata mento com a dose maior sem calagem comparäel ao tratamento com SPT sem calagem. No caso do magnésio, os teores apresentados nos tratamentos com o FCTF, com calagem foram os maiores, superando os tratamentos em SPT e FCPS. As quantidades de nutrientes absorvidos nos tratamentos com FCTF apresentaram uma 
tendência semelhante à observada para teores de nutrientes. A absorção de fósforo foi equivalente ao tratamento com SPT sem calagem, quando se usaram as doses maiores com o sem calagem.

Novamente houve grande absorção de magnésio em ambas as doses com calagem.

No terceiro corte (Tabelas 21 e 22), os tratamentos com FCPS independentemente da dose e da calagem apresentaram teores iguais estatisticamente aos encontrados nos tratamentos com SPT na dose intermediäria com e sem calagem, no teor de cälcio para a dose maior com calagem o FCPS superou estatisticamente ao SPT. Quanto a absorça total, a situação não variou muito em relacão à observada com respeito aos teores, entretanto o tratamento com a dose maior de $\mathrm{P}$ e calagem apresentou a maior absorção de magnèsio superando ao tratamento com SPT. Na comparação dos tratamentos com FCTF, vê-se que os teores encontrados para nitrogénio, fósforo, potássio, cälcio e enxôfre, não diferem dos teores encontrados nos tratamentos com SPT, independentemente da dose e da calagem, o mesmo não aconte cendo para teores de magnésio, pois os tratamentos com FCTF apresentaram os maiores valores porcentuais, esta situaça mante ve-se no caso da absorção dos nutrientes. Isto indica que em tais tratamentos houve um maior fornecimento de magnésio para a planta proveniente do termofosfato. (LOPEZ et alii, 1982; MALAVolta, 1980), e provavelmente este elemento junto ao fósforo e 
Tabela 21 - Efeito dos tratamentos sobre os teores (1) de macronutrientes contidos na matéria seca do capim Colonião apōs arroz no 39 corte (médias de 3 repetições).

\begin{tabular}{|c|c|c|c|c|c|c|}
\hline TRATAMENTOS & $\% \mathrm{~N}$ & $\% \mathrm{P}$ & $\% \mathrm{~K}$ & $\% \mathrm{Ca}$ & \%Mg & $\% \mathrm{~S}$ \\
\hline (1) Sem fösforo & $3,04 a$ & $0,02 \mathrm{~cd}$ & $2,92 \mathrm{a}$ & $0,06 \mathrm{f}$ & $0,05 \mathrm{~cd}$ & $0,41 \mathrm{a}$ \\
\hline (2) 1)+ Calagem & $1,93 \mathrm{bc}$ & $0,03 \mathrm{bcd}$ & 2, oObcd & $0,18 \mathrm{e}$ & $0,10 \mathrm{~b}$ & $0,38 \mathrm{ab}$ \\
\hline (3) FCPS $150 \mathrm{ppm} P$ & $1,27 \mathrm{de}$ & $0,06 \mathrm{abc}$ & $1,97 \mathrm{bcde}$ & $0,22 \mathrm{de}$ & $0,07 \mathrm{bcd}$ & $0,29 \mathrm{abcd}$ \\
\hline (4) 3) + Calagem & $1,08 \mathrm{de}$ & $0,05 a b c$ & $1,44 \mathrm{de}$ & $0,32 a b c$ & $0,10 \mathrm{~b}$ & $0,20 \mathrm{cde}$ \\
\hline (5) FCPS 300 ppm P & $1,08 \mathrm{de}$ & $0,06 \mathrm{abc}$ & $1,44 \mathrm{de}$ & $0,31 \mathrm{abcd}$ & $0,07 \mathrm{bcd}$ & $0,18 \mathrm{de}$ \\
\hline (6) 5) + Calagem & $1,22 \mathrm{de}$ & $0,06 \mathrm{abc}$ & $1,54 \mathrm{cde}$ & $0,38 \mathrm{ab}$ & $0,23 a$ & $0,17 \mathrm{e}$ \\
\hline (7) $\mathrm{SPT} 225 \mathrm{ppm} P$ & $1,00 \mathrm{de}$ & $0,08 a$ & $1,57 \mathrm{cde}$ & $0,23 \mathrm{cde}$ & $0,07 \mathrm{bcd}$ & $0,27 b c d e$ \\
\hline (8) 7)+Calagem & $1,11 \mathrm{de}$ & $0,08 \mathrm{a}$ & $1,56 \mathrm{cde}$ & $0,25 \mathrm{cde}$ & $0,08 \mathrm{bc}$ & $0,23 \mathrm{cde}$ \\
\hline (9) FCTF 150 ppm $P$ & $1,33 \mathrm{cde}$ & $0,03 \mathrm{bcd}$ & $1,80 \mathrm{bcde}$ & $0,19 \mathrm{e}$ & $0,11 \mathrm{~b}$ & $0,38 \mathrm{ab}$ \\
\hline$(10) 9)+C a l$ agem & $1,23 \mathrm{de}$ & $0,04 a b c d$ & $1,34 \mathrm{de}$ & $0,42 a$ & $0,21 \mathrm{a}$ & 0,20 cde \\
\hline (11) $\mathrm{FCTF} 300 \mathrm{ppm} \mathrm{P}$ & $1,44 \mathrm{cde}$ & $0,07 \mathrm{ab}$ & $1,30 \mathrm{e}$ & $0,27 \mathrm{bcde}$ & $0,24 \mathrm{a}$ & $0,23 \mathrm{cde}$ \\
\hline (12) 11) + Calagem & $0,98 \mathrm{e}$ & $0,06 \mathrm{abc}$ & $1,30 \mathrm{e}$ & $0,33 \mathrm{abc}$ & $0,20 a$ & $0,19 \mathrm{de}$ \\
\hline (13) $\mathrm{SemPe} / \mathrm{sgSO}_{4}$ & $2,07 \mathrm{~b}$ & $0,01 \mathrm{~d}$ & $2,20 a b c$ & $0,07 f$ & $0,04 \mathrm{~d}$ & $0,28 \mathrm{bcd}$ \\
\hline \multirow[t]{2}{*}{ (14) 13)+Calagem } & $1,52 \mathrm{bcd}$ & $0,01 \mathrm{~d}$ & $2,52 \mathrm{ab}$ & $0,18 \mathrm{e}$ & $0,21 \mathrm{a}$ & $0,31 a b c$ \\
\hline & $20,85 * *$ & $8,54 * x$ & $11,51 * *$ & $36,76 * *$ & $47,48 * x$ & $11,99 * *$ \\
\hline \multirow[t]{2}{*}{ (2) dms (Tukey 5\%) } & 1,38 & 0,58 & 1.55 & 0,57 & 0,45 & 0,66 \\
\hline & 6,73 & 15,42 & 6,81 & 6,92 & 7,70 & 7,52 \\
\hline
\end{tabular}

(1) Transformação das observações segundo arc sen $\sqrt{\mathrm{x} / 100}$.

(2) Médias com a mesma letra não diferem significativamente entre si. 
Tabela 22 - Efeito dos tratamentos sobre as quantidades dos macronutrien tes absorvidos pelo capim colonião após arroz no 39 corte (mg/ /vaso) (mēdias de 3 repetições).

\begin{tabular}{|c|c|c|c|c|c|c|c|}
\hline TRAT & TAMENTOS & $\mathrm{N}$ & $\mathrm{P}$ & $\mathrm{K}$ & $\mathrm{Ca}$ & $\mathrm{Mg}$ & $s$ \\
\hline (1) & Sem fösforo & $46,64 \mathrm{e}$ & $0,49 f$ & $49,42 c$ & $1,06 \mathrm{f}$ & $0,81 \mathrm{~d}$ & $6,48 \mathrm{~d}$ \\
\hline$(2)$ & 1) + Calagem & $56,35 \mathrm{de}$ & $0,93 \mathrm{ef}$ & $58,29 c$ & $5,13 \mathrm{ef}$ & $3,05 \mathrm{~cd}$ & $11,26 \mathrm{~cd}$ \\
\hline (3) & FCPS $150 \mathrm{ppm} \mathrm{P}$ & $127,05 \mathrm{ab}$ & $6,27 \mathrm{bcd}$ & $195,42 \mathrm{ab}$ & $21,60 \mathrm{~cd}$ & $6,64 \mathrm{bcd}$ & $28,78 \mathrm{ab}$ \\
\hline (4) & 3) + Calagem & $117,70 \mathrm{bc}$ & $5,78 \mathrm{bcd}$ & $159,05 \mathrm{ab}$ & $34,09 a b$ & $11,73 b$ & $21,94 a b c$ \\
\hline (5) & FCPS $300 \mathrm{ppm} P$ & $120,83 b c$ & $7,13 \mathrm{abc}$ & $160,84 a b$ & $34,84 a b$ & $4,47 \mathrm{bcd}$ & $20,15 \mathrm{abc}$ \\
\hline (6) & 5) + Calagem & $118,35 \mathrm{bc}$ & $6,16 \mathrm{bcd}$ & $143,97 b$ & $35,60 \mathrm{ab}$ & $22,19 a$ & $15,76 \mathrm{bcd}$ \\
\hline$(7)$ & SPT $225 \mathrm{ppm} P$ & $114,46 b c$ & $9,15 a b$ & $180,65 \mathrm{ab}$ & $26,37 \mathrm{bcd}$ & $7,93 \mathrm{bcd}$ & $31,39 a$ \\
\hline (8) & 7) +Calagem & $154,47 \mathrm{ab}$ & $11,12 \mathrm{a}$ & $217,37 a$ & $35,15 \mathrm{ab}$ & $11,08 \mathrm{~b}$ & $31,51 \mathrm{a}$ \\
\hline (9) & FCTF $150 \mathrm{ppm} \mathrm{P}$ & $106,96 \mathrm{bcd}$ & 2,74 def & $143,93 b$ & $14,81 \mathrm{de}$ & $9,01 \mathrm{bc}$ & $30,03 a$ \\
\hline$(10)$ & 9) + Calagem & $135,48 a b$ & $4,30 \mathrm{cde}$ & $147,98 b$ & $46,41 a$ & $23,38 \mathrm{a}$ & $24,68 \mathrm{ab}$ \\
\hline (11) & FCTF $300 \mathrm{ppm} P$ & $178,26 a$ & $9,63 a b$ & $161,57 \mathrm{ab}$ & $32,80 \mathrm{bc}$ & $27,87 a$ & $28,42 a b$ \\
\hline$(12)$ & 11) + Calagem & $104,34 \mathrm{bcd}$ & $6,57 \mathrm{bcd}$ & $145,65 b$ & $36,53 \mathrm{ab}$ & $22,56 a$ & $20,78 a b c$ \\
\hline$(13)$ & $\operatorname{Sem} \mathrm{P}$ e $\mathrm{s} / \mathrm{MgSO}$ & $0_{4} 66,20 \mathrm{cde}$ & $0,39 f$ & $54,15 c$ & $1,69 \mathrm{f}$ & $0,87 \mathrm{~d}$ & $6,62 \mathrm{~d}$ \\
\hline \multirow[t]{2}{*}{$(14)$} & 13) + Calagem & $42,81 \mathrm{e}$ & $0,36 f$ & $74,20 c$ & $5,36 \mathrm{ef}$ & $6,19 \mathrm{bcd}$ & $9,59 \mathrm{~cd}$ \\
\hline & $F$ & $13,93 * * 2$ & $20,02 * *$ & $17,06 * *$ & $39,79 * *$ & $41,86 * *$ & $12,61 * x$ \\
\hline \multirow[t]{2}{*}{ (1) } & dins (Tukey 5\%) & \%) 55,85 & 4,20 & 68,93 & 12,59 & 7,13 & 13,41 \\
\hline & $\mathrm{CV} \%$ & 17,47 & 27,50 & 17,08 & 17,73 & 20,76 & 21,82 \\
\hline
\end{tabular}

1 - Mèdias com a mesma letra não diferem significativamente entre si. 
cälcio, sejam responsäveis pelo rendimento de matéria seca obti do com FCTF nas dosagens maiores.

Para os très cortes realizados frequentemente apresentaram-se teores elevados de nutrientes nos tratamentos que não receberam fósforo (tratamentos 1, 2, 13 e 14 respectiva mente), principalmente para o nitrogēnio. Isto se pode atribuir ao efeito de concentraça, sendo que nos tratamentos em que não houve limitação de crescimento, o nitrogênio absorvido pelas raizes era distribuído em mais matëria seca. Este fato foi observado por WERNER et alii (1967) trabalhando com capim Colonião e utilizando um solo esgotado.

A ordem de absorção de elementos foi: potássio, nitrogénio, cälcio, enxofre, magnësio efósforo; com exceçãofeita do 19 corte onde o nitrogēnio foi mais absorvido do que o potássio. Esta mesma ordem, foi encontrada por HAAG et a1ii (1967) e WERNER (1971).

4.4.2. Teores e absorção de nutrientes do capim colonião apōs soja (três cortes).

Os teores e quantidades absorvidas de nutrientes do capim Colonião após soja se encontram nas Tabelas 23, $24,25,26,27$ e 28 . 
Os dados do primeiro corte estam contidos nas tabelas 23 e 24 . Pela anàlise da variancia pode-se perceber que o valor F foi altamente significativo para efeito de tratamento em todas as variäveis. Na comparaçõ das médias de trata... mentos com FCPS para teores de nutrientes, encontram-se que os teores de nitrogēnio, potássio, cālcio, magnësio e enxofre não diferiram estatisticamente dos tratamentos com SPT. No caso de fösforo os teores foram iguais para as duas doses com e sem calagem, sem chegar ao encontrado no tratamento padrão (SPT). Na quantidade total dos elementos absorvidos a situação para o nitrogénio não variou com respeito ao apresentado para teores. No caso fósforo, potàssio, cảlcio, magnésio e enxofre, os trata mentos com ICPS na dose maior, apresentaram efeito da calagem sendo os valores obtidos iguais, e no caso de potásio superio res, ao tratamento com SPT.

Com relação aos tratamentos em que se utilizou FCTF, os teores não diferiram muito dos obtidos para o tratamento com SPí, com excecão dos teores de fósforo, que foram inferiore; o teor ra dose maior alcançou o nivel médio citado por HAAG et alii (1967). Para a absorção total de nutrientes não houve diferenca significativa nos casos do nitrogēnio e potässio compaxativamente com o tratamento padrão (SPT). Para fósforo, magnésio houve efeito de doses em ausēncia e presença de calagem e para enxofre só em ausência de calagem. 
Tabela 23 - Efeitos dos tratamentos scbre os teores (1) de macronutrientes contidos na matéria seca do capim Colonião após soja no 19 corte. (médias de 3 repetições).

\begin{tabular}{|c|c|c|c|c|c|c|}
\hline TRATAMENTOS & $\% \mathrm{~N}$ & $\% \mathrm{P}$ & $\% \mathrm{~K}$ & $\% \mathrm{Ca}$ & $\% \mathrm{Mg}$ & $\% \mathrm{~S}$ \\
\hline (1) Sem fösforo & $3,41 \mathrm{abc}$ & $0,11 \mathrm{~d}$ & 1,64 def & $0,21 \mathrm{~cd}$ & $0,15 \mathrm{de}$ & $0,21 \mathrm{c}$ \\
\hline (2) 1) + Calagem & $4,18 a$ & $0,11 \mathrm{~d}$ & $2,97 \mathrm{ab}$ & $0,22 \mathrm{~cd}$ & $0,18 \mathrm{abcde}$ & $0,25 \mathrm{bc}$ \\
\hline (3) FCPS $150 \mathrm{ppm} P$ & $2,10 \mathrm{cdef}$ & $0,16 \mathrm{bcd}$ & $1,44 \mathrm{ef}$ & $0,21 \mathrm{~cd}$ & $0,15 \mathrm{de}$ & $0,37 \mathrm{ab}$ \\
\hline (4) 3) + Calagem & $3,15 \mathrm{abcde}$ & $0,15 b c d$ & $1,73 \mathrm{cdef}$ & $0,29 \mathrm{abc}$ & $0,23 \mathrm{abcd}$ & $0,34 a b$ \\
\hline (5) FCPS $300 \mathrm{ppm} P$ & $1,50 f$ & $0,19 b c$ & $1,84 \mathrm{cdef}$ & $0,38 \mathrm{a}$ & 0,14 de & $0,30 a b c$ \\
\hline (6) 5) + Calagem & $1,75 \mathrm{ef}$ & $0,22 b$ & $1,96 \mathrm{cde}$ & $0,37 a$ & $0,26 a b$ & $0,33 \mathrm{abc}$ \\
\hline (7) $\mathrm{sPT} 225 \mathrm{ppm} \mathrm{P}$ & $2,06 \mathrm{cdef}$ & $0,33 a$ & $1,73 \mathrm{cdef}$ & $0,28 \mathrm{abcd}$ & $0,17 \mathrm{bcde}$ & $0,28 \mathrm{abc}$ \\
\hline (8) 7)+Calagem & 1,80 def & $0,33 a$ & $1,69 \mathrm{def}$ & $0,36 \mathrm{ab}$ & $0,27 a$ & $0,41 \mathrm{a}$ \\
\hline (9) FCTE $150 \mathrm{ppm} P$ & $2,37 \mathrm{bcdef}$ & $0,15 \mathrm{bcd}$ & $2,32 \mathrm{bcd}$ & $0,22 \mathrm{~cd}$ & $0,15 \mathrm{de}$ & $0,30 \mathrm{abc}$ \\
\hline (10) 9)+Calagem & $3,66 \mathrm{ab}$ & $0,13 \mathrm{~cd}$ & $2,48 \mathrm{abc}$ & $0,24 \mathrm{bcd}$ & $0,20 \mathrm{abcde}$ & $0,33 a b c$ \\
\hline (11) FCTF 300 ppin $P$ & $1,50 f$ & $0,18 b c$ & $1,74 \mathrm{cdef}$ & $0,28 \mathrm{abcd}$ & $0,25 \mathrm{abc}$ & $0,40 a$ \\
\hline (12) 11) + Calagem & $1,88 \mathrm{def}$ & $0,22 b$ & $1,21 f$ & $0,23 \mathrm{~cd}$ & $0,28 \mathrm{a}$ & $0,29 a b c$ \\
\hline (13) Sem $\mathrm{P}$ e s/ $\mathrm{MgSO}$ & $4,37 \mathrm{abc}$ & $0,12 \mathrm{~d}$ & $3,22 a$ & $0,19 \mathrm{~cd}$ & $0,13 \mathrm{e}$ & $0,28 \mathrm{abc}$ \\
\hline (14) 13) + Calagem & $3,18 \mathrm{abcd}$ & $0,11 \mathrm{c}$ & $2,45 \mathrm{abcd}$ & $0,18 \mathrm{~d}$ & $0,15 \mathrm{cde}$ & $0,25 \mathrm{bc}$ \\
\hline $\mathrm{F}$ & $10,08 \times x$ & $23,26 * *$ & $14,65 \%$ & $9,31 * *$ & $8,31 * *$ & $4,67 * x$ \\
\hline \multicolumn{7}{|l|}{ ( ) dms (Tukey 5\%) } \\
\hline $\mathrm{CV}$ & 9,63 & 6,33 & 7,31 & 8,53 & 8,59 & 7,39 \\
\hline
\end{tabular}

(1) Transformações das observações segundo arc sen $\sqrt{\mathrm{X} / 100}$.

(2) Mëdias com a mesma letra não diferem sỉgnificativamente entre si. 
Tabela 24 - Efeito dos tratamentos sobre as quantidades dos macronutrientes absorvidos pelo capim Colonião após soja no 19 corte (mg/ /vaso) (nëdias de 3 repetições).

\begin{tabular}{|c|c|c|c|c|c|c|}
\hline TRATAMENTOS & $\mathrm{N}$ & $\mathrm{p}$ & $=\mathrm{K}$ & $\mathrm{Ca}$ & $\mathrm{Mg}$ & $\cdots \mathrm{S}$ \\
\hline (1) Sem fösforo & $26,01 \mathrm{e}$ & $0,85 \mathrm{e}$ & $12,68 \mathrm{e}$ & $1,54 \mathrm{~h}$ & $1,09 \mathrm{f}$ & $1,53 \mathrm{e}$ \\
\hline (2) 1) + Calagem & $49,24 \mathrm{cde}$ & $1,33 \mathrm{e}$ & $35,54 \mathrm{de}$ & $2,75 \mathrm{gh}$ & $2,25 f$ & $2,97 e$ \\
\hline (3) FCPS $150 \mathrm{ppm} \mathrm{P} 1$ & $115,93 \mathrm{abcd}$ & $9,02 \mathrm{bcd}$ & $57,08 \mathrm{cde}$ & 11,46 defg & $8,36 \mathrm{cdef}$ & $20,21 \mathrm{ab}$ \\
\hline$(4) 3)+$ Calagem & $172,85 \mathrm{a}$ & $8,33 \mathrm{bcd}$ & $92,11 \mathrm{bc}$ & $16,01 \mathrm{bcde} 1$ & $12,92 b c d$ & $18,98 \mathrm{abc}$ \\
\hline (5) FCPS $300 \mathrm{ppm} P$ & $80,20 \mathrm{bcde}$ & $10,51 b$ & $99,11 \mathrm{bc}$ & $20,57 b c$ & $7,67 \mathrm{cdef}$ & $16,12 \mathrm{bcd}$ \\
\hline (6) 5)+Calagem & $149,74 \mathrm{ab}$ & $18,98 a$ & $167,74 a$ & $31,72 a$ & $22,93 \mathrm{a}$ & $27,75 a$ \\
\hline (7) $\mathrm{SPT} 225 \mathrm{ppm} \mathrm{P}$ & $137,24 \mathrm{ab}$ & $21,71 \mathrm{a}$ & $115,08 \mathrm{~b}$ & $17,73 \mathrm{bcd}$ & $11,22 \mathrm{bcde}$ & $18,27 \mathrm{abcd}$ \\
\hline (8) 7) + Calagem & $120,70 \mathrm{abc}$ & $19,88 a$ & $120,28 b$ & $23,71 \mathrm{ab}$ & $18,17 a b$ & $26,60 a$ \\
\hline (9) FCTF 150 ppm $P$ & $68,45 \mathrm{bcde}$ & $4,49 \mathrm{cde}$ & $68,01 \mathrm{bcd}$ & $7,69 \mathrm{efgh}$ & $4,17 \mathrm{ef}$ & $8,89 \mathrm{de}$ \\
\hline (10) 9)+Calagem & 102,3 labcde & $3,70 \mathrm{de}$ & $68,20 \mathrm{bed}$ & $6,81 \mathrm{fgh}$ & $5,73 \mathrm{def}$ & $9,38 \mathrm{cde}$ \\
\hline (11) FCTF 300 ppm P & $79,60 \mathrm{bcde}$ & $9,83 \mathrm{bc}$ & $91,93 \mathrm{bc}$ & 14,95 bcdef & $13,56 \mathrm{bc}$ & $20,88 \mathrm{ab}$ \\
\hline (12) 11) + Calagem & 103,92 abcde & $11,72 b$ & $64,92 \mathrm{bcd}$ & $12,90 \mathrm{cdef}$ & $15,69 \mathrm{ab}$ & $15,68 \mathrm{bcd}$ \\
\hline (13) Sem P e s/rgSO & $4^{36,06 \mathrm{de}}$ & $1,28 \mathrm{e}$ & $34,23 \mathrm{de}$ & $2,03 \mathrm{~h}$ & $1,38 \mathrm{f}$ & $2,96 \mathrm{e}$ \\
\hline (14) 13) + Calagem & $37,68 \mathrm{de}$ & $1,32 \mathrm{e}$ & $29,05 e$ & $2,11 \mathrm{~h}$ & $1,85 f$ & $2,94 \mathrm{e}$ \\
\hline $\mathrm{F}$ & $8,23 * *$ & $43,27 x *$ & $18,00 * *$ & $29,01 * *$ & $23,73 * *$ & $21,71 * *$ \\
\hline \multirow{2}{*}{$\frac{(1) \mathrm{dms}(\mathrm{T}}{\mathrm{CV}}$} & 81,79 & 5,70 & 50,63 & 8,29 & 7,32 & 10,00 \\
\hline & 29,89 & 21,70 & 22,64 & 24,01 & 26,99 & 22,30 \\
\hline
\end{tabular}

(1) Mëdias com a mesma letra não diferem significativamente entre si. 
Como no primeiro corte do capim Colonião após arroz, o elemento mais acumulado foi o nitrogénio.

No segundo corte ( $T$ abelas 25 e 26), os teores encontrados nos tratamentos com fCPS, para nitrogênio, potássio, cälcio, magnésio e enxófre foram concordantes com os achados para os tratamentos com SPT. No caso do fósforo os tratamen tos com a dose 150 ppm de P apresentaram teores baixos e não di ferentes dos tratamentos que não receberam fósforo; mesmo assim não houve efeito de dose para teor de fósforo. o potässio passo a ser elemento absorvido em maior quantidade, seguido do nitrogēnio, cälcio, enxốre, magnésio e fósforo. Com exceção do fósforo todos os elementos apresentaram valores comparáveis aos tratamentos com SPT, independentemente da dose e da calagem; no caso do fósforo na dose maior com e sem calagem igualou-se ao SPT.

Para os tratamentos que receberam FCTF os teores encontrados foram bastante significativos para magnésio e enxôfre, para nitrogênio não houve variaça respeito do tratamento padrão, para fósforo os teores foram baixos na dose menor com e sem calagem, e o potássio e cảlcio aumentaram os teores com a calagem. As quantidades absorvidas nos tratamentos com FCTF não diferiram das obtidas com os tratamentos padröes, para o fósforo e o magnēsio foram as doses maiores com e sem calagem 
Tabela 25 - Efeito dos tratamentos sobre os teores ${ }^{(1)}$ de macronutrientes contidos na matēria seca do capim Colonião após soja no 20 corte (mëdias de 3 repetições).

\begin{tabular}{|c|c|c|c|c|c|c|}
\hline TRATAMENTOS & $\% \mathrm{~N}$ & $\% \mathrm{P}$ & $\% \mathrm{~K}$ & $\therefore \% \mathrm{Ca}$ & $\% \mathrm{Mg}$ & $\% \mathrm{~S}$ \\
\hline (1) Sem fösforo & $1,76 \mathrm{a}$ & $0,07 \mathrm{ef}$ & $2,28 \mathrm{abc}$ & $0,21 \mathrm{e}$ & $0,21 \mathrm{~cd}$ & $0,28 a b$ \\
\hline (2) 1) + Calagem & 1,29abcie & 0,07 def & $2,50 a b$ & $0,25 \mathrm{de}$ & $0,15 \mathrm{~d}$ & $0,23 \mathrm{~b}$ \\
\hline (3) FCPS $150 \mathrm{ppm} P$ & $0,69 f$ & 0,11 bcde & $1,29 \mathrm{e}$ & $0,37 \mathrm{bcd}$ & $0,11 \mathrm{~d}$ & $0,20 \mathrm{~b}$ \\
\hline (4) 3) + Calagem & 0,96 def & $0,08 \mathrm{cdef}$ & $1,42 \mathrm{de}$ & $0,31 \mathrm{cde}$ & $0,22 \mathrm{bcd}$ & $0,20 \mathrm{~b}$ \\
\hline (5) FCPS 300 ppm P & $1,05 b c d e f$ & $0,13 b$ & $1,31 \mathrm{e}$ & $0,43 \mathrm{bc}$ & $0,15 \mathrm{~d}$ & $0,19 \mathrm{~b}$ \\
\hline (6) 5) + Calagem & $0,80 \mathrm{ef}$ & $0,11 \mathrm{bcd}$ & $1,11 \mathrm{e}$ & $0,51 b$ & $0,31 \mathrm{abc}$ & $0,21 b$ \\
\hline (7) $\mathrm{SPT} 225 \mathrm{ppm} \mathrm{P}$ & $0,67 \mathrm{f}$ & $0,22 a$ & $1,40 \mathrm{e}$ & $0,37 \mathrm{bcd}$ & $0,12 d$ & $0,21 b$ \\
\hline (8) 7) + Calagem & $0,57 f$ & $0,20 a$ & $1,23 \mathrm{e}$ & $0,52 b$ & $0,33 \mathrm{abc}$ & $0,19 b$ \\
\hline (9) FCTF $150 \mathrm{ppm} P$ & $0,95 \mathrm{def}$ & $0,07 \mathrm{def}$ & $1,91 \mathrm{~cd}$ & $0,33 \mathrm{cde}$ & $0,21 \mathrm{~cd}$ & $0,23 b$ \\
\hline (10) 9) + Calagem & $1,72 \mathrm{ab}$ & $0,06 f$ & $2,32 \mathrm{abc}$ & $0,41 \mathrm{bc}$ & $0,38 \mathrm{ab}$ & $0,25 \mathrm{ab}$ \\
\hline (11) FCTF $300 \mathrm{ppm} P$ & $1,00 \mathrm{cdef}$ & 0,11 bcde & $1,29 \mathrm{e}$ & $0,41 \mathrm{bc}$ & $0,33 \mathrm{abc}$ & $0,26 a b$ \\
\hline (12) 11) + Calagem & $0,68 \mathrm{f}$ & $0,12 \mathrm{bc}$ & $2,08 \mathrm{bc}$ & $0,76 \mathrm{a}$ & $0,46 a$ & $0,26 \mathrm{ab}$ \\
\hline (13) $\mathrm{SemPes} / \mathrm{MgSO}_{4}$ & $1,46 \mathrm{abcd}$ & $0,07 \mathrm{ef}$ & $2,81 \mathrm{a}$ & $0,21 \mathrm{e}$ & $0,12 \mathrm{~d}$ & $0,38 a$ \\
\hline (14) 13) + Calagem & $1,63 a b c$ & $0,06 \mathrm{f}$ & $2,50 a b$ & $0,32 \mathrm{cde}$ & $0,13 \mathrm{~d}$ & $0,37 a$ \\
\hline $\mathrm{F}$ & $12,38 * *$ & $25,66 * *$ & $33,29 * *$ & $18,85 * *$ & $14,26 * *$ & $7,27 * *$ \\
\hline $\mathrm{CV}$ & 9,38 & 7,24 & 4,89 & 7,25 & 11,21 & 7,61 \\
\hline
\end{tabular}

(1) Transformação das observações segundo arc sen $\sqrt{X / 100}$.

(2) Mëdias com a mesma letra não diferem significativamente entre si. 
Tabela 26 - Efeito dos tratamentos sobre as quantidades dos macronutrientes absorvidos pelo capim Colonião após soja no 29 corce (ing/ /vaso) (mëdias de 3 repetições).

\begin{tabular}{|c|c|c|c|c|c|c|}
\hline TRATAMENTOS & $\mathrm{N}$ & $P$ & $\mathrm{~K}$ & $\mathrm{Ca}$ & $\mathrm{Mg}$ & $S$ \\
\hline (1) Sem fösforo & $48,89 d$ & $0,37 \mathrm{~d}$ & $82,02 c$ & $4,68 \mathrm{f}$ & $3,38 \mathrm{ef}$ & $11,83 \mathrm{~d}$ \\
\hline (2) 1) + Calagem & $42,51 d$ & $0,66 \mathrm{~d}$ & $135,56 b c$ & $8,23 \mathrm{ef}$ & $5,06 \mathrm{ef}$ & $13,91 \mathrm{~cd}$ \\
\hline (3) FCPS $150 \mathrm{ppm} P 1$ & $157,82 a$ & $5,71 \mathrm{bcd}$ & $167,54 \mathrm{ab}$ & $24,81 \mathrm{cdef}$ & $16,15 \mathrm{~cd}$ & $22,47 \mathrm{abcd}$ \\
\hline (4) 3) + Calagem & $126,54 a b$ & $5,24 \mathrm{~cd}$ & $186,30 \mathrm{ab}$ & $30,06 \mathrm{cde}$ & $18,14 \mathrm{~cd}$ & $31,89 a$ \\
\hline (5) FCPS $300 \mathrm{ppm} P 1$ & $111,79 b c$ & $11,05 \mathrm{abc}$ & $187,32 \mathrm{ab}$ & $24,14 \mathrm{cde}$ & $13,89 \mathrm{~cd}$ & $26,44 a b$ \\
\hline (6) 5) + Calagem & $130,99 \mathrm{ab}$ & $11,30 \mathrm{ab}$ & $228,92 a$ & $70,15 a$ & $19,59 \mathrm{bc}$ & $27,37 \mathrm{ab}$ \\
\hline (7) SPT 225 ppmP 1 & $109,17 \mathrm{bc}$ & $13,47 a$ & $207,81 \mathrm{ab}$ & $26,31 \mathrm{cdef}$ & 9,80 def & $24,19 \mathrm{abc}$ \\
\hline (8) 7) + Calagem & $145,62 \mathrm{ab}$ & $14,90 a$ & $185,87 \mathrm{ab}$ & $54,08 \mathrm{ab}$ & $22,05 \mathrm{bc}$ & $23,88 \mathrm{abcc}$ \\
\hline (9) FCTF $150 \mathrm{ppmP} 1$ & $130,88 \mathrm{ab}$ & $2,45 \mathrm{~d}$ & $223,88 a$ & $15,40 \mathrm{def}$ & $13,80 \mathrm{~cd}$ & $28,32 \mathrm{ab}$ \\
\hline (10) 9) + Calagem & $81,31 \mathrm{~cd}$ & $3,75 \mathrm{~d}$ & $155,43 a b c$ & 15,82 def & $10,92 \mathrm{de}$ & $22,87 \mathrm{abcd}$ \\
\hline (11) FCTF $300 \mathrm{ppm} \mathrm{P}$ & $106,38 \mathrm{bc}$ & $16,11 \mathrm{a}$ & $231,96 \mathrm{a}$ & $32,30 \mathrm{bcd}$ & $27,14 \mathrm{ab}$ & $31,96 a$ \\
\hline$(12) 11)+$ Calagem & $128,64 a b$ & $12,69 a$ & $189,52 \mathrm{ab}$ & $44,69 \mathrm{bc}$ & $35,02 a$ & $21,45 a b c c$ \\
\hline 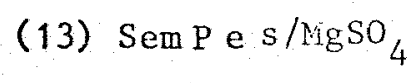 & $4^{60,38 d}$ & $2,76 \mathrm{~d}$ & $149,88 a b c$ & $6,87 \mathrm{ef}$ & $2,0 \mathrm{if}$ & $20,71 \mathrm{abcc}$ \\
\hline \multirow[t]{2}{*}{ (14) 13)+ Calagem } & $55,70 \mathrm{~d}$ & $4,99 \mathrm{~d}$ & $126,71 \mathrm{bc}$ & $9,57 \mathrm{def}$ & $4,96 \mathrm{ef}$ & $17,76 \mathrm{bcd}$ \\
\hline & $23,42 * *$ & $23,40 * *$ & $7,14 * *$ & $17,14 * *$ & $33,89 * *$ & $6,34 * x$ \\
\hline \multirow{2}{*}{$\frac{(1) \text { dms (Tukey 5\%) }}{\mathrm{CV}}$} & 40,71 & 5,88 & 83,02 & 23,98 & 8,46 & 12,27 \\
\hline & 13,26 & 26,10 & 15,79 & 30,15 & 19,60 & 17,66 \\
\hline
\end{tabular}

(1) Médias com a mesma letra não diferem significativamente entre si. 
as que forneceram as maiores quantidadea absorvidas. A menor de $\mathrm{P}$ igualou-se aos tratamentos que não receberam o elemento.

os teores de nutrientes, neste segundo corte tambëm apresentaram-se semelhantes aos encontrados por HAAG et alii (1967) e WERNER (1971).

No terceiro corte de capim Colonião (Tabelas 27 e 28) os tratamentos com FCPS não apresentaran diferenças significativas para os teores de $\mathrm{N}, \mathrm{K}, \mathrm{Ca}, \mathrm{Mg}$ e S; quando compa radas com os tratamentos padrões. Para o fösforo não houve dife rença só na dose maior com e sem calagem. Na comparação das quantidades absorvidas vê-se que para nitrogēnio não houve efei to de tratamento, para o fósforo as quantidades absorvidas aumentaram com respeito do 19 e 29 corte, mas sem se igualar ao tratamento padrão. Para potässio, cälcio, magnésio e enxofre, os tratamentos com FCPS apresentaram absorçóes semelhantes ao tratamento padrão.

Em relação aos tratamentos com FCTF as doses menores com e sem calagem apresentaram maiores teores de nitro gēnio, potāssio e enxofre que os tratamentos com SPT. o fósforo, cālcio e magnésio apresentaram teores altos com a dose maior com e sem calagem. Para quantidades absorvidas, o nitrogénio não foi significativo, para fósforo a dose maior com e sem cala 
Tabela 27 - Efeito dos tratanentos sobre oa teores (1) de macronutrientes contidos na matēria seca do capim Colonião após soja no 39 corte (médias de 3 repetições).

\begin{tabular}{|c|c|c|c|c|c|c|}
\hline TRATAMENTOS & $\% \mathrm{~N}$ & $\% \mathrm{P}$ & $\% \mathrm{~K}$ & $\% \mathrm{Ca}$ & $\% \mathrm{Mg}$ & $\% S$ \\
\hline (1) Sem fösforo & $1,31 \mathrm{abcd}$ & $0,01 \mathrm{~h}$ & $2,21 \mathrm{cde}$ & $0,13 f$ & $0,09 \mathrm{def}$ & $0,32 b c$ \\
\hline (2) 1) + Calagem & $0,85 \dot{i}$ & $0,0 \mathrm{igh}$ & $2,70 \mathrm{abc}$ & 0,16 def & $0,11 \mathrm{cde}$ & $0,28 \mathrm{bcd}$ \\
\hline (3) FCPS $150 \mathrm{ppm} P$ & $1,47 \mathrm{ab}$ & $0,05 \mathrm{ef}$ & $1,55 \mathrm{f}$ & $0,23 \mathrm{cdef}$ & $0,15 \mathrm{bcd}$ & 0,21 de \\
\hline (4) 3) + Calagem & 1,06 bcdef & $0,04 \mathrm{f}$ & $1,54 \mathrm{f}$ & 0,25 cde & $0,15 \mathrm{bcd}$ & $0,27 \mathrm{~cd}$ \\
\hline (5) FCPS $300 \mathrm{ppm} \mathrm{p}$ & $0,94 \mathrm{def}$ & $0,09 \mathrm{abcd}$ & $1,57 \mathrm{f}$ & $0,28 \mathrm{bcd}$ & $0,12 \mathrm{cde}$ & $0,22 \mathrm{de}$ \\
\hline (6) 5) + Calagem & $1,00 \mathrm{cdef}$ & $0,09 \mathrm{bcde}$ & $1,75 \mathrm{def}$ & $0,53 a$ & $0,15 \mathrm{bcd}$ & 0,21 de \\
\hline (7) $\mathrm{SPT} 225 \mathrm{ppm} P$ & $0,86 \mathrm{ef}$ & $0,11 \mathrm{ab}$ & $1,63 \mathrm{ef}$ & $0,21 \mathrm{cdef}$ & $0,08 \mathrm{ef}$ & $0,19 \mathrm{de}$ \\
\hline (8) 7) + Calagem & $1,13 \mathrm{bcdef}$ & $0,12 a b$ & $1,45 \mathrm{f}$ & $0,42 \mathrm{ab}$ & $0,17 a b c$ & $0,19 \mathrm{de}$ \\
\hline (9) FCTF $150 \mathrm{ppm} P$ & $1,75 \mathrm{a}$ & $0,03 \mathrm{fg}$ & $3,01 \mathrm{ab}$ & $0,20 \mathrm{cdef}$ & $0,18 \mathrm{abc}$ & $0,38 \mathrm{ab}$ \\
\hline (10) 9) + Calagem & $1,24 \mathrm{bcde}$ & 0,06 def & $2,36 \mathrm{bcd}$ & $0,24 \mathrm{cde}$ & $0,16 \mathrm{bcd}$ & $0,35 \mathrm{abc}$ \\
\hline (11) FCTF $300 \mathrm{ppm} P$ & $0,90 \mathrm{ef}$ & $0,14 a$ & $1,89 \mathrm{def}$ & $0,27 \mathrm{bcd}$ & $0,23 \mathrm{ab}$ & $0,16 \mathrm{e}$ \\
\hline (12) 11)+Calagem & $1,00 \mathrm{cdef}$ & $0,10 \mathrm{abc}$ & $1,48 f$ & $0,34 \mathrm{bc}$ & $0,27 a$ & $0,27 \mathrm{~cd}$ \\
\hline (13) Sem P e s/ $/ \operatorname{lgSO}_{2}$ & $4,36 a b c$ & $0,06 \mathrm{cdef}$ & $3,34 \mathrm{a}$ & $0,15 \mathrm{ef}$ & $0,04 \mathrm{E}$ & $0,46 a$ \\
\hline \multirow[t]{2}{*}{ (14) 13) + Calagem } & $1,04 \mathrm{bcdef}$ & $0,05 \mathrm{ef}$ & $2,38 \mathrm{bcd}$ & $0,18 \mathrm{def}$ & $0,09 \mathrm{def}$ & $0,33 b c$ \\
\hline & $10,21 * x$ & $37,39 \% *$ & $22,20 * *$ & $15,57 * *$ & $16,25 * *$ & $19,99 * *$ \\
\hline \multicolumn{7}{|l|}{ (2) dms (Tukey 5\%) } \\
\hline $\mathrm{CV} \%$ & 6,03 & 9,27 & 5,41 & 9,03 & 9,73 & 6,04 \\
\hline
\end{tabular}

(1) Transformação das observações segundo arc sen $\sqrt{\mathrm{X} / 100}$.

(2) Médias com a mesma letra não diferem significativamente entre si. 
Tabela 28 - Efeito dos tratamentos sobre as quantidades dos macronutrientes absorvidas pelo capim Colonião após soja no 39 corte (mg) /vaso) (mëdias de 3 repetições.

\begin{tabular}{|c|c|c|c|c|c|c|}
\hline TRATAMENTOS & $\mathrm{N}$ & $\mathrm{P}$ & $\mathrm{K}$ & $\mathrm{Ca}$ & $\mathrm{Mg}$ & s \\
\hline (1) Sein fösforo & 153,84 & $6,06 \mathrm{e}$ & $196,07 c$ & $18,63 \mathrm{f}$ & $18,08 \mathrm{f}$ & $24,85 \mathrm{de}$ \\
\hline (2) 1) + Calagem & 110,83 & $6,26 \mathrm{e}$ & $212,41 \mathrm{bc}$ & $21,24 \mathrm{ef}$ & $12,45 f$ & $19,57 \mathrm{e}$ \\
\hline (3) FCPS $150 \mathrm{ppm} \mathrm{P}$ & 152,35 & $23,99 \mathrm{bcd}$ & $285,11 \mathrm{bc}$ & $80,69 \mathrm{bcd}$ & $23,82 \mathrm{ef}$ & $44,32 \mathrm{bcd}$ \\
\hline (4) 3)+Calagem & 176,45 & $14,73 \mathrm{cde}$ & $256,24 \mathrm{bc}$ & $56,48 \mathrm{de}$ & $40,88 \mathrm{cdef}$ & $36,97 \mathrm{cde}$ \\
\hline (5) FCPS $300 \mathrm{ppm} \mathrm{P}$ & 192,39 & $24,55 \mathrm{bcd}$ & $240,72 b \mathrm{c}$ & $78,21 \mathrm{~cd}$ & $28,57 \mathrm{def}$ & $34,30 \mathrm{cde}$ \\
\hline (6) 5$)+$ Calagem & 182,43 & $25,66 \mathrm{bc}$ & $252,51 b c$ & $115,37 \mathrm{~b}$ & $69,76 b c$ & $46,84 \mathrm{bc}$ \\
\hline (7) $\mathrm{SPT} 225 \mathrm{ppmP}$ & 150,82 & $48,12 a$ & $308,04 b c$ & $79,83 \mathrm{bcd}$ & $27,00 \mathrm{def}$ & $45,39 \mathrm{bc}$ \\
\hline (8) 7) + Calagem & 99,79 & $33,44 b$ & $210,06 \mathrm{bc}$ & $89,01 \mathrm{bcd}$ & $56,08 \mathrm{bcd}$ & $32,69 \mathrm{cde}$ \\
\hline (9) FCIF $150 \mathrm{ppm} P$ & 154,63 & $12,45 \mathrm{de}$ & $309,48 b c$ & $53,61 \mathrm{de} \hat{i}$ & $35,80 \mathrm{def}$ & $37,01 \mathrm{cde}$ \\
\hline (10) 9) + Calagem & 233,57 & $8,63 \mathrm{e}$ & $313,80 \mathrm{~b}$ & $56,32 \mathrm{de}$ & 51,76 bode & 34,65 cde \\
\hline (11) FCTF $300 \mathrm{ppm} P$ & 236,08 & $25,08 \mathrm{bcd}$ & $295,44 b c$ & $93,71 \mathrm{bc}$ & $75,01 b$ & $59,19 \mathrm{ab}$ \\
\hline (12) 11) + Calagem & 180,83 & $32,66 \mathrm{~b}$ & $550,68 \mathrm{a}$ & $204,78 a$ & $121,86 a$ & $68,89 a$ \\
\hline (13) Sem $\mathrm{P}$ e $\mathrm{s} / \mathrm{MgSC}_{4}$ & 4108,39 & $7,57 \mathrm{e}$ & $304,94 b c$ & $23,29 \mathrm{ef}$ & $12,52 \mathrm{f}$ & $40,97 \mathrm{bcd}$ \\
\hline (14) 13) + Calagem & 156,77 & $6,41 e$ & $240,74 \mathrm{bc}$ & $30,38 \mathrm{ef}$ & $12,75 \mathrm{f}$ & $35,88 \mathrm{cde}$ \\
\hline F & $2,71 \mathrm{~ns}$ & $25,86 * *$ & $15,64 * *$ & $46,79 x *$ & $28,53 * *$ & $10,79 * *$ \\
\hline \multicolumn{2}{|l|}{ (1) dms (Tukey 5\%) } & 13,14 & 113,66 & 36,87 & 30,06 & 40,71 \\
\hline $\mathrm{CV}$ & 26,58 & 22,30 & 13,36 & 17,22 & 23,98 & 16,68 \\
\hline
\end{tabular}

(1) Mëdias com a mesma letra não diferem significativamente entre si. 
gem comparou-se ao tratamento com SPT. A dose maior com calagem de FCTF teve as maiores quantidades absorvidas de $\mathrm{K}$, Ca, Mg e $S$, os outros tratamentos com FCTF foram tão eficientes na absorcão destes quatro elementos, quanto o tratamento padrão.

o tratamento extra, sem fósforo e sem sulfato de magnésio em auséncia e presença de calagem teve um comportamento estatisticamente igual à testemunha, motivo pelo qual os seus resultados não foram considerados na confrontacão das médias dos tratamentos, pois comportou-se como mais uma testemurha.

4.5. Anālise conjunta dos ensaios

4.5.1. Arroz e capim Colonião

4.5.1. Matéria Seca total

Para determinar o efeito dixeto e residual dos niveis de fósforo aplicados das fontes fosfatadas estudadas e caracterizar sua eficiência agronômica, foram calculadas as relaçóes entre a produção de matéria seca total obtida em cada cultura; com cada fosfato e as obtidas com superfosfato triplo na dose intermediäria. Essas relaçóes encontran-se nas Tabelas 
$29,30,31$ e 32 e na Figura 11. Nelas pode-se verificar:

em ausencia de calagem o fosfato de Catalão parcialmente solub lizado (FCPS) e com tratamento de fusão (FCTF), nas dosagens maiores ( $300 \mathrm{ppm}$ de $\mathrm{P}$ ) mostraram-se equivalentes ao superfosfato triplo. 0 mesmo acontecendo para a dose 150 ppm de FCPS; b) o residual para o FCPS nas duas dosagens sem calagem igualou-se ao spt nos três cortes de colonião. o FCTF mostrou boa eficiência na dose 150 ppm de $\mathrm{p}$ só no segundo corte; c) A eficiência a gronômica em relação ao SPT, (Tabela 31 ), considerando-se a totalidade da matéria seca produzida, mostra dados, concordantes com estes resultados, sendo a eficiência agronōmica de $103,40 \%$ e $106,54 \%$ para as doses de $300 \mathrm{ppm}$ de $\mathrm{P}$ em ambas as fontes testadas, e de $95,14 \%$ para a dose 150 ppm de p de FCPS; d) Em presenca de calagem o FCpS na dose 150 ppm de $p$ mostrou-se equi valente ao SPT tanto para efeito direto quanto residual (Figura 11), sendo sua eficiēncia agronōmica de 93,81\% (Tabela 32), a dose maior só foi comparável ao SPT no 19 corte de colonião e sua eficiēncia foi de $78,80 \%$; e) em relação ao FCTF, foi equiva lente ao SPT só para efeito residual nas duas dosagens, sendo as suas eficiências de $90,68 \%$ e $99,54 \%$, respectivamente, com respeito ao efeito direto, este não chegou a igualar-se com o SPT, mesmo assim mostrou uma boa eficiencia (Tabe1a 30).

Em relação à Figura 11 a $1 \mathrm{guns}$ aspectos devem ser esclarecidos. As altas produções relativas obtidas no pri- 
Tabela 29 - Produção relativa de Matēria Seca em relação da produzida com SPT para o efeito direto do F.C.P.S. e F.C.T.F. sem calagem em arroz e capim Colonião (três cortes).

\begin{tabular}{|c|c|c|c|c|}
\hline Tratamentos & $\begin{array}{l}\text { Arroz } \\
---\end{array}$ & $\begin{array}{l}\text { Colonião } 19 \mathrm{c} \text {. } \\
---\% \text { de mat }\end{array}$ & $\begin{array}{l}\text { Colonião } 29 \mathrm{c} \\
\text { ria seca }--\end{array}$ & $\begin{array}{r}\text { Colonião } 39 \mathrm{c} \\
-----\end{array}$ \\
\hline Sem fösforo & 18,00 & 23,20 & 39,40 & 13,30 \\
\hline FCPS 150 ppm P & 90,90 & 108,20 & 105,30 & 87,00 \\
\hline FCPS 300 ppm P & 93,60 & 136,30 & 117,20 & 99,30 \\
\hline SPT 225 ppm $\mathrm{P}$ & 100,00 & 100,00 & 100,00 & 100,00 \\
\hline FCTF 150 ppm $\mathrm{P}$ & 76,80 & 93,00 & 125,20 & 69,70 \\
\hline FCTF 300 ppm P & 90,10 & 160,50 & 121,30 & 117,00 \\
\hline Sem fösforo e $\mathrm{s} / \mathrm{MgSO}_{4}$ & 22,20 & 23,20 & 61,40 & 21,15 \\
\hline
\end{tabular}


Tabela 30 - Produção relativa de Matéria Seca em relação a produzida com SPT para o efeito direto e residual do F.C.P.S. e F.C.T.F. com calagen em arroz e capim colonião (trés cortes).

\begin{tabular}{|c|c|c|c|c|}
\hline Tratamentos & Arroz & $\begin{array}{l}\text { Coloniäo } 1 \% \mathrm{c} \\
----\% \text { mate }\end{array}$ & $\begin{array}{l}\text { Colonião } 2{ }^{\circ} \\
\text { ria seca }--\end{array}$ & $\begin{array}{l}\text { Colonião } 39 \mathrm{c} \text {. } \\
----\end{array}$ \\
\hline Sem fōsforo & 18,20 & 15,80 & 32,50 & 21,20 \\
\hline FCPS $150 \mathrm{ppm} P$ & 93,80 & 124,00 & 95,40 & 78,90 \\
\hline FCPS 300 ppm P & 79,60 & 128,00 & 74,00 & 68,30 \\
\hline SPT $225 \mathrm{ppm} \mathrm{P}$ & 100,00 & 100,00 & 100,00 & 100,00 \\
\hline FCTF 150 ppm P & 83,31 & 135,50 & 98,30 & 80,20 \\
\hline FCTF $300 \mathrm{ppm} \mathrm{P}$ & 88,90 & 151,30 & 98,80 & 81,00 \\
\hline Sem fösforo e $\mathrm{s} / \mathrm{MgSO}_{4}$ & 24,10 & 16,40 & 36,10 & 21,20 \\
\hline
\end{tabular}


ARROZ E CAPIM COLONIĀO SEM CALAGEM

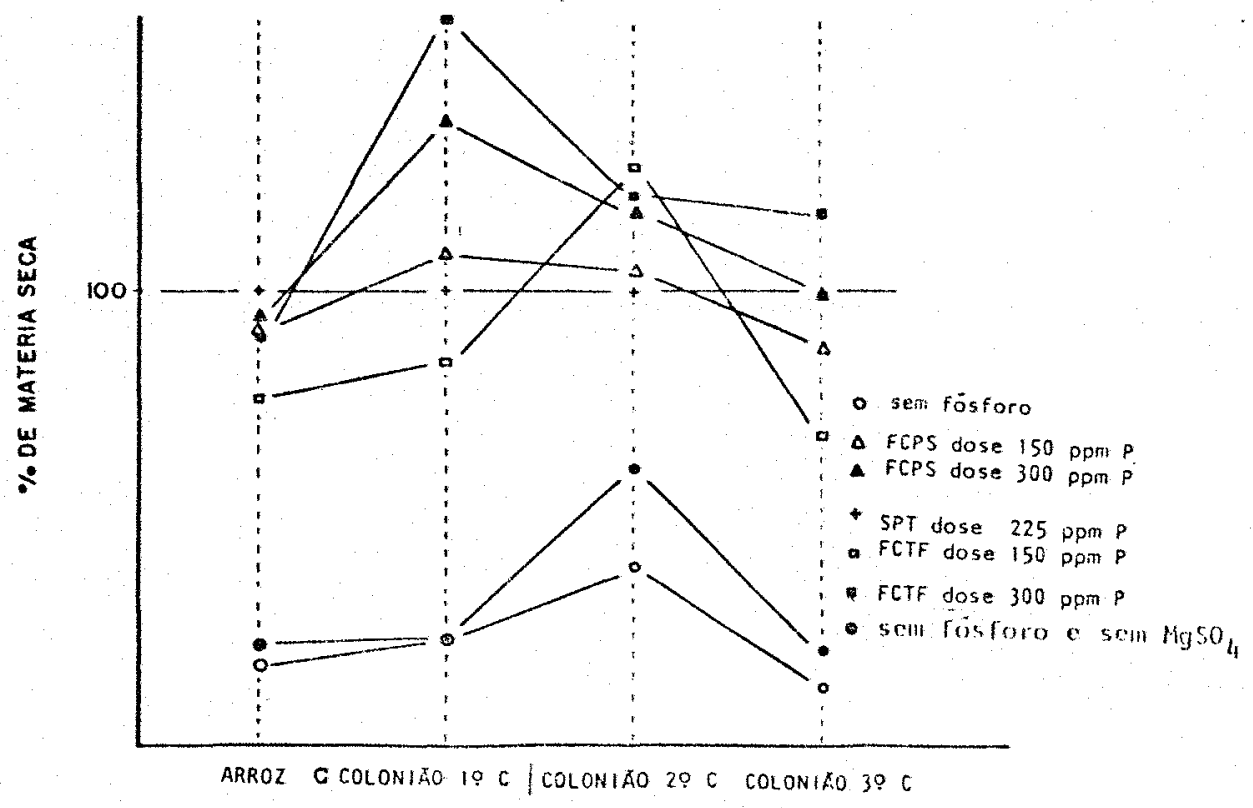

ARROZ E CAPIM COLONIĀO COM CALAGEM

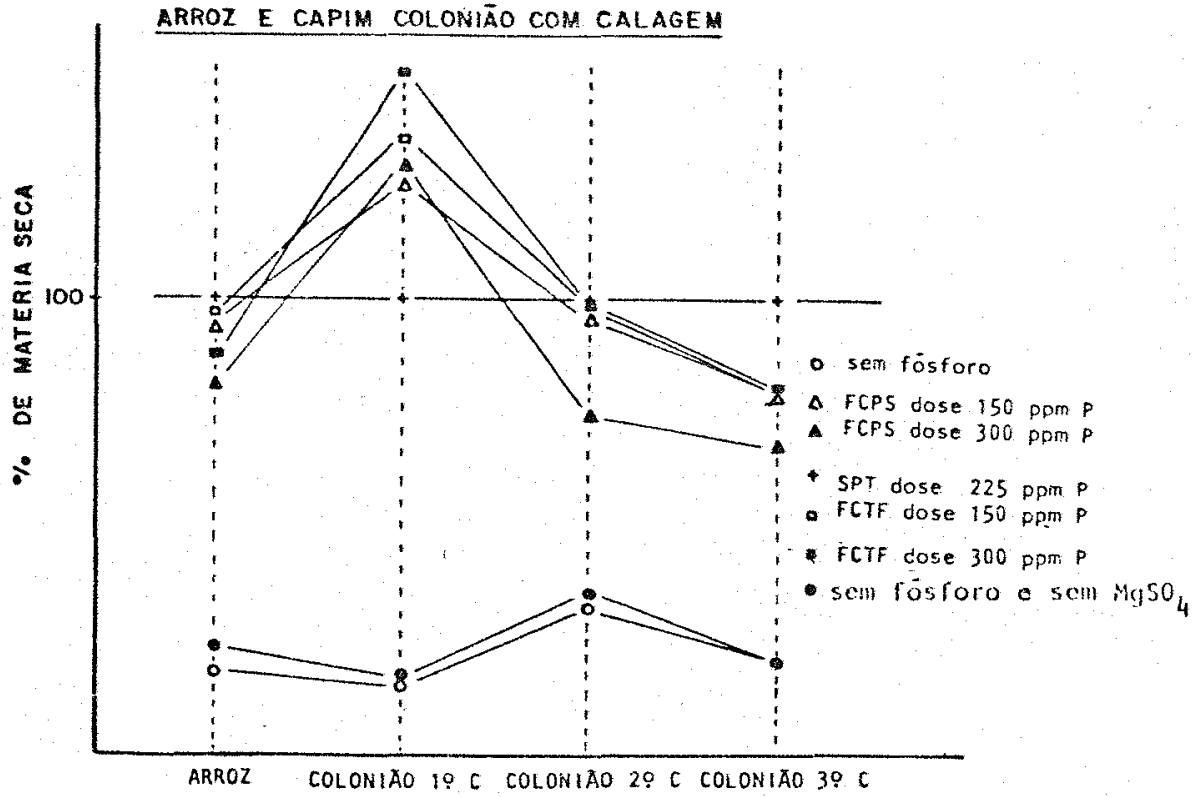

Figura 11 - Produção de matêria seca do arroz e capim Colonião (três cortes) com relação a produção com superfosfato. 
meiro corte se devem ao baixo teto máximo de produção de matëria seca, provavelmente como consequencia do menor desenvolvimento radicular das plantas nesta fase do estabelecimento inicial do Colonião, que impossibilitou uma maior exploracão do so 1o no vaso. Neste sentido NOVAES (1977) trabalhando com capim Co lonião em solos de cerrado obteve resultados semelhantes.

outro aspecto que merece destaque, é dado pela comparaça dos tratamentos em ausencia e presença de calagem, aparentemente as doses maiores sem calagem parecem ter uma efi ciência maior que as mesmas dosagens em presença da calagem, e em alguns casos o efeito parece sem inverso. Realmente o efeito da calagem foi sobre o tratamento padrão (SPT). Em outras palavras: a eficiéncia agronōmica demonstrada pelos fCPS e FCTF não mostrou efeito significativo para calagem.

4.1.2. Absorção de fósforo

A absorção de fösforo pelas culturas de arroz e Colonião em conjunto para niveis de $p$ e fontes fosfatadas tes tadas, com relação ao SPT emcontram-se nas Tabelas 33 e 34 . Pode-se observar que em ambas as tabelas a maior acumulação de fósforo ocorreu nos tratamentos padrões (SPT); das fontes testa das, o FCTF na dosagem 300 ppm de P mostrou-se como melhor for 
Tabela 31 - Matéria Seca do arroz e capim Colonião (três cortes) dos tratamentos em ausencia de calagem /g/vasc) e produção relativa em relação ao tratamento com SPT (mëdias de trēs repetições).

\begin{tabular}{|c|c|c|c|c|}
\hline Tratamentos & $\begin{array}{l}--- \\
\text { Arroz }\end{array}$ & $\begin{array}{l}\text { téria Seca } \\
\text { Colonião }\end{array}$ & $\begin{array}{l}--- \\
\text { Tota1 }\end{array}$ & $\%$ \\
\hline & -- & $--g-$ & --- & \\
\hline Sem fösforo & 5,20 & 8,82 & 14,02 & 23,17 \\
\hline FCPS dose $150 \mathrm{ppm} \mathrm{P}$ & 26,21 & 31,37 & $\div 57,58$ & 95,14 \\
\hline FCPS dose $300 \mathrm{ppm} \mathrm{P}$ & 26,95 & 35,63 & 62,58 & 103,40 \\
\hline SPT dose $225 \mathrm{ppm} \mathrm{P}$ & 28,86 & 31,66 & 60,52 & 100,00 \\
\hline FCTF dose $150 \mathrm{ppm} P$ & 22,15 & 31,98 & 54,13 & 89,44 \\
\hline FCTF dose $300 \mathrm{ppm} \mathrm{P}$ & 25,98 & 38,52 & 64,50 & 106,58 \\
\hline Sem fösforo e $\mathrm{S} / \mathrm{MgSO}_{4}$ & 6,40 & 13,25 & 19,65 & 32,47 \\
\hline
\end{tabular}


Tabela 32 - Matēria Seca do arroz e capim Colonião (trés cortes) dos tratamentos em presença de calagem (g/vaso) e produção relativa em relação ao tratamento com SPT (mëdias de trēs repetições).

\begin{tabular}{|c|c|c|c|c|}
\hline Tratamentos & $\begin{array}{l}--- \\
\text { Arroz }\end{array}$ & $\begin{array}{l}\text { Matéria Se } \\
\text { Colonião }\end{array}$ & $\begin{array}{l}---- \\
\text { Total }\end{array}$ & $\%$ \\
\hline & -- & $--g-$ & --- & \\
\hline $\begin{array}{l}\text { Sem fösforo }+ \\
\text { Calagem }\end{array}$ & 5,48 & 10,62 & 16,10 & 22,95 \\
\hline $\begin{array}{l}\text { FCPS dose } 150 \text { ppm } \mathrm{P}+ \\
\text { Calagem }\end{array}$ & 28,81 & 37,00 & 65,81 & 93,81 \\
\hline $\begin{array}{l}\text { FCPS dose } 300 \text { ppm } \mathrm{P}+ \\
\text { Calagem }\end{array}$ & 24,14 & 31,14 & 55,28 & 78,80 \\
\hline $\begin{array}{l}\text { SPT dose } 225 \text { ppm } \mathrm{P}+ \\
\text { Calagem }\end{array}$ & 30,32 & 39,83 & 70,15 & 100,00 \\
\hline $\begin{array}{l}\text { FCTF dose } 150 \text { ppm } \mathrm{P}+ \\
\text { Calagem }\end{array}$ & 25,26 & 38,35 & 63,61 & 90,68 \\
\hline $\begin{array}{l}\text { FCTF dose } 300 \text { ppm } \mathrm{P}+ \\
\text { Calagem }\end{array}$ & 27,07 & 39,41 & 66,48 & 94,77 \\
\hline $\begin{array}{l}\text { Sem fósforo es/MgSO } \\
\text { Calagem }\end{array}$ & 7,31 & 11,40 & 18,71 & 26,67 \\
\hline
\end{tabular}


Tabela 33- Quantidade de P absorvido pelo arroz e capim Colonião (três cortes), dos tratamentos em auséncia de calagem (ng/vaso), e ab sorção relativa de $\mathrm{P}$ em relação ao tratamento com SPT (médias de très repetições).

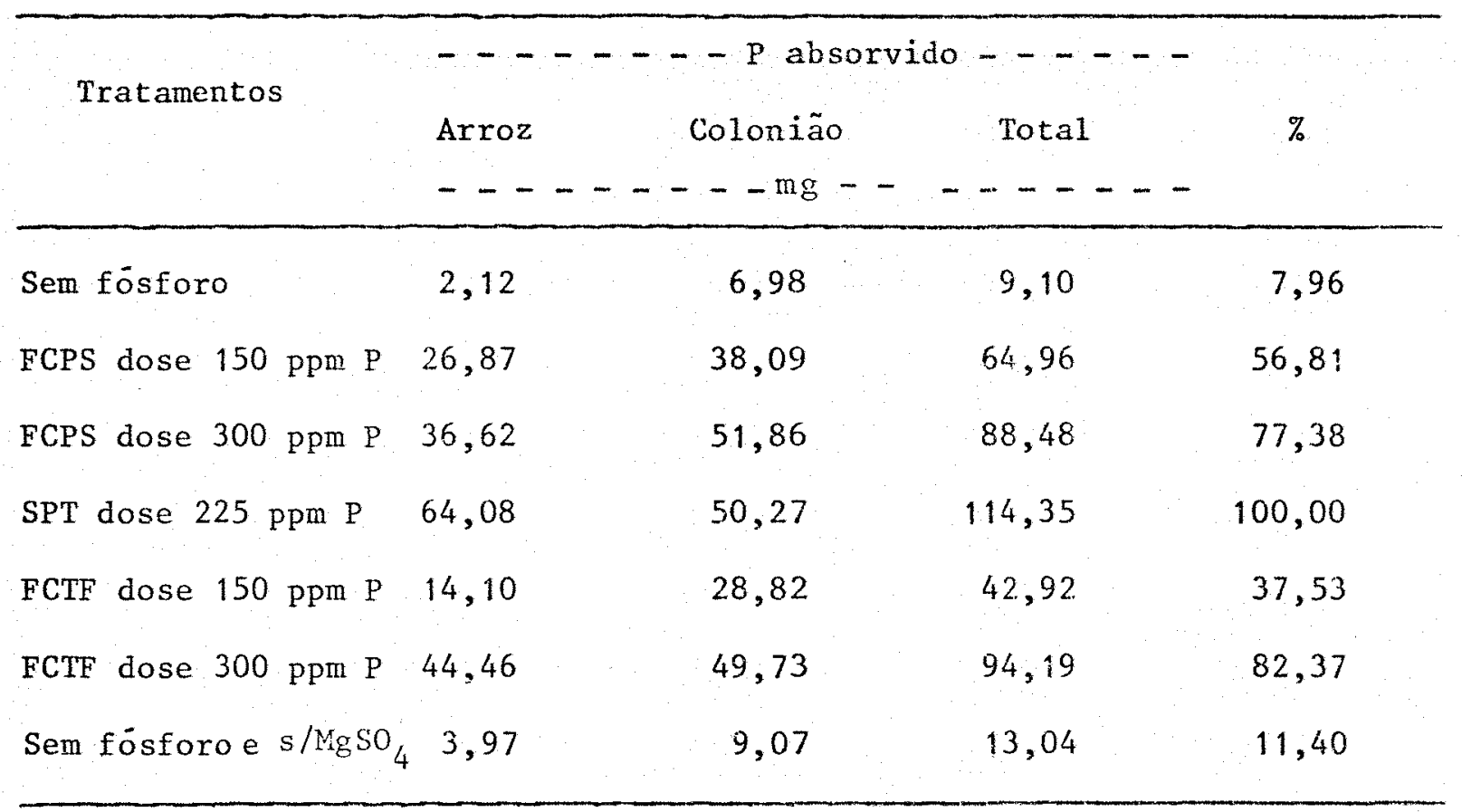


Tabela 34 - Quantidade de P absorvido pelo arroz e capim Colonião (três cor tes) dos tratamentos em presença de calagem (mg/vaso), e absorção relativa de $\mathrm{P}$ em relação ao tratamento com SPT (mëdias de trēs repetições).

\begin{tabular}{|c|c|c|c|c|}
\hline Tratamentos & $\begin{array}{l}--- \\
\text { Arroz } \\
---\end{array}$ & $\begin{array}{l}\text { P absorvi } \\
\text { Colonião } \\
--\mathrm{mg}-\end{array}$ & $\begin{array}{r}--- \\
\text { Tota1 } \\
----\end{array}$ & $\%$ \\
\hline Sem fösforo & 3,35 & 7,62 & 10,97 & 8,96 \\
\hline FCPS dose $150 \mathrm{ppm} \mathrm{P}$ & 31,39 & 36,53 & 67,92 & 55,50 \\
\hline FCPS dose $300 \mathrm{ppm} \mathrm{P}$ & 35,75 & 40,52 & 76,27 & 62,32 \\
\hline SPT dose $225 \mathrm{ppm} \mathrm{P}$ & 58,09 & 64,29 & 122,38 & 100,00 \\
\hline FCTF dose $150 \mathrm{ppm} \mathrm{P}$ & 24,34 & 37,83 & 62,17 & 50,80 \\
\hline FCTF dose $300 \mathrm{ppm} \mathrm{P}$ & 49,49 & 48,85 & 98,34 & 80,36 \\
\hline Sem fósforo e s/MgSO & 7,90 & 6,70 & 14,60 & 11,93 \\
\hline
\end{tabular}


necedor de fösforo para as plantas com relaça ao FCPS em ausēn cia e presença de calagem.

E interessante notar que a absorção total de fösforo mostrou um comportamento linear e positivo com as doses em ausēncia e presença de calagem, confirmando os resultados con seguidas com produção de matéria seca.

\subsubsection{Soja e capim Colonião}

\subsubsection{Matēria seca}

Nas Tabelas $35,36,37$ e 38 e na Eigura 12 encontram-se os dados correspondentes a efeito direto e residual que a continuação vai-se comentar: a) Em ausencia de calagem o FCPS na dose de $300 \mathrm{ppm}$ de $\mathrm{p}$ mostrou-se equivalente do SPT para efeito direto e residual, porēm a dose de $150 \mathrm{ppm}$ de $\mathrm{p}$, sua ef ciēncia no efeito direto foi inferior; sendo suas eficiências agronömicas em relação ao SPT (Tabela 37 ) de $95,18 \%$ e $100,44 \%$ para a primeira e segunda dose respectivamente; b) Com respeito ao FCTF a dose 150 ppm de $P$, mostrou-se ineficiente no efeito direto e residual, sendo sua eficiēncia de $68,76 \%$ com relaço ao SPT; a dose de 300 ppm P mostrou-se equivalente ao SPT somen 
Tabela 35- Produção relativa de Matéria Seca em relação da produzida com SPT para o efeito direto e residual do F.C.P.S. e F.C.T.F. sem calagem em soja e capim Colonião (três cortes).

\begin{tabular}{|c|c|c|c|c|c|}
\hline & Tratamentos & $\begin{array}{l}\text { Arroz } \\
---\end{array}$ & $\begin{array}{l}\text { Colonião } 19 \mathrm{c} \\
-----\%\end{array}$ & $\begin{array}{l}\text { Colonião } 29 \mathrm{c} \text {. } \\
\text { matéria seca }\end{array}$ & $\begin{array}{l}\text { Coloniăo } 39 \mathrm{c} \text {. } \\
-------\end{array}$ \\
\hline Sem & fósforo & 29,20 & 11,30 & 39,50 & 29,40 \\
\hline FCPS & S $150 \mathrm{ppm} \mathrm{P}$ & 66,70 & 82,80 & 99,50 & 85,10 \\
\hline FCPS & $\mathrm{S} 300 \mathrm{ppm} \mathrm{P}$ & 87,50 & 81,00 & 90,60 & 94,00 \\
\hline SPT & $225 \mathrm{ppm} \mathrm{P}$ & 100,00 & 100,00 & 100,00 & 100,00 \\
\hline FCTF & $\mathrm{F} 150 \mathrm{ppm} \mathrm{P}$ & 53,20 & 44,40 & 74,00 & 58,90 \\
\hline FCTF & F. $300 \mathrm{ppm} P$ & 69,30 & 79,40 & 104,00 & 93,10 \\
\hline Sem & fösforo e $\mathrm{s} / \mathrm{Mg} \mathrm{SO}_{4}$ & 435,40 & 15,70 & 49,30 & 35,50 \\
\hline
\end{tabular}


Tabela 36 - Produção relativa de Matëria Seca em relação à produzida com SPT para o efeito direto e residual do F.C.P.S. e OF.C.T.F.com calagem em soja e capim Colonião (trés cortes).

\begin{tabular}{|c|c|c|c|c|}
\hline Tratamentos & $\begin{array}{l}\text { Arroz } \\
---\end{array}$ & $\begin{array}{l}\text { Colonião } 1 \% \mathrm{c} \text {. } \\
-----\% \mathrm{de}\end{array}$ & $\begin{array}{l}\text { Coloniãa } 29 \mathrm{c} \text {. } \\
\text { matéria seca - }\end{array}$ & 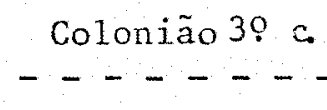 \\
\hline Sem fösforo & 33,80 & 18,40 & 46,20 & 39,30 \\
\hline FCPS $150 \mathrm{ppm} \mathrm{P}$ & 62,50 & 18,40 & 46,20 & 39,30 \\
\hline FCPS $300 \mathrm{ppm} \mathrm{P}$ & 69,30 & 130,60 & 122,60 & 102,00 \\
\hline SPT 225 ppm P & 100,00 & 100,00 & 100,00 & 100,00 \\
\hline FCTF 150 ppm P & 41,00 & 42,20 & 73,50 & 51,30 \\
\hline FCTF $300 \mathrm{ppm} \mathrm{P}$ & 58,30 & 83,00 & 144,00 & 101,00 \\
\hline Sem fösforoe $\mathrm{S} / \mathrm{MgSO}_{4}$ & 25,90 & 18,10 & 52,00 & 41,50 \\
\hline
\end{tabular}



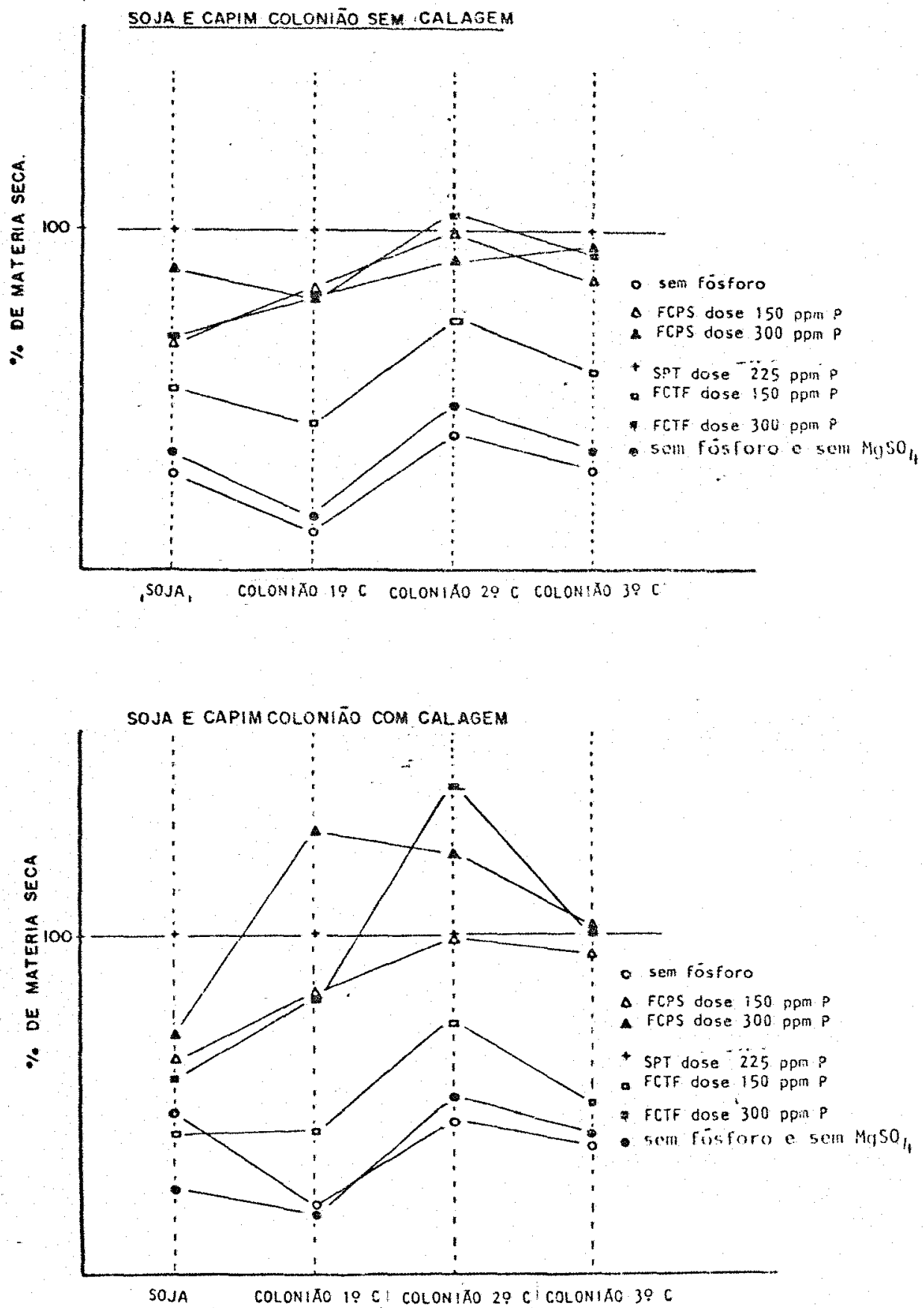

Figura 12 - Produção de matéria seca da soja e capim Colonião (três cortes), com relação à produção em superfosfato triplo. 
Tabela 37 - Matēria Seca da soja e capim Colonião (trés cortes) dos tratamentos em auséncia de calagem (g/vaso), e produção relativa em relação ao tratamento com SPT (mëdias de trés repetições).

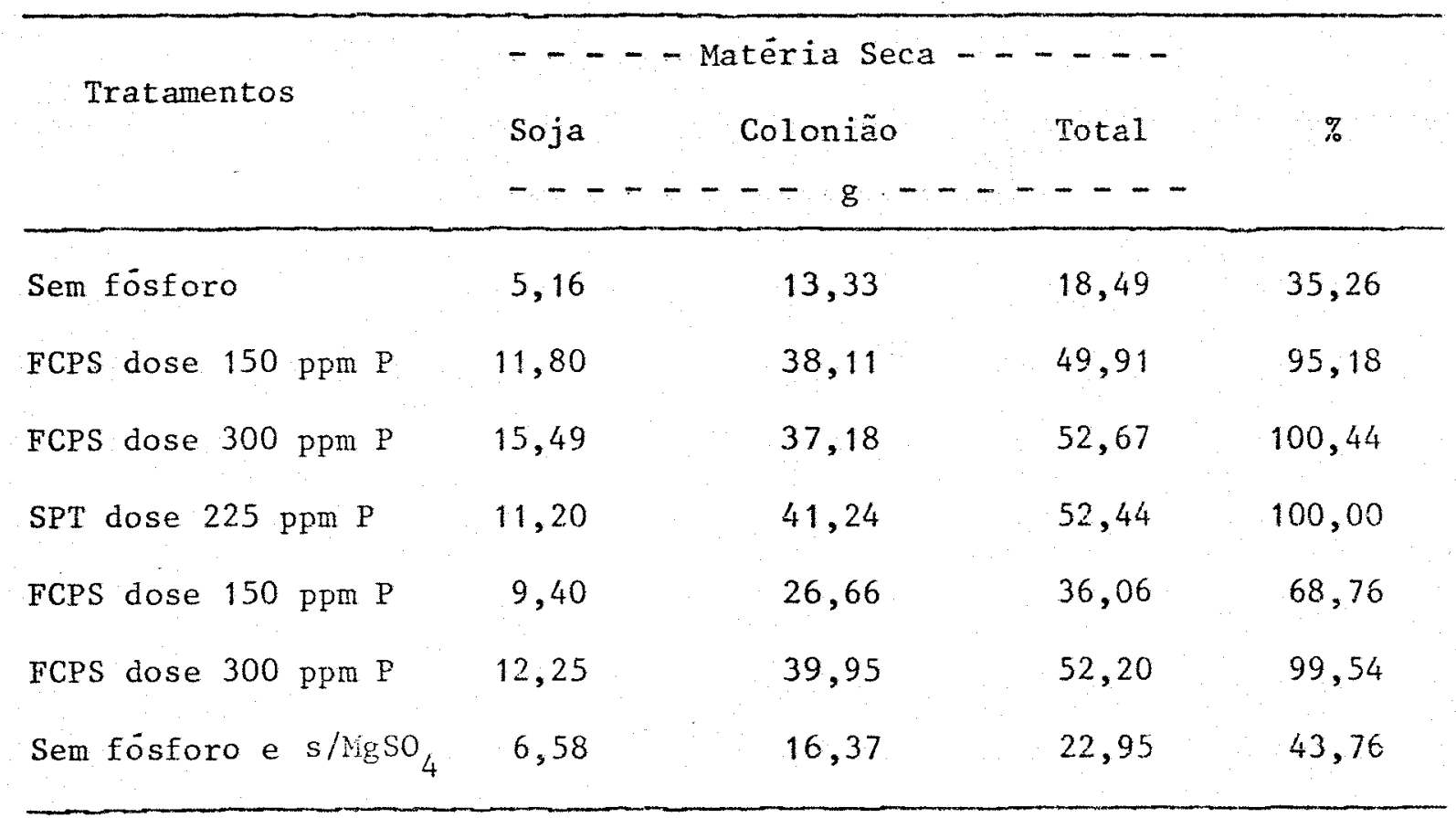


Tabela 38 - Matèria Seca da soja e capim Colonião (três cortes) dos tratamentos em presença de calagem (g/vaso) e produção relativa em relação ao tratamento com SPT (mëdias de três repetições).

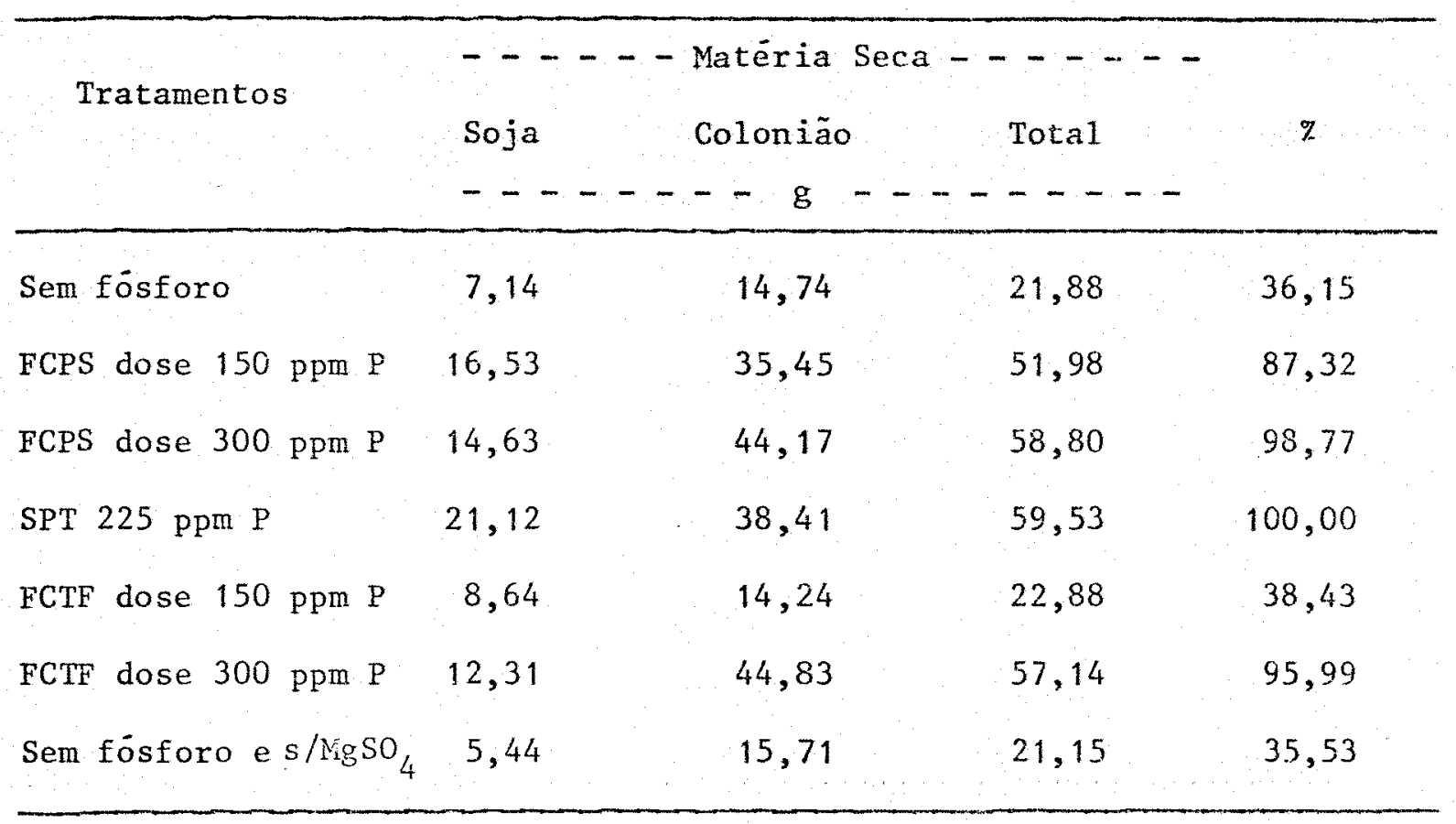


te no efeito residual, com uma eficiéncia de $99,54 \%$; c) Em presença de calagem, o fCPS mostrou uma boa eficiēncia para ambas as doses, mas sem igualar ao SPT para efeito direto, porén, para efeito residual foi equivalente ao tratamento padrão. A eficiēncia (Tabela 38) para ambas as doses foi de $87,32 \%$ e 98,77 respectivamente; d) o FCTF não mostrou variacão com respeito a sua eficiēncia mostrada nos tratamentos em ausencia de calagem, sendo a dose de $300 \mathrm{ppm}$ de $\mathrm{P}$ a que mostrou-se igual estatistica mente ao SPT no efeito residual, com eficiēncias de $38,43 \%$ e $95,99 \%$ respectivamente.

Alèm dos aspectos esclarecidos na Figura 11 , deve-se acrescentar que os fosfatos testados mostraran uma ef ciēncia inferior nos ensaios com soja e colonião, quando comparados com os ensaios com arroz e Colonião. Isso pode-se explicar pelas caracteristicas intrinsecas das plantas testes utilizadas. O arroz de sequeiro é uma planta tolerante à acidez e apresenta respostas maiores com as menores doses de fósforo (cos TA, 1980). A soja é mais sensivel a condicões de acidez e mais exigente quanto a fósforo, além de cảlcio e magnésio. Segundo FERREIRA et alii (1976), além das respostas altamente significativas para fornecimento de fösforo a soja apresentou efeito benéfico da calagem. Resultados semelhantes foram obtidas por (SAN Tos et alii, 1977, 1978a, 1978b) e SANTOS (1980). Enquanto ao capim Colonião, WERNER et alii (1967) atravës de ensaios em 
vasos, verificaram que o fósforo foi o elemento que mais limitou o crescimento, seguido de nitrogēnio e enxofre, a adição de cálcio e magnésio teve um efeito ligeiramente depressivo.

\subsubsection{Absorção de fósforo}

Nas Tabelas 39 e 40 , encontram-se os dados cor respondentes à absorção total de fósforo para soja e Colonião nos três cortes. Pelos resultados obtidos verifica-se que houve um pequeno efeito da calagem, demonstrando o comentario jà exposto. Novamente o maior acumulo de fósforo ocorreu no tratamen to padrão en auséncia e presença da calagem,

o FCPS mostrou-se como um bom fornecedor de fósforo nas duas dosagens, entanto que o FCTF, a dose de 300 ppm de $P$ mostrou-se eficiente e superior ao FCPS.

Novamente o efeito dos niveis das fontes fosfa tadas empregadas mostrou um comportamento linear e positivo, em ausēncia e presença de calagem, do mesmo modo que em arroz e Colonião.

os resultados gerais da anälise conjunta, demonstram que, em termos de equivalēncia das fontes fosfatadas em relação ao superfosfato triplo, ofosfato de Catalão parcial 
Tabela 39 - Quantidade de P absorvido pela soja e capim Colonião (três cor tes), dos tratamentos em auséncia de calagem (mg/vaso), e absorção relativa de $\mathrm{p}$ em relação ao tratamento com SPT (mẻdias de trēs repetições).

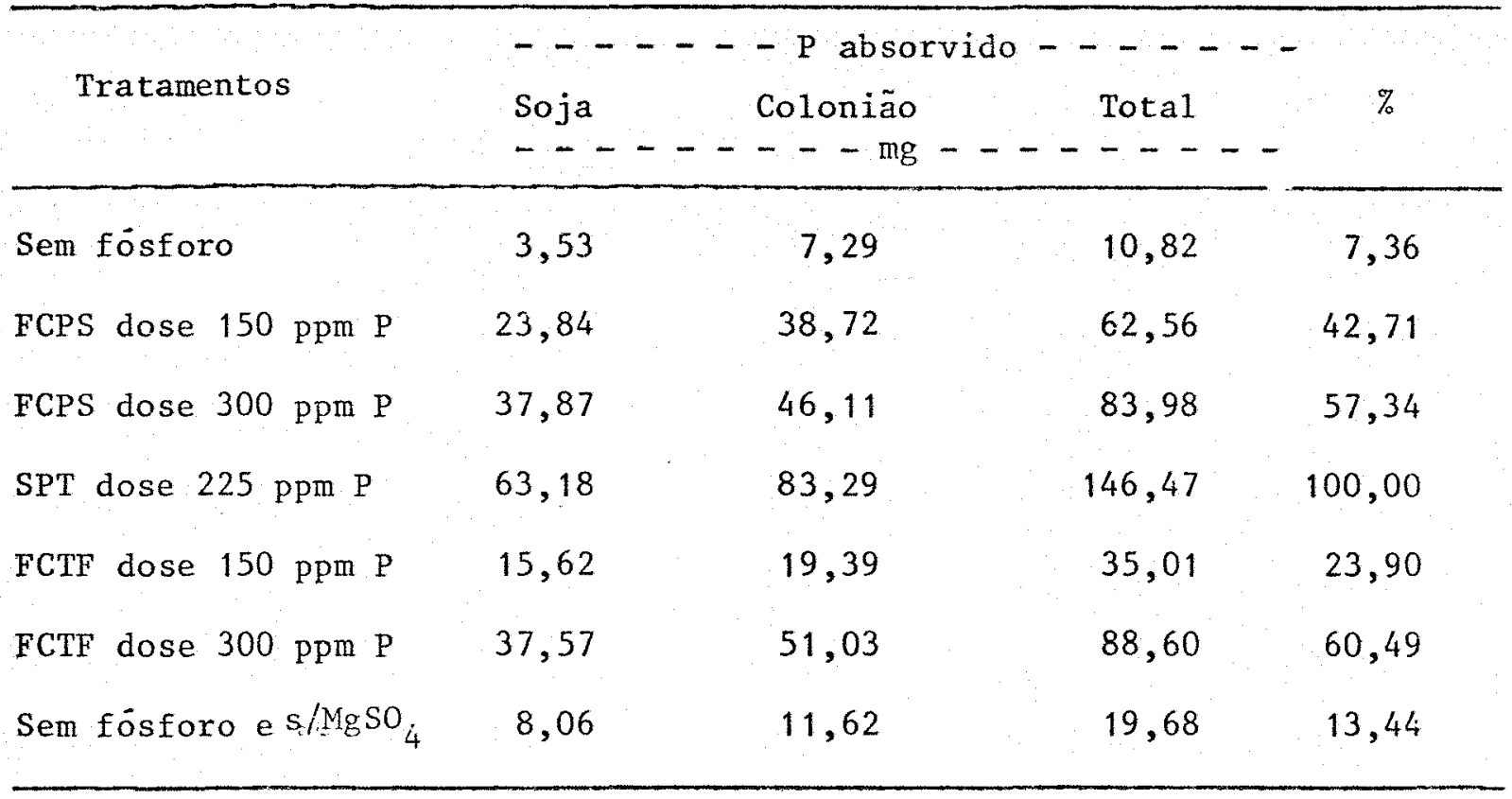


Tabela 40 - Quantidade de P absorvida pela soja e capim Colonião (trēs cor tes), dos tratamentos em presença de calagem (mg/vaso), e absor ção relativa de $\mathrm{P}$ em relação ao tratamento com SPT (médias de 3 repetições).

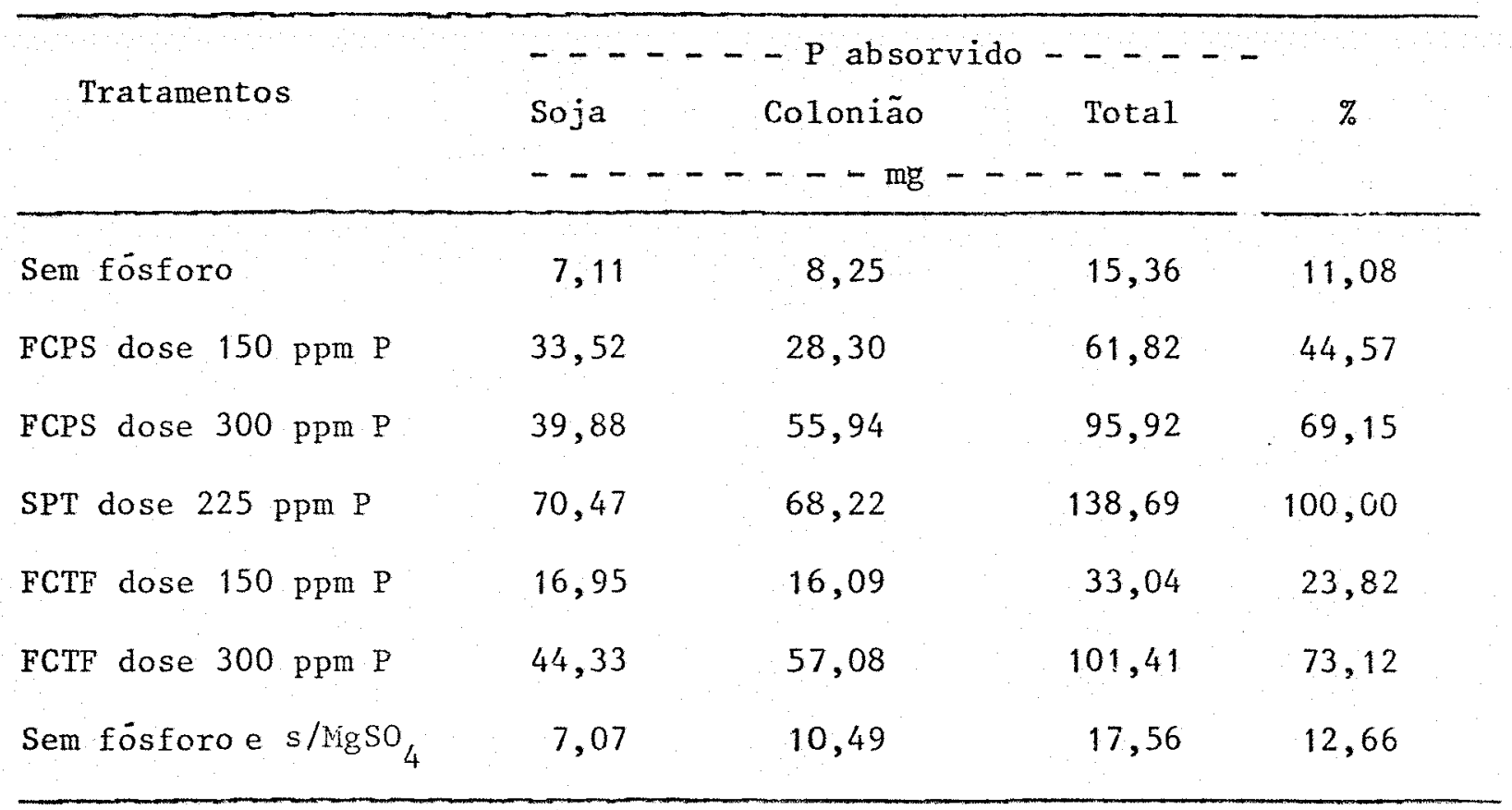


mente solubilizado (FCPS) encontra-se numa posição quase equiva lente. Este comportamento do FCPS pode ser atribuido, a sua menor proporcão de fósforo solúvel em água quando comparada a dos superfosfatos, pois, forma-se menor proporcão de ácido fosföricono solo. A fração não aciciulada de fCPS,pode competir com - Fe e Al do solo como consequéncia, em vez de ter a reversão do $\mathrm{H}_{2} \mathrm{PO}_{\overline{4}}$ a formas não disponiveis (fosfatos de Fe e Al) aumenta ria o conteüdo de $P$ aproveitáve1. McLEAN \& WHELER (1964), atribuiram a eficiência do FNPA a altos poderes de fixação de $P$ do solo e a altos níveis de A1 trocável. Tais exp1icaçós fazem compreensivel a eficiência mostrada pelo fCPS em ausência de calagem. Na presença de calagem, segundo (KHASAWNEN \& DOLL, 1978), da acidulação parcial deve resultar também uma fração de fosfato bicálcico que poderá gerar no solo ácido fosfórico que se somaria à daquele oriundo diretamente do fosfato monocálcico contido no produto.

Com relação ao fosfato de Catalão com tratamen to térmico de fusão (FCTF), o fato dele receber o tratamento tér mico em forma moderada, seja a razão de ter apresentado uma ef ciência inferior a outros termofosfatos, mesmo asim a sua ef $\underline{i}$ ciência nas doses maiores foi em uns casos comparável ao SPT e ainda até superior. 


\subsection{Efeitos sobre as caracteristicas do solo}

Ao final dos ensaios realizou-se as anälises químicas do solo, os resultados aprecem nas Tabe 1 as 41 e 42 e nelas pode-se verificar:

o pH apresentou-se muito baixo e inferior ao pH do solo antes dos ensaios, experimentando ligeiros aumentos com a adição de fósforo, porém, o valor de pli mais alto foi verificado com o FCTF, provavelmente como resultados de seu alto teor em silicato de magnésio (YoST et alii, 1982).

Pelos resultados obtidos, nota-se em primeiro lugar, que as quantidades de corretivo para elevar o pH original de 4,8 para 6,0 , de acordo com as necessidades para elevar a porcentagem de saturação de bases (RAIJ, 1981), não alcan cou o nivel desejado, provavelmente o uso de uréia, neutralizou em parte, a aça do calcário na correça o da acidez do solo.

Por outro lado a calagem provocou aumento do teor de fösforo no solo, porëm, os teores de Ca+Mg trocāveis apresentaram-se com valores em geral inferiores aos valores origi nais com excecão do tratamento com FCTF.

Em termos gerais as quantidades de fösforo no solo aumentaram com o uso dos adubos fosfatados e os níveis em pregados nos ensaios. os niveis encontrados após a colheita de 


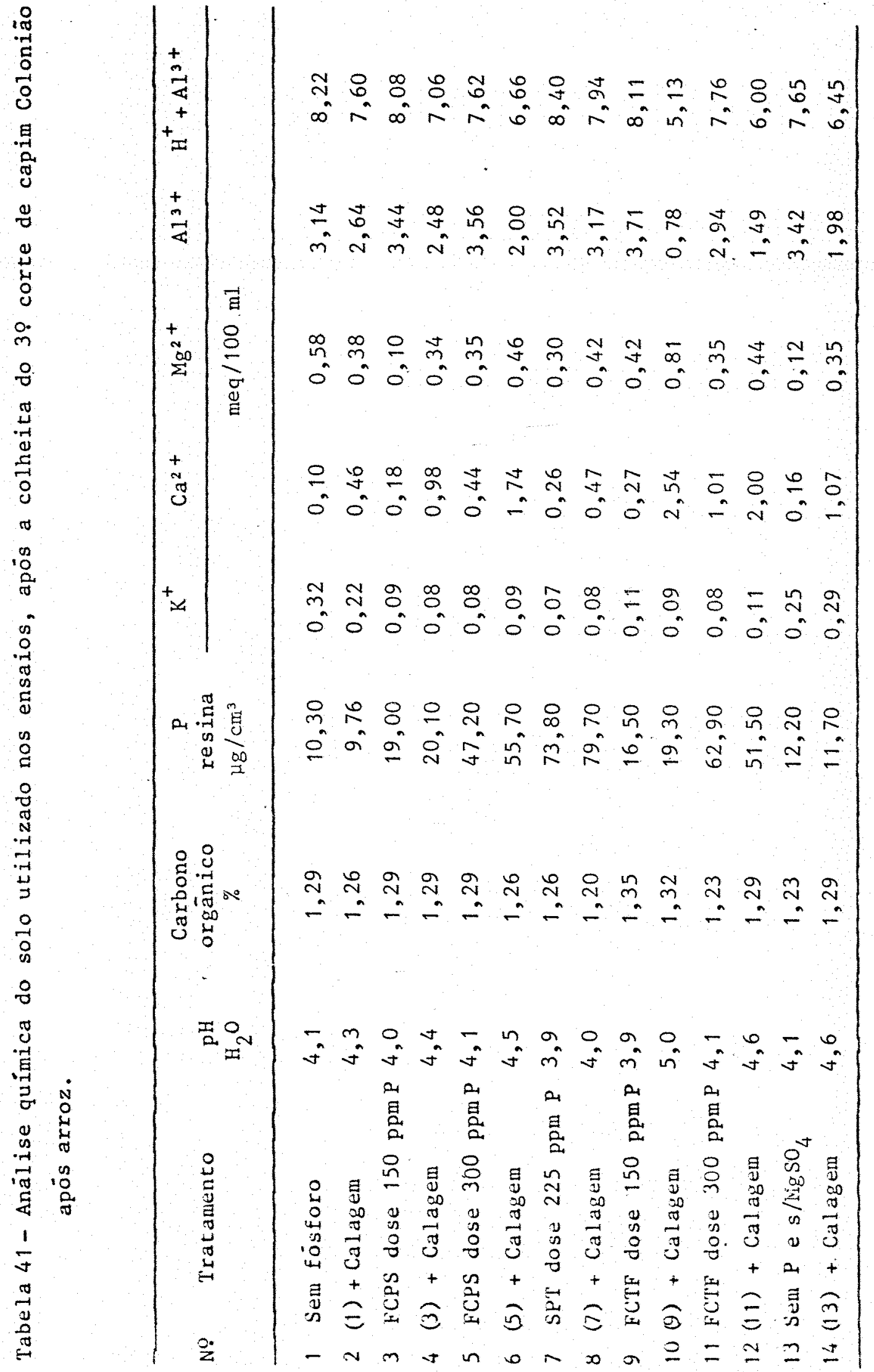


.111.

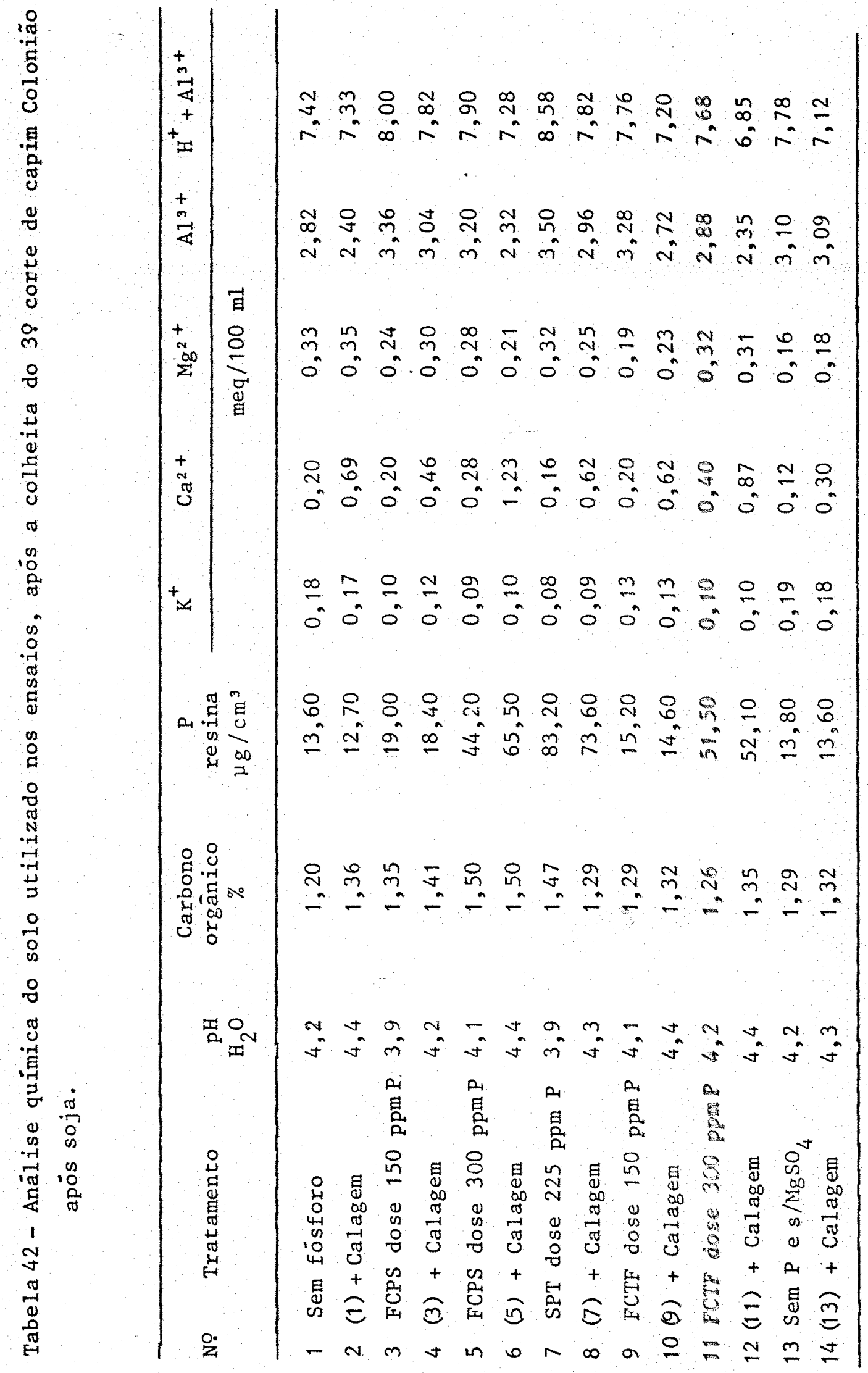


Colonião são ainda bastante altas para permitir novas produçóes, caso seja corrigida a acidez excessiva, como pode ser ob servada pelos valores de $\mathrm{pH}$ e $\mathrm{H}^{+}+\mathrm{Al}^{+3}$. 
5. CONCLUSOES

Nas condições em que foram realizados os ensaios, os resultados obtidos permitem concluir:

a) o tratamento padrão ( $\mathrm{SPI}^{\prime}$ ), foi mais eficien te nas duas primeiras culturas, e a calagem influenciou positivamente este comportamento quando se considera ofeito direto;

b) O fosfato de Catalão parcialmente solubilizado (FCPS) mostrou boa eficiēncia na cultura de soja, comparāvel ao SPT, e no caso do arroz chegou a superar ao SPT na produ ção de grãos.

c) O fosfato de Catalão tratamento de fusão 
(FCTF) mostrou boa eficiencia agronómica sö nas doses maiores ( 300 ppm de P), em ausência e presença de calagem.

d) O SPT foi superior às fontes testadas, como fornecedor de fósforo para as plantas.

e) A calagem não teve efeito significativo para ambas as fontes testadas, tanto no efeito direto como residua 1 .

f) Os fosfatos testados mostraram-se boa fonte de fósforo, cälcio e magnésio.

g) Para o efeito residual o FCPS foi equivalen te ao SPT nos trēs cortes de Colonião realizados, e o FCTF somente nas doses maiores.

h) A produção de matéria seca, grãos e vagens em termos gerais mostraram um efeito linear e positivo para os niveis de fósforo, em ambas as fontes estudads (FCTS e FCTF).

i) A maior eficiéncia agronómica do superfosfa to triplo nas primeiras culturas (efeito direto), ē um fator im portante a se considerar na anälise económica, porque a vantagem inicial da fonte solüvel pode não ser compensada com o efei 
.115 .

to residual das fontes menos solúveis, mais, ainda se as dosagens a usar tem que ser maiores que as utilizadas com as fontes solüveis. 


\section{LITERATURA CITADA}

ALCARDE, J.C. \& PONCHIO, C.O. Caracterização das solubilidades das rochas fosfatadas brasileiras e termofosfatos em diferen tes extratores químicos. Revista Brasizeira de Ciência do Solo. São Paulo. 4: 196-200, 1980 .

ANDREASI, F.; VEIGA, J.S.M.; MENDONÇA Jr., C.X.; PRADA, F. \& BARNABE, J.C. Levantamento dos Elementos Minerais em Plantas Forrageiras de Āreas Delimitadas do Estado de São Paulo. I. Cálcio, Fösforo e Magnësio. Rev. da Fac. Med. Vet., são Pau1o, 군 3 : 583-604, 1966/1967a.

ASSOCIAÇÃO NACIONAL PARA DIFUSÃO DE ADUBOS. Manual de Adubação; Coord. MAlavolta, E. e RoMer, J.P. 2a Ed. São Paulo. Ed. Ave Maria. 1975. p. 95-100. 
ATANASIU, N. Comparative study on the effects of water and citrate soluble phosphatic fertilizer of field and P - uptake on tropical and subtropical soils. Indian Soc. Sci, New Delhi, $19: 119-127,1971$.

BAHIA FILHO, A.F. de C. Fósforo em Latossolos do Estado de Minas Gerais: interisidade e quantidade de fósforo, fósforo "dis ponível" e crescimento vegetal. Tese de M.S. Universidade Federal de Viçosa, Viçosa, Minas Gerais. 1974.

BLANCO, H.G.; VENTURINI, W.R.; GARGANTINI, H. Comportamento de fertilizantes fosfatados em diferentes condiçóes de acidez de solo, para o trigo, em estudo de efeito residual para a soja. Bragantia, Campinas, 24(22): 261-290, 1965.

BORGES, L.C.V.; COSTA, A.V.; MACHADO, S.C.; FARIAS, F.C.; MONTEIRO, P.M.F.o; KLIEMANN, H.J. Calibração de anālise química do solo, caracterização da curva de resposta e efeito residual de três fontes de fósforo em solos do Estado de Goiās. Goiās. Empresa Goiānia de Pesquisa Agropecuária. 1979. p. $192-193$. 
BORKET, C.M.; CORDEIRO, D.S.; SFREDO, G.J.; PALHANO, J.B.; DIT TRICH, R.C. Efeito de doses de fósforo de diferentes fosfatos naturais brasileiros na produção de soja, em condicões de primeiro cultivo. In: SEMINĀRIO NACIONAL DE PESQUISA DE SOJA, 1, Londrina. Anais. 1978. p. 291-7.

BRAGA, J.M. Comparação de fosfatos aplicados ao feijoeiro: 1. Trabalhos de casa de vegetação. Revista Ceres, 16 (88): $88-101,1969$

BRAGA, J.M.; NOVAES, R.F. de; DEFELIPO, B.V.; BARROS, L. G.; COUTINHO, M.; REIS, M.S.; BARROS, N. Contribuição ao estü do do fosfato de abaeté como fonte de fósforo para a ferti 1 ização do solo. Revista Ceres 31(72): 46-57, 1971.

BRAGA, J.M.; FRANCO, M.; THIEBAUT, J.T.L. Efeito de fosfatos naturais parcialmente acidificados com $\mathrm{H}_{3} \mathrm{PO}_{4}$, $\mathrm{HCl}_{1} \mathrm{e}_{2} \mathrm{SO}_{4}$ em sorgo granífero (Sorghum bicolor (L.) Moench). II. Fós foro absorvido. Rev. Agron. Ceres, 26: 131-144, 1979.

BRAGA, N.R.; MASCARENHAS, H.A.A.; FEITOSA, C.T.; RAIJ, B.V. Efeitos de fosfatos sobre o crescimento e produção de soja. Rev. Bras. Sei. Solo. Campinas, 4: 36-39, 1980 . 
BUENO, M.; BRAGA, J.M.; THIEBAUT, J.T.L.; FRANCO, M. Efeito re sidual de fosfatos naturais parcialmente acidificados com $\mathrm{H}_{3} \mathrm{PO}_{4}$, HCl e $\mathrm{H}_{2} \mathrm{SO}_{4}$ em sorgo granifero (Sorghumbicolor (L.) Moench.), produção de matéria seca total. Revista Ceres, 26 $(146): 330-340,1979$.

CPSEMG - COMISSÃO DE FERTILIDADE DO SOLO DO ESTADO DE MINAS GERAIS. Recomendações para o uso de corretivos e fertilizantes em Minas Gerais. 3a Aproximąão. EPAMIG. Belo Horizon te, MG, $1976.80 \mathrm{p}$.

COSTA, A.V.; BORGES, L.C.V.; FARIAS, J.G.; MONTEIRO, P.M.F.O.; KLIEMANN, H.J. 1978. Efeito residual de três fontes de fós foro em soja (Glycine max (L.) Merril). Goiânia. Empresa Goiānia de Pesquisa Agropecuāria. 1978. p. 161.

Costa, A. Uso de fertilizantes na cultura de arroz. In: INSTI TUTO AGRONÔMICO DO PARANĀ. Londrina - PR. Uso de fertilizantes na agricultura paranaense. Londrina. 1980. p. 61-7 (circular 16).

DYNIA, J.F. Efeito do $p H$ e da capacidade de retenção de fósforo dos solos na eficiência de adubos fosfatados. Dissertação de Mestrado. Universidade Federal do Rio Grande do Sul. Porto Alegre, 1977 . 
EMBRAPA. Empresa Brasileira de Pesquisa Agropecuäria. Centro de Pesquisa Agropecuāria dos Cerrados, Planaltina, DF, Rela törio Técnico Anual, 1978-1979. 170 p.

EMBRAPA. Empresa Brasileira de Pesquisa Agropecuäria. Adubacão fosfatada no Brasil. Brasilia-DF. 1982.

FEITOSA, C.T.; RAIJ, B.V.; DECHEN, A.R.; ALCARDE, J.C. Determinação preliminar da eficiência relativa de fosfatos, para trigo em casa de vegetação. Rev. Bras. Ci. Solo. 2:193-195, 1978.

FERRARI, R.A.R.; BRAGA, J.M.; SEDIYAMA, C.A. \& OLIVEIRA, L.M. de. Respostas do cultivar de Soja "Santa Rosa" a aplicação de P, $\mathrm{K}$ e calcário em latossolos do Triângulo Mineiro. I - Produ ção e caracteristicas agronômicas. Revista ceres, 23(125): $11-20,1976$.

FERREIRA, J.C. \& CARVALHO, M.M. Efeito de niveis de fosfatos naturais de Patos de Minas e Gafsa puras e modificados por acidulação e calcinação. Rev. Bras. de Ciêne. Solo. 3:158162,1978 
FERREIRA, T.N. \& KAMINSKI, J. Eficiência agronômica dos fosfatos naturais de Patos de Minas e Gafsa puros e modificados por acidulação e calcinação. Rev. Bras. Ci. Solo. 3:158,62, 1979.

FRANCO, M.; BRAGA, J.M. \& THIEBAUT, J.T.L. Efeito de fosfatos naturais parcialmente acidificados com $\mathrm{H}_{3} \mathrm{PO}_{4}, \mathrm{HCl}$ e $\mathrm{H}_{2} \mathrm{SO}_{4}$ em sorgo granifero (Sorghum bicolor (L.) Moench.): e peso da parte aérea, das raízes e total. Revista Ceres, 26 (114): $113-130,1979$.

FREIRE, F.M.; BRAGA, J.M.; MARTIN FILHO, S.C.A. Valor fertilizante de fosfatos solúveis, Araxā e parcialmente acidulado. Rev. Bras. Ci. Solo. 7:65-68, 1983 .

FRENCH, N.H. \& CHAPARRO, L.M. Contribuição a1 Estudio de la composición química de los pastos em Venezuela durante 1 a es tación seca. Agron. Trop. Maracay. 10:57-60, 1960.

GOEADERT, W.J. \& LOBATo, E. Avaliação agronômica de fosfatos em solos de cerrado. Rev. Bras. Ci. Solo. 8: 97-102, 1984 .

GOEDERT, W. \& LOBATO, E. Eficiência Agronômica de fosfatos em solos de cerrado. Pesquisa Agropec. Bras., Brasília, 15: $311-318,1980$. 
HAAG, H.P.; BOSE, M.L.V. \& ANDRADE, R.G. Absorção dos macronutrientes pelos capins Colonião, Gordura, Jaraguá, Napier e Pangola. Anais da E.S.A. "Luiz de Queiroz", Piracicaba, $24:$ $177-188,1967$.

KHASAWINEH, F.E. \& DOLL, E.C. The use of phosphate rock for direct application to soils. Advances in Agronomy, 30:159208,1978 .

KLIEMANN, H.J.; COSTA, A.V.; NUNES, M.R.; JARDIM, P.M. Calibra ção de análise química do solo, caracterização da curva de resposta e efeito residual de três fontes de fósforo em soja (Glycine max (L.) Merril). Goiânia. Empresa Goiânia de Pesquisa Agropecuäria. 1975. p. 74-75.

KORNDORFER, G.H. Capacidade de fosfatos naturais e artificiais fornecerem fósforo para plantas de trigo. Porto Alegre (RS), Universidade Federal do Rio Grande do Su1. 1978. 61 p. (Te ses e Monografias, 7).

LEAL, J.R. \& VElloso, A.C.X. Adsorção de fosfatos em Latossolos sob vegetação de cerrado. Pesq. Agropecuãria Bras. Serv. Agric. $8: 81-88$. 
LEHR, J.R. \& MCCLELLAN, G.H. A Reviced Laboratory Reactivity Scale for Evaluating Phosphate Rock for Direct Application Tenneesse Valley Authovity. U.S.A. 1972. 36p. (Bu11. Y-43).

LEHR, J.R.; MCCLELLAN, G.H.; SMITH, J.P.; FRAZIER, A.W. Characterization of apatites in commercial phosphate rock. COILOQUE INTERNATIONAL SURILES PHOSPHATE MINERAUX SOLIDES, Toulouse. 1967. p. 29-44.

LIMA, E. Resposta do sofgo sacarino (Sorghum bicolor (L) Moench.) ao emprego de fontes e doses de fösforo em condiçóes de casade-vegetação. Piracicaba, ESALQ/USP, 1981. 107p. (Dissertação de Mestrado).

LOBO, M.G. \& SILVA, R.M. Produção de fertilizantes fosfatados. In: Anais do Simpósio sobre Fertilizantes na Agricultura Brasizeira. EMBRAPA, Brasilia, 1984. p. 73.

LOPEZ, A.S.; VASCONCELOS, C.A.; NOVAIS, R.F. de. Adubaçãofosfatada em algumas culturas nos Estados de Minas Gerais, Espi rito santo e Rio de Janeiro. In: Adubação fosfatada no Brasiz. EMBRAPA, Brasilia, 1982. p. 176-178.

LUTZ Jr., J.A. Companison of partially acidulated rock phosphate and concentrated superphosphate as sources of phosphorus for corn. Agronomy Journal. Vol.6 63. Nov-Dec. 1971. 
LUTZ Jr., J.A. Effect of partially acidulated rock phosphate and concentrated superphosphate on yie1d and chemical composition of alfafa and orchard-grass. Agronomy Journal. Vol. 65. March-April. 1973.

MACHADO, S.C.; BORGES, L.C.V.; FARIAS, J.G.; MENDONÇA, A.T.C. Niveis de adubação fosfatada e efeito residual na cultura do milho. Goiânia. Empresa Goiânia de Pesquisa Agropecuãria, 1978. p. $154-155$.

MALAVOLTA, E. O fósforo na agricultura brasileira. IPT. Bol. $9: 187-206, \quad 1980$.

MALAvolta, E. Manual de Quimica Agricola - Adubos e Adubação. $3^{a}$. ed. Edit. Agron. Ceres Ltda., São Paulo. 1981 . p. 596.

MALAVOLTA, E.; VITTI, G.C.; ALCARDE, J.C.; ROSELEM, C.A.; FORNA SIERI FILHO, D. Aproveitamento de um fosfato natural parcialmente solubilizado pelas culturas do arroz, milho e so ja. 1. Resultados preliminares. Anais da E.S.A. "Luiz de Queiroz". Volume XXXVIII, 801-818, 1981.

MALAVOLTA, E.; PEIXE, C.A.; RUIVO, F.P.; CARVALHO, J.G. de; GUI MARÃES, P.G.; VITTI, G.C. Aproveitamento de um fosfato natu ral parcialmente solubilizado pela cultura da cana-de-açücar. 1. Cana planta. Trabalho no prelo dos Anais da E.S.A. "Luiz de Queiroz" - vol. 39, 1982. 
MCLEAN, E.0. \& WHELLER, R. Partially acidulated rock phosphate as a source of phosphorus to plants: I Gowth chamber studies. Proc. Soiz. Sci. Soc. Am. 28:245-550, 1964.

MASCARENHAS, H.A.A.; BATAGLIA, O.C.; FEITOSA, C.T.; NAGAL, V. HIROCE, R.; BRAGA, N.R. Respostas da soja a adubos fosfatados e calagem em solos de cerrado. Campinas, Instituto Agro nômico. 1978. 28p. (Boletim Tëcnico, 54).

MENDONÇA, A.T.C.; BORGES, L.C.V.; FARIAS, J.G.; MACHADO, S.C. Competição de fontes de fösforo em solos de cerrado do Brasil Central. Goiânia. Empresa Goiânia de Pesquisa Agropecuäria. 1978. p. 206-207.

MORAIS, O.P. \& GONTTJO, V. de P.M. Resposta da cultura do arroz (Oriza sativa L.) de sequeiro a fertilização NPK e a calagem. Proj. Arroz, Rel. Anual.75/76. Belo Horizonte. 1978. p. $93-146$.

MURAOKA, T. \& NEPTUNE, A.M.L. Eficiência de vārios adubos fosfatados I Efeito imediato. Anais da E.S.A. "Luiz de Queiroz". Volume XXXIV. 1977. p. 586-594.

MURAOKA, T. \& NEPTUNE, A.M.L. Eficiência de värios adubos fosfatados II Efeito Residual. Anais da E.S.A. "Luiz de Queiroz". Volume XXXV. 1978. p. 535-543. 
MUZILLI, 0. \& KALCKMANN, R.E. Sugestões de calagem e adubação para recuperação de solos da região Nordeste do Estado do Pa ranā. Arq. Biol. Tecnol. Curitiba, 14:54-60. 1971.

MUZILLI, 0.; RISPOLI, J.C.S. \& CostA, N.A. Efeito da adubação fosfatada em solos àcidos do sul do Paraná (nota preliminar) B. Univ. Fed. Paranā Agron. Curitiba, (9): 1-7, 1971.

NAKAYAMA, L.H.I. Estudos agricolas sobre o aproveitamento do fosfato de Araxá parcialmente solubilizado. Piracicaba, ESALQ/USP. 1982..97p. (Dissertação de Mestrado).

NEME, A.N. Adubos fosfatados e calcārio na produção de forragem de soja perene (Glycine javanica) em terra roxa misturada In: Anais do IX Congresso Internacional de Pastagem; s. Paulo, Departamento de Produção Animal, 1:677-681, 1965.

NOVAES, N.J. Efeitos de macronutrientes em capim Colonião cul tivado num solo de campo cerrado. Piracicaba. ESALQ/USP. 1977. 93p. (Tese de Mestrado).

RAIJ, B.V.; ROSAND, C.P. \& LOBATO, E. Adubação fosfatada no Bra sil - Apreciação geral, conclusões e recomendações. In: Adu bagão fosfatada no Brasiz. EMBRAPA, Brasilia, 1982. p. 19. 
RAIJ, B.V. Avaliação da fertilidade do solo. Piracicaba, Instituto da Potassa e Fosfato. Ed. Franciscana, 1981. $142 \mathrm{p}$.

RAIJ, B.V. \& QUAGGIO, J.A. Mëtodos de anälise de solo para fins de fertilidade. Campinas, Instituto Agronōmico, 1983 , 31p. (Boletim Técnico no 82).

RochA, D. Adubação fosfatada em eucalipto no viveiro. Tese Mestrado. Viçosa, Universidade Federal de Viçosa, 65p. 1981.

RUSSEL, E.W. Soil conditions and plant growth. 10a. Londres Longman, 1973, p. 535-603.

SANTOS, P.R.R.S.; BRAGA, J.M.; FRANÇA, G.E. de \& SANTOS, H. L. dos. Efeito da calagem e da adubação P, K sobre a produção de soja em três solos do Triângulo Mineiro e Alto Paranaiba. 73/74 e 74/75. Proj. Soja, Rel. Anu. 74/75 - Belo Horizonte. 1977. p. 84-104. Resumo.

SANTOS, P.R.R.S.; BRAGA, J.M.; PAULA, M.B.; FRANÇA, G.E. de \& SANTOS, H.L. dos. Efeito da calagem e da adubação fosfatada e potássica sobre a produção de soja do Triângulo Mineiro e Alto Paranaiba no ano 75/76. Belo Horizonte. 1978a. p. 51 -6 . 
SANTOS, P.R.R.S.; BRAGA, J.M.; PAULA, M.B.; FRANÇA, G.E. de \& SANTOS, H.L. dos. Calibração de anälise química do solo e caracrerização de curva de resposta na soja para calcārio e fósforo em Minas Gerais. Proj.Soja, Ret. Anu. 75/76, Belo Horizonte. 1978b. p. 41-50. Resumo.

SANTOS, P.R.R.S. Efeito da calagem e da adubação fosfatada e potássica sobre a produção de soja (Glycine max (L.) Merri1) em solos do triângulo Mineiro e Alto Paranaíba. s.n. Em fa se de redação.

SARRUGE, J.R. \& HAAG, H.P. Anälises químicas em plantas. Pira cicaba. 1979. 40p. mimeo.

SILVA Jr., A.F. Rocha fosfäticas brasileiras. Curso de Tecnologia de Fertilizantes Fosfatados. São Paulo. I.P.T. - CEFER. 1979. 28p. Mimeo.

SOUZA, M.A. de; MORAIS, O.P. de \& TAKAHASHI, C. Adubação NPK na cultura de trigo (Triticum aestivum L.) Proj. Trigo ReZ. Anual 75/76. Belo Horizonte. p. 51-6. Resumo. 
TANAKA, R.T. Disponibilidade de fósforo do fosfato de Patos pa ra a cultura de milho (Zea mays L.) em Latossolo Roxo Distró fico sob condiçöes de casa de vegetação. Tese de M.s., Departamento de ciência do So1o, E.S.A. de Lavras, Lavras, Mi nas Gerais, $1978.68 \mathrm{p}$.

WAVER, R.M. Soils of the Central Plateau of Brazi1. Chemical and mineralogical properties agronomy. Mimeo. 74-8. Corne11 University, Ithaca, New York, 1974. 45pp,

WERNER, J.C.; QUAGLIATO, J.L.; MARTINELLI, D. Ensaio de fertilização de colonião com solo de novoeste. Bol. Ind. Anim. São Pau1o, 24: $159-167,1967$.

YOST, R.S.; NADERMAN, G.C.; KAMPRATH, E.J. \& LOBATO, E. A vailability of rock phosphate as measured by an acid to lerant, pasture grass and extractable phosphorus. Agron. J. Madison, 1982. 74-462-468. 